\title{
VENTCF2: AN ALGORITHM AND ASSOCIATED FORTRAN 77 SUBROUTINE FOR CALCULATING FLOW THROUGH A HORIZONTAL CEILING/FLOOR VENT IN A ZONE-TYPE COMPARTMENT FIRE MODEL
}

Leonard Y. Cooper

Building and Fire Research Laboratory

Gaithersburg, Maryland 20899

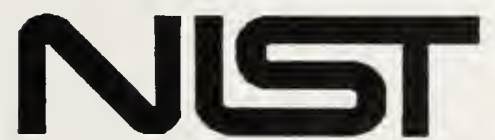

United States Department of Commerce echnology Administration

$Q C$ Jational Institute of Standards and Technology 

VENTCF2: AN ALGORITHM AND ASSOCIATED FORTRAN 77 SUBROUTINE FOR CALCULATING FLOW THROUGH A HORIZONTAL CEILING/FLOOR VENT IN A ZONE-TYPE COMPARTMENT FIRE MODEL

Leonard Y. Cooper

August 1994

Building and Fire Research Laboratory

National Institute of Standards and Technology

Gaithersburg, MD 20899

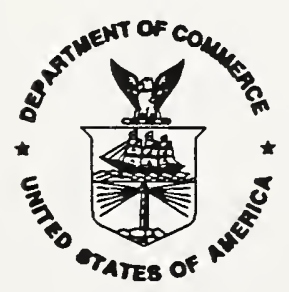

U.S. Department of Commerce

Ronald H. Brown, Secretary

Technology Administration

Mary L. Good, Under Secretary for Technology

National Institute of Standards and Technology

Arati Prabhakar, Director 

TABLE OF CONTENTS $\ldots \ldots \ldots \ldots \ldots \ldots \ldots \ldots \ldots \ldots \ldots \ldots \ldots \ldots \ldots \ldots \ldots$ lii

LIST OF TABLES AND FIGURES $\ldots \ldots \ldots \ldots \ldots \ldots \ldots \ldots \ldots \ldots \ldots \ldots \ldots \ldots$ iv

ABSTRACT $\ldots \ldots \ldots \ldots \ldots \ldots \ldots \ldots \ldots \ldots \ldots \ldots \ldots \ldots \ldots \ldots \ldots \ldots \ldots \ldots \ldots \ldots$

INTRODUCTION ................................... 2

THE BASIC PROBLEM $\ldots \ldots \ldots \ldots \ldots \ldots \ldots \ldots \ldots \ldots \ldots \ldots \ldots \ldots \ldots \ldots$

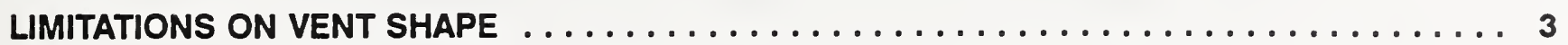

THE ALGORITHMS AND ASSOCIATED FORTRAN 77 SUBROUTINES VENTCF2 AND VENTCF2A FOR CALCULATING THE EFFECTS OF FLOW THROUGH HORIZONTAL CEILING/FLOOR VENTS .......................... 3

TESTING OF THE SUBROUTINES $\ldots \ldots \ldots \ldots \ldots \ldots \ldots \ldots \ldots \ldots \ldots \ldots \ldots \ldots \ldots$

REFERENCES $\ldots \ldots \ldots \ldots \ldots \ldots \ldots \ldots \ldots \ldots \ldots \ldots \ldots \ldots \ldots \ldots \ldots \ldots \ldots \ldots$

NOMENCLATURE $\ldots \ldots \ldots \ldots \ldots \ldots \ldots \ldots \ldots \ldots \ldots \ldots \ldots \ldots \ldots \ldots \ldots \ldots$

APPENDIX A: VENTCF2 - CALCULATION OF THE FLOW THROUGH A HORIZONTAL CEILING/FLOOR VENT CONNECTING TWO SPACES . . . . . . . . . VENTCF2 - 1

APPENDIX B: VENTCF2A - CALCULATION OF THE FLOW THROUGH A HORIZON-

TAL CEILING/FLOOR VENT CONNECTING TWO SPACES WITH "SMOO. THING" OF LAYER EXTRACTION RATES AT TIMES OF RELATIVELY THIN ADJACENT-VENT LAYERS 


\section{LIST OF TABLES AND FIGURES}

Page

Table 1. Configurations/Environments Used to Test the VENTCF2 Subroutine . . . . . . 9

Flgure 1. Plots of the calculated mass flow rate to upper space $1, \dot{M}_{\mathrm{VENT}, 1}$, and to lower space 2, $\dot{M}_{\text {VENT,2, }}$ as functlons of the computed (coarse-scale) cross-vent pressure difference, $\Delta p$, for Cases 28, 29, and 30 (see Table 1) . . . . . . 18

Flgure 2. Plots of the calculated mass flow rate to upper space 1, $\dot{M}_{\mathrm{VENT}, 1}$, and to lower space 2, $\dot{M}_{\mathrm{VENT}, 2}$, as functlons of the computed (fine-scale) cross-vent pressure difference, $\Delta p$, for Cases 28, 29, and 30 (see Table 1) . . . . . . 19 


\title{
VENTCF2: AN ALGORITHM AND ASSOCIATED FORTRAN 77 SUBROUTINE FOR CALCULATING FLOW THROUGH A HORIZONTAL CEILING/FLOOR VENT IN A ZONE-TYPE COMPARTMENT FIRE MODEL
}

\author{
Leonard Y. Cooper
}

\begin{abstract}
An algorithm and associated FORTRAN 77 subroutine, called VENTCF2, is presented for calculating the effects on two-layer compartment fire environments of the quasi-steady flow through a circular, shallow (i.e., small ratio of depth to diameter), horizontal vent connecting two spaces. The two spaces can be either two inside rooms of a multi-room facility or one inside room and the outside ambient environment local to the vent. The description of the flow through the vent is determined by combining considerations of the uni-directional-type of flow driven by a cross-vent pressure difference and, when appropriate, the combined pressure- and buoyancy-driven flows which occur when the density configuration across the vent is unstable, i.e., a relatively cool, dense gas in the upper space overlays a less dense gas in the lower space. In the algorithm, calculation of the rates of flow exchange between the two spaces is based on previously reported model equations. Characteristics of the geometry and the instantaneous environments of the two spaces are assumed to be known and specified as inputs. The outputs calculated by the algorithm/subroutine are the rates and the properties of the vent flow at the elevation of the vent as it enters the top space from the bottom space and/or as it enters the bottom space from the top space. Rates of mass, enthalpy, and products of combustion extracted by the vent flows from upper and lower layers of inside room environments and from outside ambient spaces are determined explicitly. VENTCF2 is an advanced version of the algorithm/subroutine VENTCF in that it includes an improved theoretical and experimental basis. The subroutine is completely modular and it is suitable for general use in two-layer, multi-room, zone-type fire model computer codes. It has been tested over a wide range of input variables and these tests are described.
\end{abstract}

Keywords: bullding flres; compartment flres; computer models; flre models; flre research; mathematical models; vents; zone models 


\section{INTRODUCTION}

This work presents an algorithm and associated FORTRAN 77 subroutine, called VENTCF2, to calculate under arbitrary conditions the instantaneous effects on two-layer fire environments of the quasi-steady flow through a horizontal vent connecting two spaces involved in a compartment fire. The subroutine is designed to be modular and easy to integrate into any two-layer zone-type compartment fire model. The algorithm VENTCF2, which was developed in [2], is based on ideas outlined in [1], theoretical considerations of [3], and experimental data from reduced-scale hot-air/cool-air experiments of [4] and salt-water/fresh-water experiments of [5] and [6]. VENTCF2 is an advanced version of the algorithm/subroutine VENTCF $[1,7]$ which was developed without benefit of [3]-[5].

Flow through horizontal vents is a general problem associated with ventilation of enclosed, heated/cooled spaces. It is a problem whose general solution is required, for example, if one is to be able to predict the spread of smoke (i.e., fire-heated and -contaminated air) and the flow of fresh air (i.e., oxygen, which could sustain a fire, lack of which could extinguish a fire) during fires in multi-room facilities. Reference here is to smoke spread between contiguous rooms, or between a smoky room and the outside environment, separated by a horizontal partition (i.e., ceiling/floor) with penetrations (i.e., vents), where room-to-room or room-to-outside, cross-vent, pressure differences of arbitrary magnitude and direction can be generated by forced-ventilation HVAC systems, thermal buoyancy forces (i.e., stack effect), and/or wind effects. The problem has application in fire scenarios involving top-vented atria, stairwells, ship holds, etc. The purpose for this work is to provide a computational tool that can be used to predict these phenomena.

\section{THE BASIC PROBLEM}

Consider the flow through a horizontal ceiling/floor vent connecting two spaces, one on top of the other, involved in a fire-generated environment. The two spaces can be two inside rooms of a multi-room facility, as depicted in Figure 1a of APPENDIX A (page VENTCF2 - 15), or they can be comprised of one inside room of a facility and one outside space, either above or below the room, which is used to simulate conditions, local to the vent, of the outside ambient. The latter configurations are depicted in Figures $1 \mathrm{~b}$ and $1 \mathrm{c}$ of APPENDIX $A$, respectively.

When the upper gas is less dense than the lower gas, i.e., the fluid configuration is stable, the flow through the vent is determined by a traditional orifice-type flow model. Then, flow is determined by the cross-vent pressure difference without any regard for buoyancy effects (see, e.g., References [8] and [9]). When the configuration is unstable and the upper gas is more dense than the lower gas, the effects of combined pressure and buoyancy forces can be significant. For example if the cross-vent pressure is relatively small, less than the critical value, $\Delta p_{F L O O D}$, the unstable density configuration leads to an exchange-type of flow, with gas in the lower space rising into the upper space and gas from the upper space dropping into the lower space, where the flow rate from the high- to the low-pressure side of the vent is the larger of the two. Even when the cross-vent pressure difference is large enough to produce uni-directional flow, the effect of buoyancy can be great enough to reduce significantly the flow rate from what it would be in the absence of a cross-vent density difference. In the present algorithm, for the case of unstable configurations the calculation of the flow between the two spaces is based on the analysis of [2], which uses theoretical considerations of [3], and experimental data of [4] (hot-air/cool-air in the unidirectional flow regime, flow from top to bottom) and of [5] and [6] (salt-water/fresh/water vent flows in the exchange-flow regime).

The algorithm/subroutine VENTCF2 would be used to calculate the net instantaneous rates of addition of mass, enthalpy, and products of combustion of interest and the properties of the vent flows to each of the two connected spaces at the elevation of the vent. A determination of where such flows go once they 
enter the receiving spaces would be determined with the use of additional algorithms and associated subroutines. These additional algorithms, which would use the output of the present algorithm/subroutine, would be based on considerations beyond the scope of the present work.

A flow through the horizontal vent which enters one of the spaces joined by the vent is extracted from the other space. Depending on the configuration of the two spaces, the direction of the flow, and, in the case of inside rooms, the elevation of the two-layer interface (i.e., at the floor, ceiling, or in-between), the present algorithm determines explicitly the rates of extraction of mass, enthalpy, and products of combustion from the upper and lower layers of the one or two inside rooms and/or from an outside ambient space joined by the vent under consideration. Along with other components of flow to or from the layers of the inside rooms, determined with the use of other algorithms, these rates would be used to continue in time the solution to the equations of the overall fire model. These are the equations used to simulate mathematically the facility's overall dynamic fire environment.

\section{LIMITATIONS ON VENT SHAPE}

For unstable density configurations, the model of [2] and, therefore, the algorithm/subroutine presented here is for flow through a circular, shallow (i.e., small ratio of depth-to-diameter), horizontal vent. It is expected that the model will give reasonable estimates of flow even for non-circular vents, provided the aspect ratio (maximum-to-minimum span) of a vent shape of interest is not too much different than unity. Indeed, one of the example calculations of [2], which includes comparisons with some relevant experimental data, provides limited support for the applicability of the model in the case of square vents. However, when cross-vent pressure differences are small-to-moderate compared to $\Delta p_{F L O O D}$ use of the model for high-aspect-ratio and/or moderate-to-large-depth vents is not valid. Results beyond those developed in [2] are required before the present work can be evaluated for its use in predicting flows through the latter types of vent shapes.

\section{THE ALGORITHMS AND ASSOCIATED FORTRAN 77 SUBROUTINES VENTCF2 AND VENTCF2A FOR CALCULATING THE EFFECTS OF FLOW THROUGH HORIZONTAL CEILING/FLOOR VENTS}

The algorithm VENTCF2 and a listing of its associated subroutine, coded in FORTRAN 77, is presented in APPENDIX A. This is a stand-alone document that can be inserted as a new entry into the catalog of modular algorithms and associated FORTRAN 77 subroutines of [10]. APPENDIX B includes stand-alone documentation and the associated subroutine for VENTCF2A, a modification of VENTCF2. VENTCF2A provides special considerations for "smoothing" rates of layer extraction from the flow source room at times of relatively thin adjacent-vent layers. When used in a full zone model, and depending on the integration software for the particular model, the considerations in VENTCF2A eliminate singularities that may cause convergence problems in fire simulations at times when adjacent-vent layers are growing or shrinking from near-zero depths.

Reference [10] is a catalog of algorithms/subroutines useful for simulating the physical phenomena in multi-room zone-type compartment fire model computer codes. Pagination of the two documents of the present APPENDIXES A and B, and of all entries of the Reference [10] catalog is according to name of the particular algorithm/subroutine (in this case, VENTCF2 and VENTCF2A) and page number of the catalog entry.

The catalog of [10] was conceived of as a growing document where the entries would be available for general use by people interested in: developing or improving, for their own particular needs, a general or special-purpose multi-room zone-type compartment fire model; or predicting isolated compartment fire phenomena, for whatever reason. 
The development, technology transfer, and use of a Reference-[10]-type of catalog of algorithms and associated subroutines is enhanced by maintaining guidelines for a uniform format of algorithm/subroutine documentation. In this regard a prototype format was developed and used in all Reference-[10] algorithm/subroutine catalog entries. This format, which is followed here, includes the following elements:

\begin{tabular}{|c|c|c|}
\hline TITLE & - & Should indicate the main purpose of the algorithm/subroutine. \\
\hline DESCRIPTION & - & General description of the algorithm. \\
\hline OUTPUT & - & List of output variables, including definitions and units. \\
\hline INPUT & - & List of input variables, including definitions and units. \\
\hline CALCULATIONS & - & $\begin{array}{l}\text { Concise description of the rules for obtaining the output variables } \\
\text { from the input variables. This would include or refer explicitly to } \\
\text { all equations required in the calculation. If other algo- } \\
\text { rithms/subroutines are required, then these should be readily } \\
\text { available and referenced. }\end{array}$ \\
\hline
\end{tabular}
SUBROUTINES - Listing of or explicit reference to each
USED algorithm/subroutine used to carry out the calculations.
REFERENCES - - A list of references.
SUBROUTINE $\quad$ - $\quad$ cross-reference of all nomenclature (including
VARIABLES units) introduced in the above sections to the nomenclature used in the FORTRAN 77 subroutine.

PREPARED BY - N Names of those who prepared the algorithm/subroutine and date of preparation.

SUBROUTINE - Listing of the subroutine. This would be well-commented and would include a summary of the purpose of the subroutine and definitions (including units) of its input and output variables.

\section{TESTING THE SUBROUTINES}

\section{Subroutine VENTCF2}

Extensive parametric testing of the subroutine VENTCF2 has been carried out. A wide range of environment scenarios were considered for each of the three basic configurations of Figure 1 of VENTCF2 (page VENTCF2 - 15 of the APPENDIX A). For each configuration, parameters were varied in a manner as to simulate all possible combinations of the following:

a. for the two layers of an inside space: the usual case with two non-zero-thickness layers (i.e., layer interface between the ceiling and the floor), or one non-zero-thickness layer and one zero-thickness layer (i.e., layer interface at the ceiling or floor);

b. Stable or unstable cross-vent density configuration; 
c. the reference elevation for an outside space is above, at, or below the vent elevation;

d. $\quad 1.0$ atmosphere reference pressure, $p_{R E F, 1}$, in the top space (i.e., $p_{D A T}=101325 P a$ with $\delta p_{R E F, 1} \equiv p_{R E F, 1}-p_{D A T}=0$ ) with reference pressure in the bottom space, $p_{R E F, 2}$, varying from 0.01 atmospheres to 2.0 atmospheres (i.e., $-0.99 p_{D A T}<\delta p_{R E F, 2} \leq p_{D A T}$ ); and

e. $\quad 1.0$ atmosphere reference pressure, $p_{R E F, 2}$ in the bottom space (i.e., $p_{D A T}=101325 \mathrm{~Pa}$ with $\delta p_{R E F, 2} \equiv p_{R E F, 2}-p_{D A T}=0$ ) with reference pressure in the top space, $p_{R E F, 1}$, varying from 0.01 atmospheres to 2.0 atmospheres (i.e., $-0.99 p_{D A T}<\delta p_{R E F, 1} \leq p_{D A T}$ )

Five distinct elevations (relative to a datum elevation), $y_{N}, N=1$ to 5 , and three distinct densities, $\rho_{N}, N$ $=1$ to 3 , were required to construct the environment scenarios. These were chosen to be:

$$
\begin{aligned}
& y_{1}=0.0 \mathrm{~m} ; y_{2}=1.5 \mathrm{~m} ; y_{3}=3.0 \mathrm{~m} ; y_{4}=4.5 \mathrm{~m} ; y_{5}=6.0 \mathrm{~m} \\
& \rho_{1}=1.00 \mathrm{~kg} / \mathrm{m}^{3} ; \rho_{2}=0.50 \mathrm{~kg} / \mathrm{m}^{3} ; \rho_{3}=0.25 \mathrm{~kg} / \mathrm{m}^{3}
\end{aligned}
$$

When the environment of an inside room involved two layers, the layer densities were specified to be in a stable configuration (i.e., a low density layer above a high density layer).

All scenarios involve an example vent of area $A_{V}=1 \mathrm{~m}^{2}$.

Table 1 identifies all configurations and environment specifications that were used in the parametric testing of the subroutine. This involved 162 basic Cases. Each Case involved a separate parametric study of over two thousand calls to the subroutine. These covered the above pressure range of either condition $\mathrm{d}$. or condition e. The calls involved incremental changes of the relative reference pressures, $\delta p_{R E F, 1}$ for condition $e$ and $\delta p_{R E F, 2}$ for condition $d$, which were small enough to reveal details of the exchange-flow phenomena, these being sensitive to fractional-pascal-level variations in cross-vent pressure differences.

For each Case, Table 1 identifies values of the parameters which define the configuration of the two spaces, as illustrated in Figure 1 of VENTCF2, and the states of the environments in the spaces. These are the parameters used to call the subroutine. (The reader is referred to the NOMENCLATURE Section for explanation of terms used in the table.) Also explicitly identified in the table are those Cases which involve unstable cross-vent density configurations. When cross-vent pressure differences are small enough in magnitude, such Cases lead to the exchange-flow phenomena which are of particular interest.

Presented in Figures 1 and 2 are plots of the calculated mass flow rates to upper room $1, \dot{M}_{\text {VENT, },}$, and to lower room 2, $\dot{M}_{\mathrm{VENT}, 2}$, as functions of the computed cross-vent pressure difference, $\Delta p$, for Cases 28 , 29, and 30. As in Eq. (2) of VENTCF2, $\triangle p$, an output variable of the subroutine, is defined as

$$
\Delta p=p_{2}-p_{1}
$$

where $p_{1}$ and $p_{2}$ are the pressures in the top and bottom spaces at the elevation of the vent (see Figure 2 of VENTCF2).

As indicated in Table 1, Cases 28, 29, and 30 involve two inside rooms where, as depicted in Figure 1a of VENTCF2, both of these have an upper and a lower layer. Case 28 involves a neutrally-stable cross- 
vent density configuration since the density immediately above the vent (in the lower layer of room 1), $\rho_{L, 1}$ $=\rho_{2}=0.50 \mathrm{~kg} / \mathrm{m}^{3}$, is identical to the density immediately below the vent (in the upper layer of room 2 ). Cases 29 and 30 involve an unstable cross-vent density configuration since the density immediately above the vent, $\rho_{\mathrm{L}, 1}=\rho_{1}=1.0 \mathrm{~kg} / \mathrm{m}^{3}$, is greater than the density immediately below the vent, $\rho_{\mathrm{U}, 2}=\rho_{2}=$ $0.50 \mathrm{~kg} / \mathrm{m}^{3}$.

The scale of the $\Delta p$ abscissa of Figure 1 is relatively coarse, and the plots reveal the calculated mass flow rates through the vent as a result of large cross-vent pressure differences, i.e., when effects of compressibility become significant as could be the case, for example, for fires in nearly-hermetically-sealed facilities. In the figure, the sharp breaks in the $\dot{M}_{\mathrm{VENT}, 1}$ and $\dot{M}_{\mathrm{VENT}, 2}$ plots for Cases 28 and 30 and for Case 29 , respectively, correspond to cross-vent pressure differences, $\Delta p$, which separate choked from unchoked flow through the vent. Define $p_{H I G H}$ and $p_{\text {LOW }}$ as the absolute pressures on the high- and lowpressure side of the vent, respectively. Then, consistent with Eqs. (7)-(15) of VENTCF2, such choking occurs for air (i.e., $\gamma=1.40$ ) when $[9,11]$

$$
\mathrm{P}_{\mathrm{LOW}} / \mathrm{P}_{\mathrm{HIGH}} \leq[2 /(\gamma+1)]^{\gamma /(\gamma-1)}=0.528
$$

As indicated in Figure 1, for Case 29 the parameters specified in Table 1 lead to a prediction of choked vent flow from room 1 to room 2 approximately when $\Delta p \leq-0.472 p_{D A T}=-0.478\left(10^{5}\right) \mathrm{Pa}$. Similarly, for Cases 28 and 30 the parameters specified in Table 1 lead to a prediction of choked vent flow from room 1 to room 2 approximately when $\Delta \mathrm{p} \leq-0.894 \mathrm{p}_{\mathrm{DAT}}=-0.906\left(10^{5}\right) \mathrm{Pa}$. Also, for Cases 28 and 30 , choked flow from room 2 to room 1 is predicted when $\Delta p \geq 0.472 p_{D A T}=0.478\left(10^{5}\right) \mathrm{Pa}$. Finally, for Case 29 , choked flow from room 2 to room 1 is predicted when $\Delta p \geq 0.894 p_{D A T}=0.906\left(10^{5}\right) \mathrm{Pa}$.

The scale of the $\Delta p$ abscissa of Figure 2 is relatively fine, and the plots reveal the calculated mass flow rates through the vent when the cross-vent pressure differences are at or close to zero. Since the Case28 density configuration is neutrally-stable, i.e., only uni-directional or zero flow is possible, the mass flow rates through the vent corresponding to $\Delta p=0$ are seen to be identically zero. However, for the unstable cross-vent density configurations of Cases 29 and 30 , the vent flow algorithm is seen to lead to the exchange-flow phenomenon. In particular, there is a non-zero vent flow exchange between the top and bottom spaces whenever $|\Delta p|<\Delta p_{F L O O D}$, where $\Delta p_{F L O O D}$ is defined in Eq. (20) of VENTCF2.

\section{Subroutine VENTCF2A}

The subroutine VENTCF2A was found to give plausible results when tested in CCFM.VENTS [10, 12-14] with a variety of time-dependent one- and two-room fire scenarios. Except for the small-scale, limitedregime data of [4-6], which were used to develop VENTCF2, the algorithm has not been validated experimentally. 


\section{REFERENCES}

[1] Cooper, L.Y., Calculation of the Flow Through a Horizontal Ceiling/Floor Vent, NISTIR 89-4052, National Institute of Standards and Technology, Gaithersburg MD, March 1989.

[2] Cooper, L.Y., Combined Buoyancy- and Pressure-Driven Flow Through a Horizontal Vent, NISTIR 5384, National Institute of Standards and Technology, Gaithersburg MD, April 1994.

[3] Cooper, L.Y., Combined Buoyancy- and Pressure-Driven Flow Through a Horizontal Vent: Theoretical Considerations, NISTIR 5252, National Institute of Standards and Technology, Gaithersburg MD, September 1993.

[4] Heskestad, G. and Spaulding, R.D., Inflow of Air Required at Wall and Ceiling Apertures to Prevent Escape of Fire Smoke, Proceedings of the 3rd International Symposium on Fire Safety Science, Elsevier, pp. 919-928, 1991.

[5] Epstein, M., Buoyancy-Driven Exchange Flow Through Small Openings in Horizontal Partitions, J. Heat Transfer, 110, pp. 885-893, 1988.

[6] Epstein, M. and Kenton, M.A., Combined Natural Convection and Forced Flow Through Small Openings in a Horizontal Partition With Special Reslference to Flows in Multicomparment Enclosures, J. Heat Transfer, 111, pp. 980-987, 1989.

[7] Cooper, L.Y., An Algorithm and Associated Computer Subroutine for Calculating Flow Through a Horizontal Ceiling/Floor Vent in a Zone-Type Compartment Fire Model, NISTIR 90-4402, National Institute of Standards and Technology, Gaithersburg MD, October 1990.

[8] Emmons, H., SFPE Handbook of Fire Protection Engineering, Sect. 1/Chapter 8, SFPE, Boston, pp. 130-138, 1988.

[9] Cooper, L.Y., Calculating Flows Through Vertical Vents in Zone Fire Models, Combustion Science and Technology, Vol. 63, Nos. 1-3, pp. 43-50, 1989.

[10] Cooper, L.Y. and Forney, G.P., Editors, The Consolidated Compartment Fire Model (CCFM) Computer Code Application CCFM.VENTS - Part III: Catalog of Algorithms and Subroutines, NISTIR 90-4344, National Institute of Standards and Technology, Gaithersburg MD, 1990.

[11] Shapiro, A.H., The Dynamics and Thermodynamics of Compressible Fluid Flow, Rowland Press, 1953.

[12] Cooper, L.Y. and Forney G.P., The Consolidated Compartment Fire Model (CCFM) Computer Code Application CCFM.VENTS - Part I: Physical Basis, NISTIR 90-4342, National Institute of Standards and Technology, Gaithersburg MD, 1990.

[13] Forney G.P. and Cooper, L.Y., The Consolidated Compartment Fire Model (CCFM) Computer Code Application CCFM.VENTS - Part II: Software Reference Guide, NISTIR 90-4343, National Institute of Standards and Technology, Gaithersburg MD, 1990.

[14] Forney, G.P., Cooper, L.Y., and Moss, W., The Consolidated Compartment Fire Model (CCFM) Computer Code Application CCFM.VENTS - Part IV: User's Reference Guide, NISTIR 90-4345, National Institute of Standards and Technology, Gaithersburg MD, 1990. 


\section{NOMENCLATURE}
$A_{V}$
Area of vent
$\dot{M}_{\text {VENT, }, ~} I=1$ to 2
Mass flow rate of vent flow component entering space I
PDAT
Datum absolute pressure
$\mathrm{P}_{\text {HIGH }}$
Maximum of $\left(p_{1}, p_{2}\right)$
PLow
Minimum of $\left(p_{1}, p_{2}\right)$
$p_{\text {REF, }, ~} I=1,2$
Absolute pressure in space $I$ at reference elevation $y_{R E F, I}$
$p_{1}\left[p_{2}\right]$
Absolute hydrostatic pressure in top [bottom] space at vent elevation
$y_{C}, y_{L}, y_{R}$ for space $I \quad y_{C E I L,}, y_{L A Y E R, l}$ and $y_{R E F, l}$, respectively
$\mathrm{Y}_{\mathrm{CEILI}}\left[\mathrm{y}_{\mathrm{REF}, \mathrm{I}}\right] ; \mathrm{I}=1,2$ If space $\mathrm{I}$ is inside room: elevation of ceiling [floor] of room I above datum elevation; if space $I$ is "Outside room": $y_{C E I L, I}$ and $y_{R E F, I}$ are identical and equal to reference elevation of space I above datum elevation, i.e., $y_{\text {CEILI }} \equiv y_{\text {REF,I }}$
$Y_{\text {LAYER, }, i} I=1,2$ If space $I$ is inside room: elevation of upper/lower layer interface in room I above datum elevation; if space I is "outside room": $y_{\text {LAYER,I }} \equiv y_{\text {REF,I }}$
YVENT
Elevation of vent above datum elevation
$\Delta p$
$p_{2}-p_{1}$

$\triangle \mathrm{p}_{\mathrm{FLOOD}}$

Minimum value of $|\Delta p|$, in cases of unstable cross-vent density configurations, leading to uni-directional vent flow; Eq. (20) of APPENDIX A

$\Delta \mathrm{p}_{\mathrm{FLOOD}, \mathrm{l}} ; \mathrm{I}=1,2 \quad \Delta \mathrm{p}_{\mathrm{FLOOD}}$ for onset of uni-directional flow into space I $\begin{array}{ll}\delta p_{R E F, l} ; I=1,2 & \text { Pressure at reference elevation, } y_{R E F, I} \text { in space } I \text { above datum absolute pressure, } \\ & P_{D A T} ; \text { if space } I \text { is inside room, then } \delta p_{R E F, I} \text { and } y_{R E F, I} \text { correspond to pressure and }\end{array}$ elevation, respectively, within the room and at floor

$\rho_{L I}\left[\rho_{U, I}\right] ; I=1,2$ If space $I$ is inside room: density of lower [upper] layer in room I if volume of lower [upper] layer is non-zero (if lower [upper] layer volume is zero then $\rho_{L, I}$ $\left[\rho_{U, 1}\right]$ is not used in calculation); if space $I$ is "outside room": $\rho_{L, 1}$ is uniform density there and $\rho_{U, I} \equiv \rho_{L, I}$ 
TABLE 1: Configurations/Environments Used to Test the VENTCF2 Subroutine

$$
\begin{aligned}
& \rho_{1}=1.00 \mathrm{~kg} / \mathrm{m}^{3}>\rho_{2}=0.50 \mathrm{~kg} / \mathrm{m}^{3}>\rho_{3}=0.25 \mathrm{~kg} / \mathrm{m}^{3} \\
& y_{1}=0.0 \mathrm{~m}<y_{2}=1.5 \mathrm{~m}<y_{3}=3.0 \mathrm{~m}<y_{4}=4.5 \mathrm{~m}<y_{5}=6.0 \mathrm{~m} \\
& P_{\text {DAT }}=1.01325\left(10^{5}\right) \mathrm{Pa} ; A_{V}=1 \mathrm{~m}^{2}
\end{aligned}
$$

CASES 1-54: SPACE 1 (TOP SPACE) IS INSIDE ROOM, SPACE 2 (BOTTOM SPACE) IS INSIDE ROOM FIGURE 1a of APPENDIX A

\begin{tabular}{lll} 
CASE & SPACE & SPACE \\
NO. & 1 & 2 \\
\hline
\end{tabular}

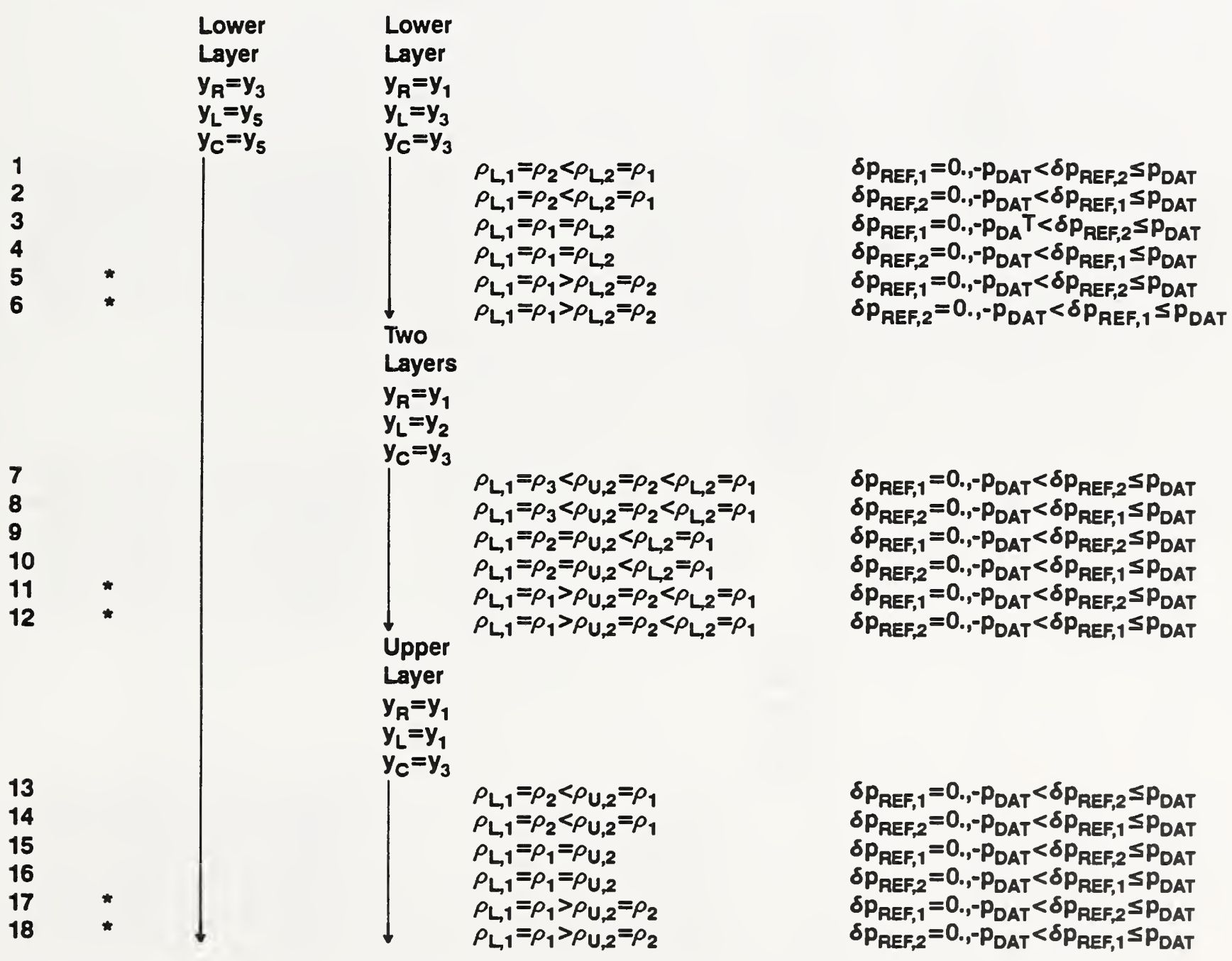

* Unstable cross-vent density configuration 
TABLE 1: Configurations/Environments Used to Test the VENTCF2 Subroutine (Cont'd)

$$
\begin{aligned}
& \rho_{1}=1.00 \mathrm{~kg} / \mathrm{m}^{3}>\rho_{2}=0.50 \mathrm{~kg} / \mathrm{m}^{3}>\rho_{3}=0.25 \mathrm{~kg} / \mathrm{m}^{3} \\
& y_{1}=0.0 \mathrm{~m}<y_{2}=1.5 \mathrm{~m}<y_{3}=3.0 \mathrm{~m}<y_{4}=4.5 \mathrm{~m}<y_{5}=6.0 \mathrm{~m} \\
& \text { PDAT }_{\text {DA }}=1.01325\left(10^{5}\right) P a ; A_{V}=1 \mathrm{~m}^{2}
\end{aligned}
$$

CASES 1-54: SPACE 1 (TOP SPACE) IS INSIDE ROOM, SPACE 2 (BOTTOM SPACE) IS INSIDE ROOM (CONT'D) FIGURE 1a of APPENDIX A

\begin{tabular}{lll} 
CASE & SPACE & SPACE \\
NO. & 1 & 2 \\
\hline
\end{tabular}

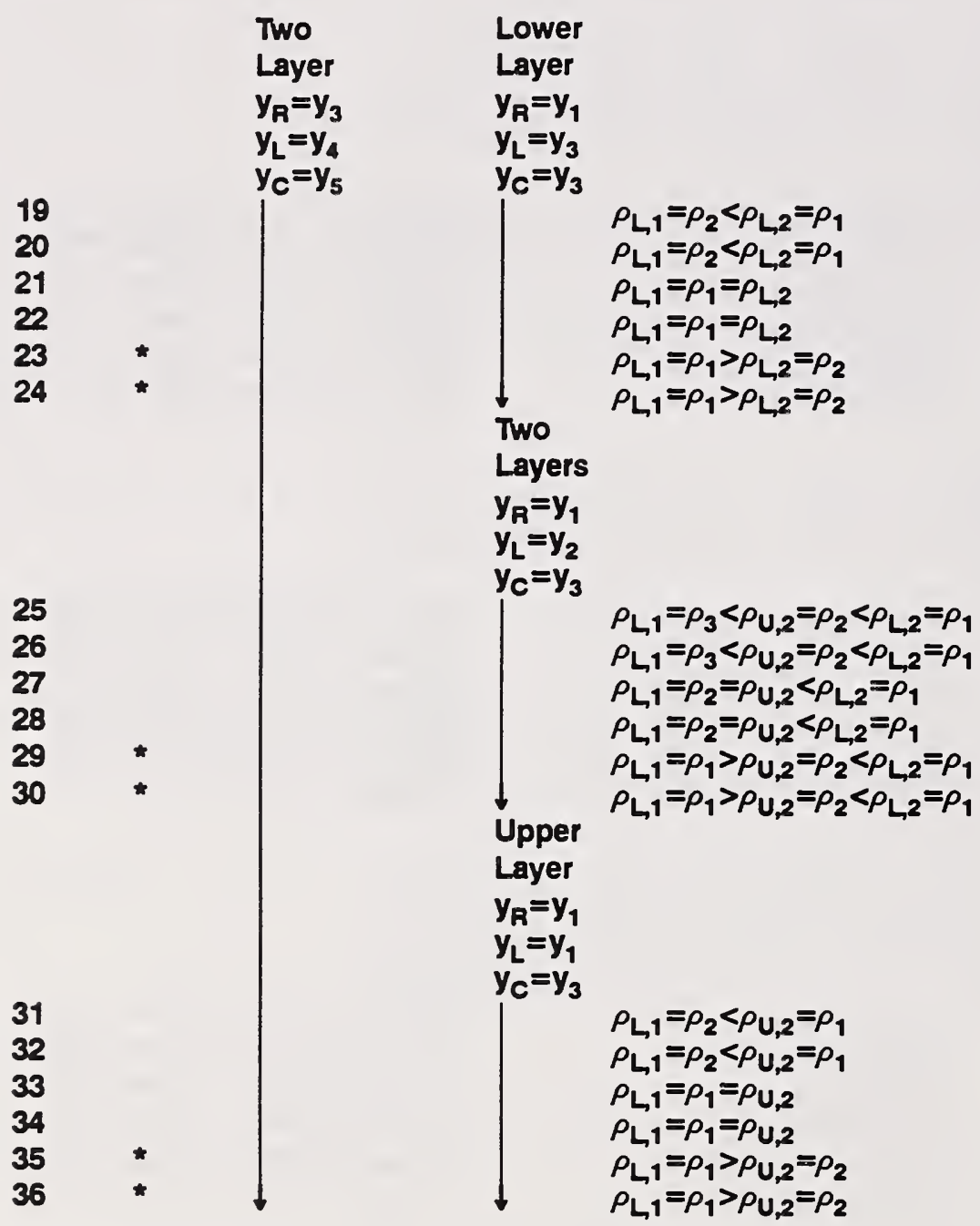

$\delta p_{\text {REF, },}=0 .,-p_{D A T}<\delta p_{R E F, 2} \leq p_{D A T}$ $\delta p_{\text {REF, } 2}=0 .,-p_{\text {DAT }}<\delta p_{\text {REF, } 1} \leq P_{\text {DAT }}$ $\delta p_{\text {REF, } 1}=0,-p_{D A T}<\delta p_{\text {REF }, 2} \leq p_{D A T}$ $\delta p_{\text {REF, } 2}=0 .,-P_{D A T}<\delta p_{R E F, 1} \leq P_{D A T}$ $\delta p_{\text {REF }, 1}=0 .,-p_{D A T}<\delta p_{R E F, 2} \leq P_{D A T}$ $\delta p_{\text {REF,2 }}=0 .,-p_{D A T}<\delta p_{\text {REF, } 1} \leq p_{\text {DAT }}$

$\delta p_{R E F, 1}=0 .,-p_{D A T}<\delta p_{R E F, 2} \leq p_{D A T}$ $\delta p_{\text {REF }, 2}=0 .,-p_{D A T}<\delta p_{\text {REF }, 1} \leq p_{D A T}$ $\delta p_{R E F, 1}=0 .,-P_{D A T}<\delta p_{R E F, 2} \leq P_{D A T}$ $\delta p_{R E F, 2}=0 .,-P_{D A T}<\delta p_{R E F, 1} \leq P_{D A T}$ $\delta p_{R E F, 1}=0,-p_{D A T}<\delta p_{R E F, 2} \leq p_{D A T}$ $\delta p_{R E F, 2}=0 .,-p_{D A T}<\delta p_{R E F, 1} \leq p_{D A T}$

$\delta p_{\text {REF, } 1}=0 .,-p_{D A T}<\delta p_{R E F, 2} \leq p_{D A T}$ $\delta p_{\text {REF }, 2}=0,-p_{\text {DAT }}<\delta p_{\text {REF }, 1} \leq p_{\text {DAT }}$ $\delta p_{R E F, 1}=0,-p_{D A T}<\delta p_{R E F, 2} \leq p_{D A T}$ $\delta p_{\text {REF }, 2}=0,,-P_{D A T}<\delta p_{\text {REF }, 1} \leq p_{D A T}$ $\delta p_{R E F, 1}=0,-p_{D A T}<\delta p_{R E F, 2} \leq P_{D A T}$ $\delta p_{\text {REF }, 2}=0 .,-p_{D A T}<\delta p_{R E F, 1} \leq p_{D A T}$

* Unstabie cross-vent density configuration 
TABLE 1: $\quad$ Configurations/Envlronments Used to Test the VENTCF2 Subroutine

(Cont'd)

$\rho_{1}=1.00 \mathrm{~kg} / \mathrm{m}^{3}>\rho_{2}=0.50 \mathrm{~kg} / \mathrm{m}^{3}>\rho_{3}=0.25 \mathrm{~kg} / \mathrm{m}^{3}$

$y_{1}=0.0 m<y_{2}=1.5 m<y_{3}=3.0 m<y_{4}=4.5 m<y_{5}=6.0 m$

$P_{D A T}=1.01325\left(10^{5}\right) \mathrm{Pa} ; A_{V}=1 \mathrm{~m}^{2}$

CASES 1-54: SPACE 1 (TOP SPACE) IS INSIDE ROOM, SPACE 2 (BOTTOM SPACE) IS INSIDE ROOM (CONT'D) FIGURE 1a of APPENDIX A

\begin{tabular}{lll} 
CASE & SPACE & SPACE \\
NO. & 1 & 2 \\
\hline
\end{tabular}

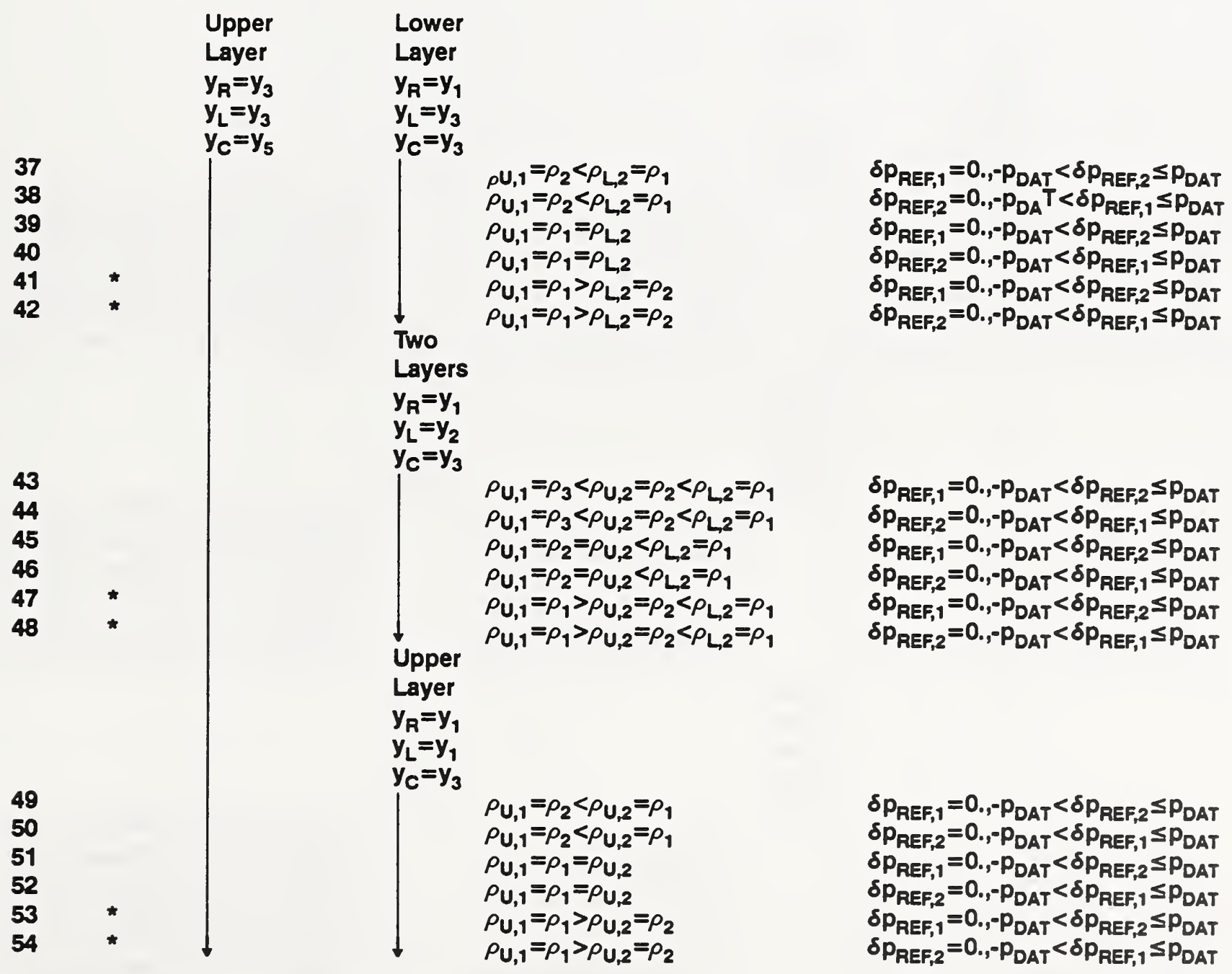

* Unstabie cross-vent density configuration 
TABLE 1: Configurations/Environments Used to Test the VENTCF2 Subroutine (Cont'd)

$$
\begin{aligned}
& \rho_{1}=1.00 \mathrm{~kg} / \mathrm{m}^{3}>\rho_{2}=0.50 \mathrm{~kg} / \mathrm{m}^{3}>\rho_{3}=0.25 \mathrm{~kg} / \mathrm{m}^{3} \\
& y_{1}=0.0 \mathrm{~m}<\mathrm{y}_{2}=1.5 \mathrm{~m}<y_{3}=3.0 \mathrm{~m}<\mathrm{y}_{4}=4.5 \mathrm{~m}<\mathrm{y}_{5}=6.0 \mathrm{~m} \\
& P_{\text {DAT }}=1.01325\left(10^{5}\right) \mathrm{Pa} ; A_{\mathrm{V}}=1 \mathrm{~m}^{2}
\end{aligned}
$$

CASES 55-108: SPACE 1 (TOP SPACE) IS OUTSIDE SPACE, SPACE 2 (BOTTOM SPACE) IS INSIDE ROOM FIGURE $1 b$ of APPENDIX A

\begin{tabular}{lll} 
CASE & SPACE & SPACE \\
NO. & 1 & 2 \\
\hline
\end{tabular}

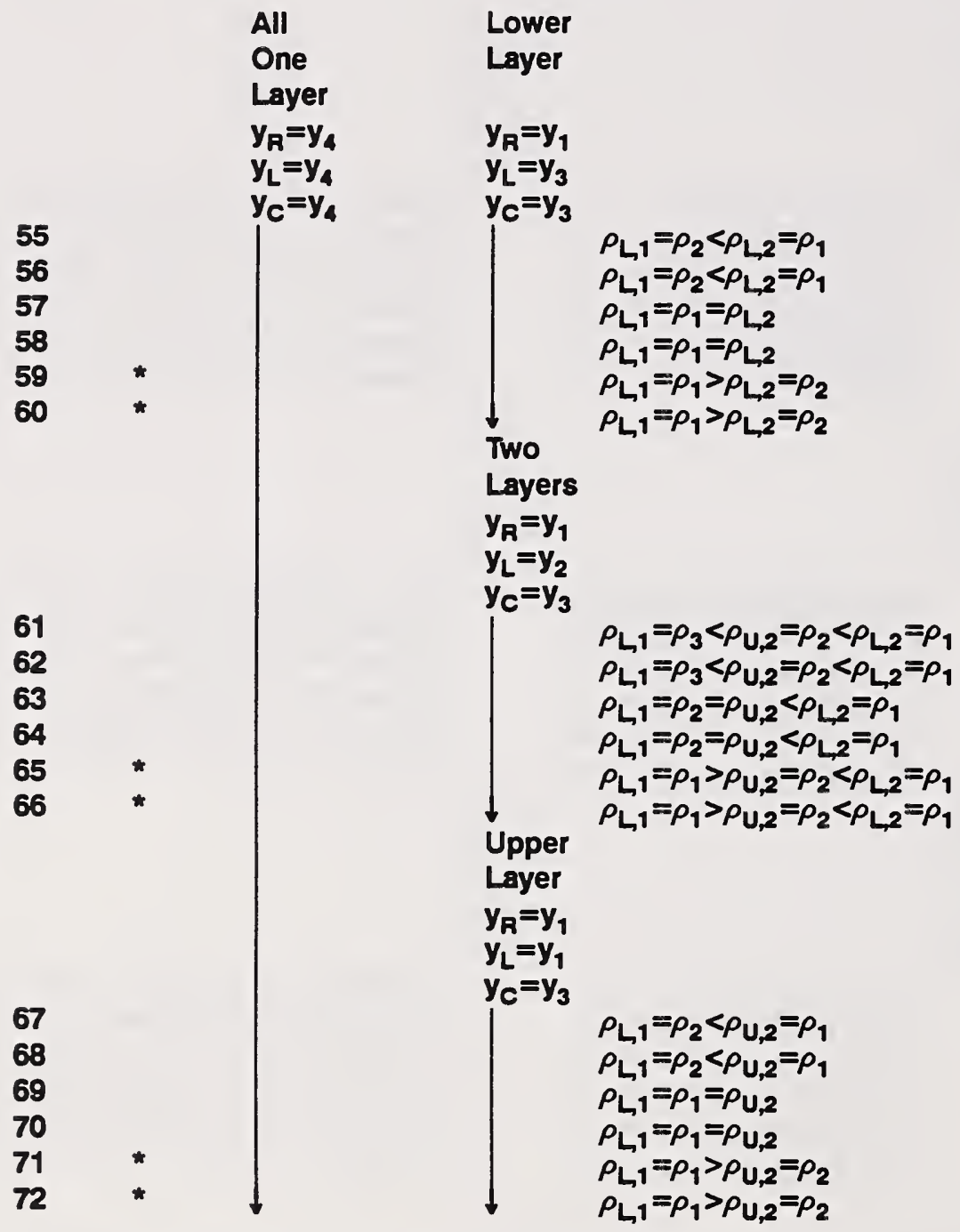

$\delta p_{R E F, 1}=0 .,-p_{D A T}<\delta p_{R E F, 2} \leq p_{D A T}$ $\delta p_{\text {REF }, 2}=0 .,-p_{\text {DAT }}<\delta p_{\text {REF }, 1} \leq p_{\text {DAT }}$ $\delta P_{R E F, 1}=0 .,-P_{D A} T<\delta P_{R E F, 2} \leq P_{D A T}$ $\delta p_{\text {REF }, 2}=0 .,-P_{D A T}<\delta p_{\text {REF }, 1} \leq P_{\text {DAT }}$ $\delta p_{\text {REF }, 1}=0 .,-P_{D A T}<\delta p_{\text {REF, } 2} \leq P_{D A T}$ $\delta p_{\text {REF, } 2}=0 .,-p_{D A T}<\delta p_{R E F, 1} \leq p_{D A T}$

$\delta p_{R E F, 1}=0 .,-p_{D A T}<\delta p_{\text {REF,2 }} \leq p_{D A T}$ $\delta p_{R E F, 2}=0 .,-p_{D A T}<\delta p_{R E F, 1} \leq p_{D A T}$ $\delta p_{R E F, 1}=0,-P_{D A T}<\delta P_{R E F, 2} \leq P_{D A T}$ $\delta p_{R E F, 2}=0,-P_{D A T}<\delta p_{R E F, 1} \leq P_{D A T}$ $\delta p_{R E F, 1}=0 .,-P_{D A T}<\delta p_{R E F, 2} \leq P_{D A T}$ $\delta p_{\text {REF,2 }}=0 .,-p_{\text {DAT }}<\delta p_{\text {REF, } 1} \leq p_{\text {DAT }}$

$\delta p_{R E F, 1}=0 .,-p_{D A T}<\delta p_{R E F, 2} \leq p_{D A T}$ $\delta p_{R E F, 2}=0 .,-p_{D A T}<\delta p_{\text {REF }, 1} \leq P_{D A T}$ $\delta p_{R E F, 1}=0 .,-p_{D A T}<\delta p_{R E F, 2} \leq p_{D A T}$ $\delta p_{R E F, 2}=0 .,-P_{D A T}<\delta p_{R E F, 1} \leq P_{D A T}$ $\delta p_{\text {REF }, 1}=0,,-P_{D A T}<\delta p_{\text {REF }, 2} \leq P_{D A T}$ $\delta P_{R E F, 2}=0 .,-p_{D A T}<\delta p_{R E F, 1} \leq p_{D A T}$

* Unstable cross-vent density configuration 
TABLE 1: Configurations/Environments Used to Test the VENTCF2 Subroutine

(Cont'd)

$$
\begin{aligned}
& \rho_{1}=1.00 \mathrm{~kg} / \mathrm{m}^{3}>\rho_{2}=0.50 \mathrm{~kg} / \mathrm{m}^{3}>\rho_{3}=0.25 \mathrm{~kg} / \mathrm{m}^{3} \\
& y_{1}=0.0 \mathrm{~m}<y_{2}=1.5 \mathrm{~m}<y_{3}=3.0 \mathrm{~m}<y_{4}=4.5 \mathrm{~m}<y_{5}=6.0 \mathrm{~m} \\
& P_{\text {DAT }}=1.01325\left(10^{5}\right) \mathrm{Pa} ; A_{V}=1 \mathrm{~m}^{2}
\end{aligned}
$$

CASES 55-108: SPACE 1 (TOP SPACE) IS OUTSIDE SPACE, SPACE 2 (BOTTOM SPACE) IS INSIDE ROOM (CONT'D) FIGURE $1 \mathrm{~b}$ of APPENDIX A

\begin{tabular}{lll} 
CASE & SPACE & SPACE \\
NO. & 1 & 2 \\
\hline
\end{tabular}

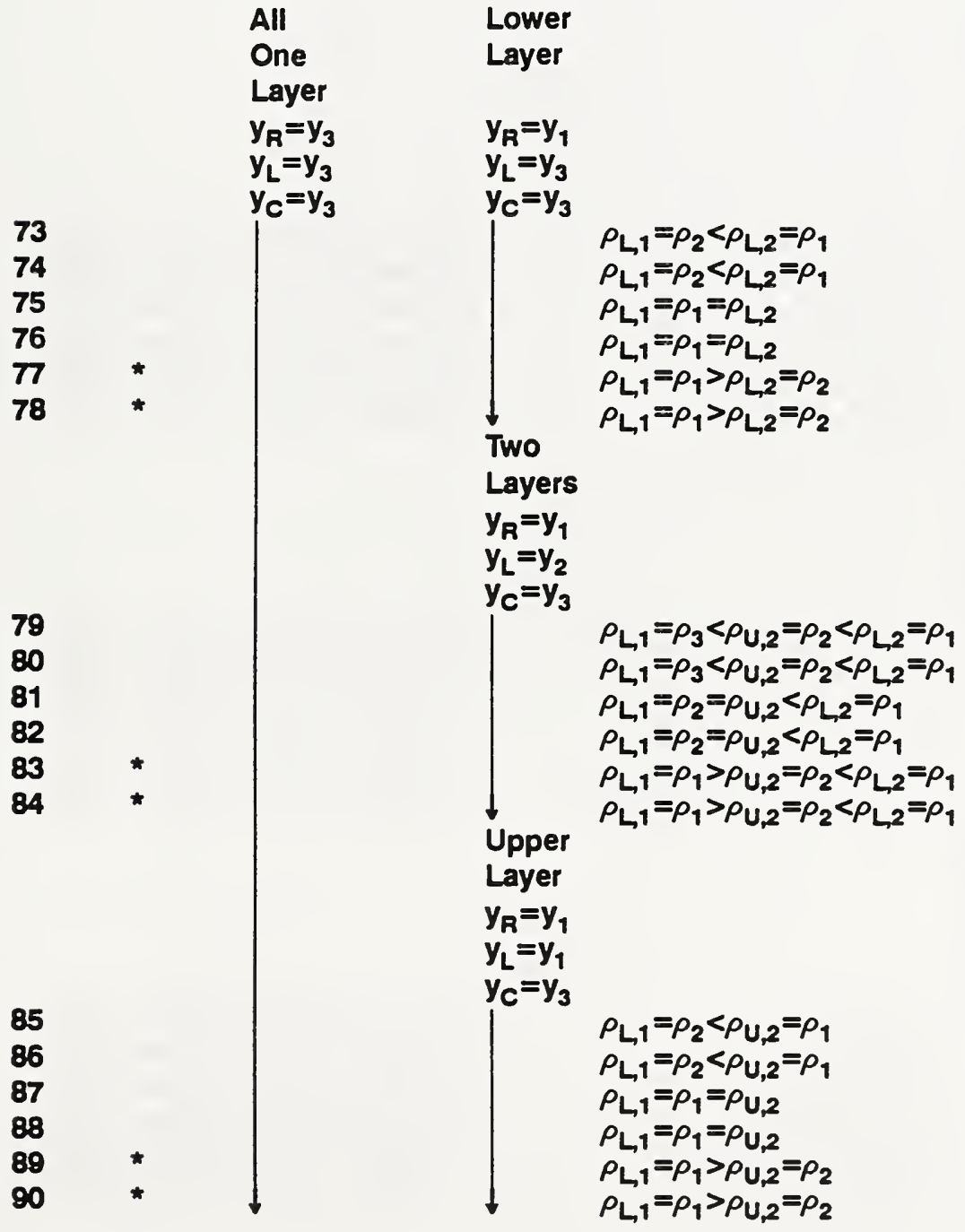

$$
\begin{aligned}
& \delta p_{R E F, 1}=0,,-p_{D A T}<\delta p_{R E F, 2} \leq p_{D A T} \\
& \delta p_{R E F, 2}=0,,-p_{D A T}<\delta p_{R E F, 1} \leq p_{D A T} \\
& \delta p_{R E F, 1}=0,,-p_{D A T}<\delta p_{R E F, 2} \leq p_{D A T} \\
& \delta p_{R E F, 2}=0,,-p_{D A T}<\delta p_{R E F, 1} \leq p_{D A T} \\
& \delta p_{R E F, 1}=0,,-p_{D A T}<\delta p_{R E F, 2} \leq p_{D A T} \\
& \delta p_{R E F, 2}=0,--p_{D A T}<\delta p_{R E F, 1} \leq p_{D A T}
\end{aligned}
$$$$
\delta p_{R E F, 1}=0 .,-p_{D A T}<\delta p_{R E F, 2} \leq p_{D A T}
$$$$
\delta P_{R E F, 2}=0,-P_{D A T}<\delta P_{R E F, 1} \leq P_{D A T}
$$$$
\delta P_{R E F, 1}=0,-P_{D A T}<\delta P_{R E F, 2} \leq P_{D A T}
$$$$
\delta P_{\text {REF }, 2}=0 .,-P_{D A T}<\delta P_{R E F, 1} \leq P_{D A T}
$$$$
\delta P_{R E F, 1}=0 .,-P_{D A T}<\delta p_{R E F, 2} \leq P_{D A T}
$$$$
\delta p_{\text {REF }, 2}=0,-P_{D A T}<\delta p_{R E F, 1} \leq P_{D A T}
$$

$\delta p_{R E F, 1}=0 .,-p_{D A T}<\delta p_{R E F, 2} \leq p_{D A T}$ $\delta P_{R E F, 2}=0,-P_{D A T}<\delta P_{R E F, 1} \leq P_{D A T}$ $\delta p_{R E F, 1}=0,-p_{D A T}<\delta p_{R E F, 2} \leq P_{D A T}$ $\delta p_{R E F, 2}=0 .,-p_{D A T}<\delta p_{R E F, 1} \leq P_{D A T}$ $\delta P_{R E F, 1}=0,-P_{D A T}<\delta P_{R E F, 2} \leq P_{D A T}$ $\delta p_{\text {REF }, 2}=0,,-p_{D A T}<\delta p_{\text {REF }, 1} \leq p_{\text {DAT }}$

* Unstable cross-vent density configuration 
TABLE 1: Configurations/Environments Used to Test the VENTCF2 Subroutine (Cont'd)

$$
\begin{aligned}
& \rho_{1}=1.00 \mathrm{~kg} / \mathrm{m}^{3}>\rho_{2}=0.50 \mathrm{~kg} / \mathrm{m}^{3}>\rho_{3}=0.25 \mathrm{~kg} / \mathrm{m}^{3} \\
& y_{1}=0.0 \mathrm{~m}<y_{2}=1.5 \mathrm{~m}<y_{3}=3.0 \mathrm{~m}<y_{4}=4.5 \mathrm{~m}<y_{5}=6.0 \mathrm{~m} \\
& P_{\text {DAT }}=1.01325\left(10^{5}\right) \mathrm{Pa} ; A_{V}=1 \mathrm{~m}^{2}
\end{aligned}
$$

CASES 55-108: SPACE 1 (TOP SPACE) IS OUTSIDE SPACE, SPACE 2 (BOTTOM SPACE) IS INSIDE ROOM (CONT'D) FIGURE 1b of APPENDIX A

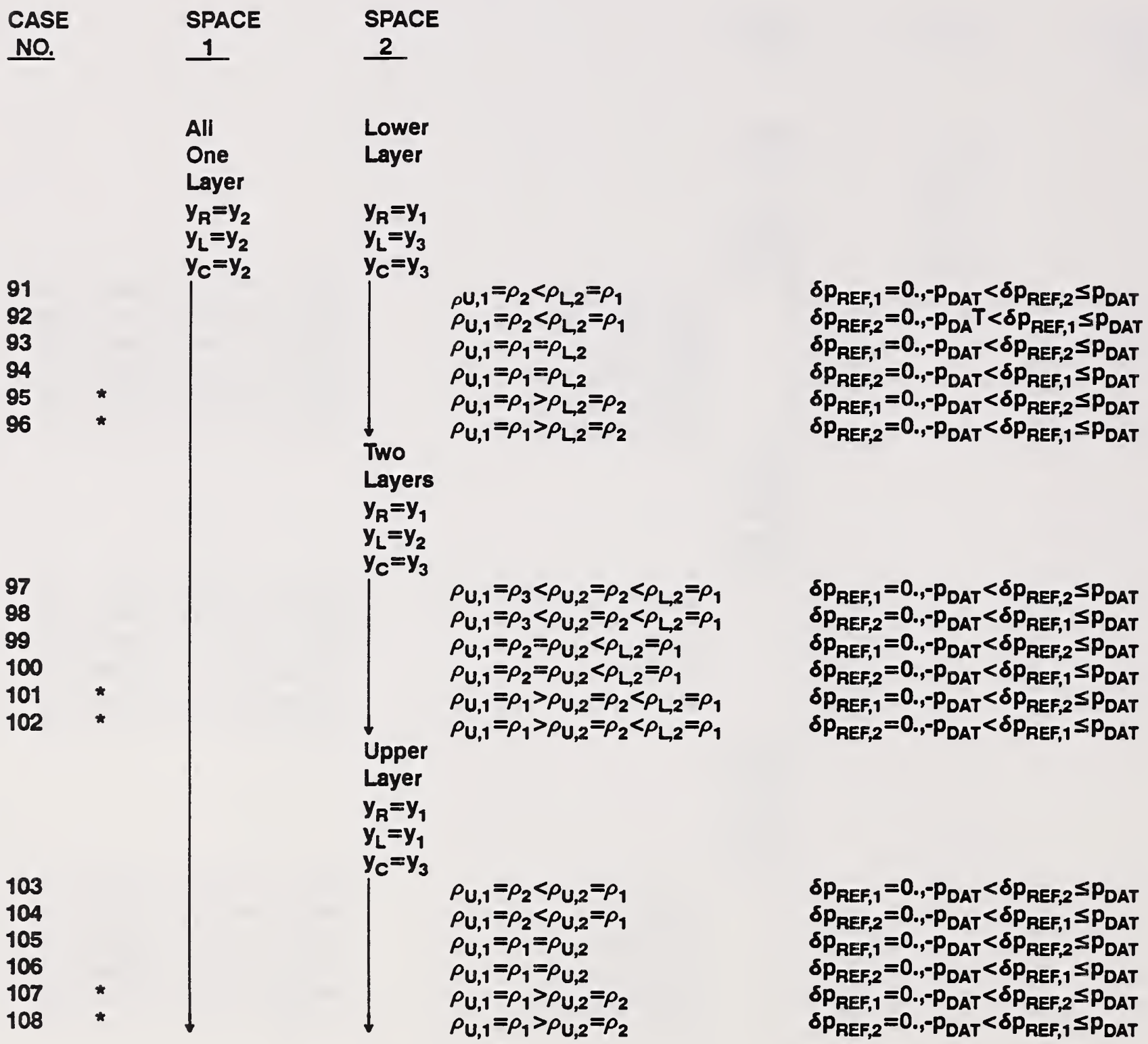

* Unstable cross-vent density conflguration 
TABLE 1: Configurations/Environments Used to Test the VENTCF2 Subroutine

(Cont'd)

$$
\begin{aligned}
& \rho_{1}=1.00 \mathrm{~kg} / \mathrm{m}^{3}>\rho_{2}=0.50 \mathrm{~kg} / \mathrm{m}^{3}>\rho_{3}=0.25 \mathrm{~kg} / \mathrm{m}^{3} \\
& y_{1}=0.0 \mathrm{~m}<y_{2}=1.5 \mathrm{~m}<y_{3}=3.0 \mathrm{~m}<y_{4}=4.5 \mathrm{~m}<y_{5}=6.0 \mathrm{~m} \\
& P_{\text {DAT }}=1.01325\left(10^{5}\right) \mathrm{Pa} ; A_{V}=1 \mathrm{~m}^{2}
\end{aligned}
$$

CASES 109-162:

SPACE 1 (TOP SPACE) IS INSIDE ROOM, SPACE 2 (BOTTOM SPACE) IS OUTSIDE SPACE - FIGURE 1C Of APPENDIX A

CASE

NO.

SPACE

1

Lower

All

One

Layer

$y_{R}=y_{3}$

$\mathbf{y}_{L}=\mathbf{y}_{5}$

109

110

111

112

113

114

115

116

117

118

119

120

$y_{R}=y_{3}$

$y_{L}=y_{3}$

$y_{c}=y_{3}$
$\rho_{L, 1}=\rho_{2}<\rho_{L, 2}=\rho_{1}$

$\rho_{L, 1}=\rho_{2}<\rho_{L, 2}=\rho_{1}$

$\rho_{L, 1}=\rho_{1}=\rho_{L, 2}$

$\rho_{L, 1}=\rho_{1}=\rho_{L, 2}$

$\rho_{L, 1}=\rho_{1}>\rho_{L, 2}=\rho_{2}$

$\rho_{L, 1}=\rho_{1}>\rho_{L, 2}=\rho_{2}$

$\rho_{L, 1}=\rho_{3}<\rho_{U, 2}=\rho_{2}<\rho_{L, 2}=\rho_{1}$

$\rho_{L, 1}=\rho_{3}<\rho_{U, 2}=\rho_{2}<\rho_{L, 2}=\rho_{1}$

$\rho_{L, 1}=\rho_{\mathbf{2}}=\rho_{\mathrm{U}, 2}<\rho_{L, 2}=\rho_{1}$

$\rho_{\mathrm{L}, 1}=\rho_{2}=\rho_{\mathrm{U}, 2}<\rho_{\mathrm{L}, 2}=\rho_{1}$

$\rho_{L, 1}=\rho_{1}>\rho_{\mathrm{U}, 2}=\rho_{2}<\rho_{L, 2}=\rho_{1}$

$\rho_{L, 1}=\rho_{1}>\rho_{U, 2}=\rho_{2}<\rho_{L, 2}=\rho_{1}$

$y_{R}=y_{2}$

$y_{L}=y_{2}$

$y_{c}=y_{2}$

126
$\rho_{L, 1}=\rho_{2}<\rho_{U, 2}=\rho_{1}$

$\rho_{L, 1}=\rho_{2}<\rho_{U, 2}=\rho_{1}$

$\rho_{L, 1}=\rho_{1}=\rho_{U, 2}$

$\rho_{\mathrm{L}, 1}=\rho_{1}=\rho_{\mathrm{U}, 2}$

$\rho_{L, 1}=\rho_{1}>\rho_{U, 2}=\rho_{2}$

$\rho_{L, 1}=\rho_{1}>\rho_{U, 2}=\rho_{2}$ $\delta p_{R E F, 1}=0 .,-p_{D A T}<\delta p_{R E F, 2} \leq p_{D A T}$ $\delta p_{\text {REF,2 }}=0 .,-p_{D A T}<\delta p_{R E F, 1} \leq p_{D A T}$ $\delta P_{R E F, 1}=0 .,-P_{D A} T<\delta P_{R E F, 2} \leq P_{D A T}$ $\delta P_{R E F, 2}=0 .,-P_{D A T}<\delta p_{R E F, 1} \leq P_{D A T}$ $\delta P_{R E F, 1}=0 .,-P_{D A T}<\delta P_{R E F, 2} \leq P_{D A T}$ $\delta p_{R E F, 2}=0 .,-p_{\text {DAT }}<\delta p_{\text {REF, } 1} \leq p_{\text {DAT }}$

$\delta p_{\text {REF, },}=0 .,-p_{D A T}<\delta p_{R E F, 2} \leq p_{D A T}$ $\delta P_{\text {REF }, 2}=0 .,-P_{D A T}<\delta p_{R E F, 1} \leq P_{D A T}$ $\delta p_{\text {REF }, 1}=0,-p_{D A T}<\delta p_{R E F, 2} \leq p_{D A T}$ $\delta p_{R E F, 2}=0,-P_{D A T}<\delta p_{R E F, 1} \leq P_{D A T}$ $\delta p_{R E F, 1}=0 .,-P_{D A T}<\delta P_{R E F, 2} \leq P_{D A T}$ $\delta P_{R E F, 2}=0 .,-P_{D A T}<\delta P_{R E F, 1} \leq P_{D A T}$

* Unstable cross-vent density conflguration 
TABLE 1: Configurations/Environments Used to Test the VENTCF2 Subroutine (Cont'd)

$$
\begin{aligned}
& \rho_{1}=1.00 \mathrm{~kg} / \mathrm{m}^{3}>\rho_{2}=0.50 \mathrm{~kg} / \mathrm{m}^{3}>\rho_{3}=0.25 \mathrm{~kg} / \mathrm{m}^{3} \\
& y_{1}=0.0 \mathrm{~m}<y_{2}=1.5 \mathrm{~m}<y_{3}=3.0 \mathrm{~m}<y_{4}=4.5 \mathrm{~m}<y_{5}=6.0 \mathrm{~m} \\
& P_{\text {DAT }}=1.01325\left(10^{5}\right) \mathrm{Pa} ; A_{V}=1 \mathrm{~m}^{2}
\end{aligned}
$$

CASES 109-162: (CONT'D)

CASE

NO.

SPACE
1

Two

Layer

128

129

130
SPACE 1 (TOP SPACE) IS INSIDE ROOM, SPACE 2 (BOTTOM SPACE) IS OUTSIDE SPACE - FIGURE 1C Of APPENDIX A $\delta p_{R E F, 1}=0 .,-p_{D A T}<\delta p_{R E F, 2} \leq p_{D A T}$ $\delta P_{R E F, 2}=0,-P_{D A T}<\delta p_{R E F, 1} \leq P_{D A T}$ $\delta P_{R E F, 1}=0,-P_{D A T}<\delta P_{\text {REF, } 2} \leq P_{D A T}$ $\delta p_{R E F, 2}=0,-p_{D A T}<\delta p_{R E F, 1} \leq P_{D A T}$ $\delta p_{R E F, 1}=0,-p_{D A T}<\delta p_{R E F, 2} \leq P_{D A T}$ $\delta p_{R E F, 2}=0,,-p_{D A T}<\delta p_{R E F, 1} \leq p_{D A T}$

$\delta p_{R E F, 1}=0 .,-p_{D A T}<\delta p_{R E F, 2} \leq p_{D A T}$ $\delta p_{R E F, 2}=0,-p_{D A T}<\delta p_{R E F, 1} \leq P_{D A T}$ $\delta P_{R E F, 1}=0,-P_{D A T}<\delta P_{R E F, 2} \leq P_{D A T}$ $\delta p_{R E F, 2}=0,-P_{D A T}<\delta p_{R E F, 1} \leq P_{D A T}$ $\delta p_{\text {REF }, 1}=0 .,-P_{D A T}<\delta p_{\text {REF }, 2} \leq P_{\text {DAT }}$ $\delta p_{R E F, 2}=0 .,-p_{D A T}<\delta p_{R E F, 1} \leq p_{D A T}$

\footnotetext{
* Unstable cross-vent density configuration
}

$\rho_{L, 1}=\rho_{2}<\rho_{U, 2}=\rho_{1}$

$\rho_{L, 1}=\rho_{2}<\rho_{U, 2}=\rho_{1}$

$\rho_{L, 1}=\rho_{1}=\rho_{U, 2}$

$\rho_{L, 1}=\rho_{1}=\rho_{U, 2}$

$\rho_{\mathrm{L}, 1}=\rho_{1}>\rho_{\mathrm{U}, 2}=\rho_{2}$

$\rho_{L, 1}=\rho_{1}>\rho_{U, 2}=\rho_{2}$ $\delta p_{R E F, 1}=0 .,-p_{D A T}<\delta p_{R E F, 2} \leq p_{D A T}$ $\delta p_{\text {REF }, 2}=0,-p_{D A T}<\delta p_{R E F, 1} \leq p_{D A T}$ $\delta p_{R E F, 1}=0 .,-p_{D A T}<\delta p_{R E F, 2} \leq P_{D A T}$ $\delta p_{\text {REF }, 2}=0 .,-p_{D A T}<\delta p_{R E F, 1} \leq P_{D A T}$ $\delta P_{\text {REF }, 1}=0$, - $_{\text {DAT }}<\delta P_{\text {REF }, 2} \leq P_{D A T}$ $\delta P_{\text {REF, } 2}=0,,-P_{D A T}<\delta p_{R E F, 1} \leq P_{D A T}$ 
TABLE 1: Configurations/Environments Used to Test the VENTCF2 Subroutine

(Cont'd)

$$
\begin{aligned}
& \rho_{1}=1.00 \mathrm{~kg} / \mathrm{m}^{3}>\rho_{2}=0.50 \mathrm{~kg} / \mathrm{m}^{3}>\rho_{3}=0.25 \mathrm{~kg} / \mathrm{m}^{3} \\
& y_{1}=0.0 \mathrm{~m}<\mathrm{y}_{2}=1.5 \mathrm{~m}<\mathrm{y}_{3}=3.0 \mathrm{~m}<\mathrm{y}_{4}=4.5 \mathrm{~m}<\mathrm{y}_{5}=6.0 \mathrm{~m} \\
& P_{\text {DAT }}=1.01325\left(10^{5}\right) \mathrm{Pa} ; A_{V}=1 \mathrm{~m}^{2}
\end{aligned}
$$

CASES 109-162: (CONT'D)

CASE

NO.

SPACE

1

$\begin{array}{ll}\text { Upper } & \text { All } \\ \text { Layer } & \text { One } \\ & \text { Layer } \\ y_{F}=y_{3} & y_{R}=y_{4} \\ y_{L}=y_{4} \\ y_{C}=y_{3} & y_{C}=y_{4}\end{array}$

151

152

153

154

155

156

157

158

159

160

161

162

\section{SPACE}

$\underline{2}$

SPACE 1 (TOP SPACE) IS INSIDE ROOM, SPACE 2 (BOTTOM SPACE) IS OUTSIDE SPACE - FIGURE 1C Of APPENDIX A

$\rho_{\mathrm{U}, 1}=\rho_{2}<\rho_{\mathrm{L}, 2}=\rho_{1}$

$\rho_{U, 1}=\rho_{2}<\rho_{L, 2}=\rho_{1}$

$\rho_{\mathrm{U}, 1}=\rho_{1}=\rho_{\mathrm{L}, 2}$

$\rho_{\mathrm{U}, 1}=\rho_{1}=\rho_{\mathrm{L}, 2}$

$\rho_{U, 1}=\rho_{1}>\rho_{L, 2}=\rho_{2}$

$\rho_{\mathrm{U}, 1}=\rho_{1}>\rho_{\mathrm{L}, \mathrm{Z}}=\rho_{2}$

$y_{R}=y_{3}$

$y_{L}=y_{3}$

$y_{C}=y_{3}$
$\rho_{\mathrm{U}, 1}=\rho_{3}<\rho_{\mathrm{U}, 2}=\rho_{2}<\rho_{\mathrm{L}, 2}=\rho_{1}$

$\rho_{\mathrm{U}, 1}=\rho_{3}<\rho_{\mathrm{U}, 2}=\rho_{2}<\rho_{\mathrm{L}, 2}=\rho_{1}$

$\rho_{\mathrm{U}, 1}=\rho_{\mathbf{2}}=\rho_{\mathrm{U}, 2}<\rho_{\mathrm{L}, 2}=\rho_{1}$

$\rho_{\mathrm{U}, 1}=\rho_{2}=\rho_{\mathrm{U}, 2}<\rho_{\mathrm{L}, 2}=\rho_{1}$

$\rho_{U, 1}=\rho_{1}>\rho_{U, 2}=\rho_{2}<\rho_{L, 2}=\rho_{1}$

$\rho_{\mathrm{U}, 1}=\rho_{1}>\rho_{\mathrm{U}, 2}=\rho_{2}<\rho_{\mathrm{L}, 2}=\rho_{1}$

$y_{R}=y_{2}$

$y_{L}=y_{2}$

$y_{c}=y_{2}$
$\rho_{\mathrm{U}, 1}=\rho_{2}<\rho_{\mathrm{U}, 2}=\rho_{1}$

$\rho_{\mathrm{U}, 1}=\rho_{2}<\rho_{\mathrm{U}, 2}=\rho_{1}$

$\rho_{\mathrm{U}, 1}=\rho_{1}=\rho_{\mathrm{U}, 2}$

$\rho_{\mathrm{U}, 1}=\rho_{1}=\rho_{\mathrm{U}, 2}$

$\rho_{\mathrm{U}, 1}=\rho_{1}>\rho_{\mathrm{U}, 2}=\rho_{2}$

$\rho_{\mathrm{U}, 1}=\rho_{1}>\rho_{\mathrm{U}, 2}=\rho_{2}$ $\delta p_{R E F, 1}=0,-p_{D A T}<\delta p_{R E F, 2} \leq p_{D A T}$

$\delta P_{R E F, 2}=0 .,-P_{D A} T<\delta P_{R E F, 1} \leq P_{D A T}$

$\delta p_{R E F, 1}=0,-p_{D A T}<\delta p_{\text {REF, } 2} \leq P_{D A T}$

$\delta p_{\text {REF,2 }}=0,-p_{D A T}<\delta p_{\text {REF, } 1} \leq P_{D A T}$

$\delta p_{\text {REF }, 1}=0,-p_{\text {DAT }}<\delta p_{\text {REF, } 2} \leq P_{D A T}$

$\delta p_{\text {REF }, 2}=0,-p_{D A T}<\delta p_{R E F, 1} \leq P_{D A T}$

$\delta p_{R E F, 1}=0 .,-p_{D A T}<\delta p_{R E F, 2} \leq P_{D A T}$ $\delta P_{R E F, 2}=0,-p_{D A T}<\delta p_{R E F, 1} \leq P_{D A T}$ $\delta p_{\text {REF }, 1}=0 .,-p_{D A T}<\delta p_{R E F, 2} \leq p_{D A T}$ $\delta p_{\text {REF, }}=0,-p_{\text {DAT }}<\delta p_{\text {REF }, 1} \leq P_{D A T}$ $\delta p_{R E F, 1}=0,-p_{D A T}<\delta p_{\text {REF }, 2} \leq P_{D A T}$ $\delta p_{R E F, 2}=0,-p_{D A T}<\delta p_{R E F, 1} \leq P_{D A T}$ $\delta p_{R E F, 1}=0,--p_{D A T}<\delta p_{R E F, 2} \leq P_{D A T}$ $\delta p_{\text {REF }, 2}=0,-p_{D A T}<\delta p_{R E F, 1} \leq P_{D A T}$ $\delta p_{\text {REF }, 1}=0,-p_{D A T}<\delta p_{\text {REF, } 2} \leq P_{D A T}$ $\delta p_{\text {REF }, 2}=0,-p_{D A T}<\delta p_{R E F, 1} \leq P_{D A T}$ $\delta p_{\text {REF, } 1}=0 .,-P_{D A T}<\delta p_{R E F, 2} \leq P_{D A T}$ $\delta P_{R E F, 2}=0 .,-P_{D A T}<\delta p_{R E F, 1} \leq P_{D A T}$

* Unstable cross-vent density conflguration 


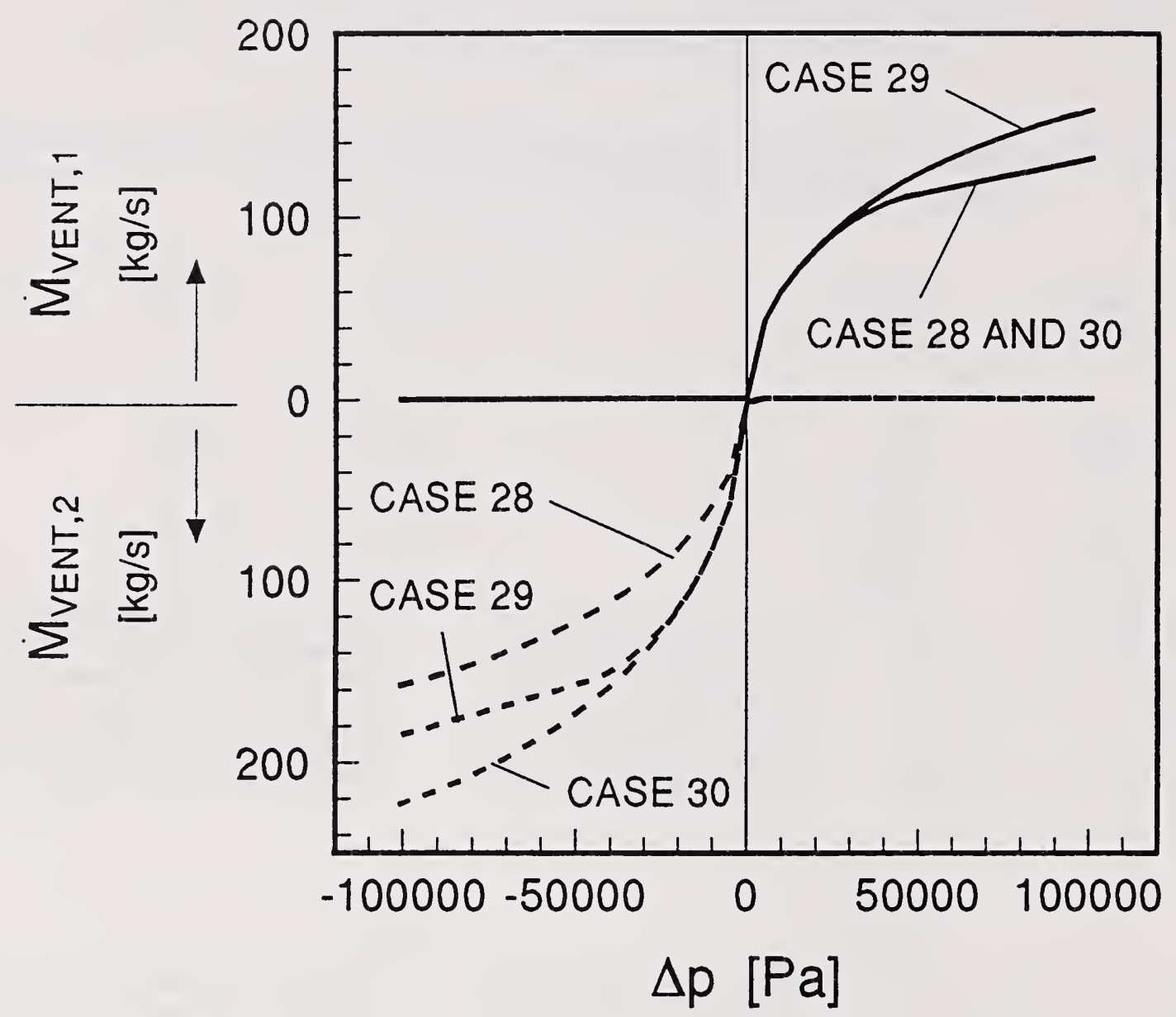

Figure 1. Plots of the calculated mass flow rate to upper space 1, $\dot{M}_{\mathrm{VENT}, 1}$, and to lower space 2, $\dot{M}_{\mathrm{VENT}, 2}$, as functions of the computed (coarse-scale) cross-vent pressure difference, $\Delta p$, for Cases 28, 29, and 30 (see Table 1). 


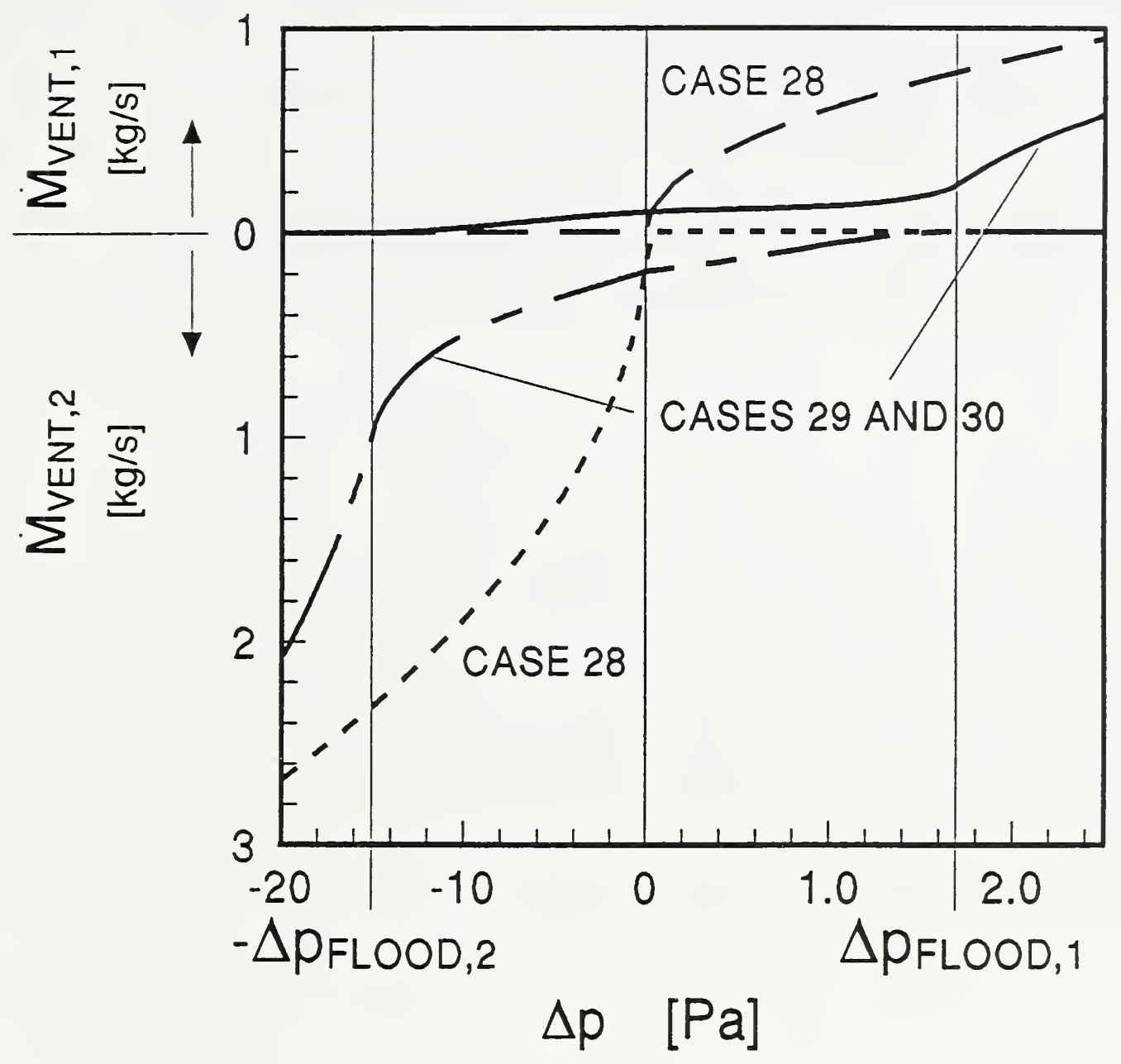

Figure 2. Plots of the calculated mass flow rate to upper space $1, \dot{M}_{\text {VENT,1 }}$, and to lower space 2, $\dot{M}_{\mathrm{VENT}, 2}$, as functions of the computed (fine-scale) cross-vent pressure difference, $\Delta p$, for Cases 28, 29, and 30 (see Table 1). 

APPENDIX A (pages VENTCF2-1 to VENTCF2-22)

VENTCF2 - CALCULATION OF THE FLOW THROUGH A HORIZONTAL CEILING/FLOOR VENT CONNECTING TWO SPACES

APPENDIX B (pages VENTCF2A-1 to VENTCF2A-25)

VENTCF2A - CALCULATION OF THE FLOW THROUGH A HORIZONTAL CEILING/FLOOR VENT CONNECTING TWO SPACES WITH "SMOOTHING" OF LAYER EXTRACTION RATES AT TIMES OF RELATIVELY THIN ADJACENT-VENT LAYERS 


CONNECTING TWO SPACES

\section{DESCRIPTION}

Consider an instant of time during the simulation of a multi-room compartment fire environment. This algorithm calculates the flow of mass, enthalpy, oxygen, and other products of combustion through a horizontal vent located in a ceiling/floor partition common to any two inside rooms of the facility or between an inside room and the outside environment local to the vent. VENTCF2, is an advanced version of the algorithm/subroutine VENTCF [1] in that it includes an improved theoretical [2, 3] and experimental basis.

Depicted in Figure 1a is the vent and the two spaces when they are both inside rooms of a multi-room facility. Figures $1 \mathrm{~b}$ and $1 \mathrm{c}$ depict the situation when the two spaces involve one inside room of the facility and one outside space, either above or below the room, in which is simulated the outside environment local to the vent.

As in Figure 1, designate the top space as space 1 and the bottom space as space 2. It is assumed that the temperature, density, concentration of oxygen and of other products of combustion of interest in the upper and lower layer of each inside room and in the environment local to the vent of an outside space are specified. Also specified in each inside room are: the elevation above the datum elevation of the floor, and the upper-layer/lower-layer interface; and the pressure at the floor above the specified datum pressure. Specified in an outside space are: a reference elevation above the datum elevation, and the pressure at this reference elevation above the specified datum pressure.

When the upper gas is less dense than the lower gas, i.e., the fluid configuration is stable, the flow through the vent is determined by a traditional orifice-type flow model. Then, flow is determined by the cross-vent pressure difference without any regard for buoyancy effects (see, e.g., [4] and [5]) and the present algorithm/subroutine is identical to that of VENTCF [1]. When the configuration is unstable and the upper gas is more dense than the lower gas, the effects of combined pressure and buoyancy forces can be significant. For example if the cross-vent pressure is relatively small, the unstable density configuration leads to an exchange-type of flow, with gas in the lower space rising into the upper space and gas from the upper space dropping into the lower space, where the flow rate from the high- to the low-pressure side of the vent is the larger of the two. Also, even when the cross-vent pressure difference large enough to produce uni-directional flow, the effect of buoyancy can be great enough to reduce significantly the flow rate from what it would be in the absence of a cross-vent density difference. In the present algorithm, for the case of unstable configurations the calculation of the flow between the two spaces is based on the theory and analysis of [3] and [2], respectively.

For unstable density configurations, the model of [2] and, therefore, the VENTCF2 algorithm/subroutine itself is for flow through a circular, shallow (i.e., small ratio of depth to diameter), horizontal vent. It is also expected that the model will give reasonable estimates of flow even for non-circular vents, provided the aspect ratio (maximum-to-minimum span) of a vent shape of interest is not too much different than 1. Indeed, one of the example calculations of [2], which includes comparisons with some relevant experimental data, provides limited support for the applicability of the model in the case of square vents. However, USE OF VENTCF2 IN HIGH-ASPECT-RATIO AND/OR MODERATE-TO-LARGE-DEPTH VENT SCENARIOS IS NOT VALID when cross-vent pressure differences are small-to-moderate compared to $\Delta \mathrm{p}_{\mathrm{FLOOD}}$. Results beyond those developed in [2] are required before the present work can be used for the latter types of vent shape. 
The geometry and the conditions local to the vent which determine the characteristics of the vent flow are depicted in Figure 2. These include: the densities, $\rho_{1}$ and $\rho_{2}$, and the hydrostatic pressures, $p_{1}$ and $p_{2}$, at the elevation, but away from the immediate vicinity of the vent in the upper and lower spaces, respectively, and the area, $A_{v}$, and shape of the vent. Regarding the shape, at the present time results for horizontal vent flows are only available for circular or square vents. Other properties local to the vent and indicated in Figure 2 are $T_{1}$ and $T_{2}$, the absolute temperatures, $c_{02,1}$ and $c_{02,2}$, the concentrations of oxygen, and $\mathrm{c}_{\mathrm{K}, 1}$ and $\mathrm{c}_{\mathrm{K}, 2}, \mathrm{~K}=2$ to $\mathrm{N}_{\mathrm{PROD}}$, the concentrations of a product of combustion $\mathrm{K}$.

To simulate fire scenarios at times when vent flows are driven by arbitrarily high cross-vent pressure differences (i.e., when compressibility effects begin to be significant), whether for stable or unstable crossvent density configurations, VENTCF2 implements the ideas introduced in reference [5] and implemented previously in the algorithm/subroutines VENTHP [6] and VENTCF [1]. Such high cross-vent pressure differences could occur, for example, in fire scenarios involving flows through cracks in otherwise hermetically-sealed fire compartments.

The VENTCF2 subroutine has been subjected to extensive parametric testing in a "stand-alone" mode [7].

\section{OUTPUT}

$c_{02,1}\left[c_{02,2}\right]$

Concentration of oxygen in the top [bottom] space at the elevation of the vent. [(kg of oxygen)/(kg of layer)]

$c_{K, 1}\left[c_{K, 2}\right]$

Concentration of product $K$ in the top [bottom] space at the elevation of the vent. [(unit of product $\mathrm{K}) /(\mathrm{kg}$ of layer)]

GENT,O2,i I $=1$ or 2

Concentration of oxygen in the component of the vent flow entering space I, provided such vent flow component is non-zero, i.e., provided $\dot{M}_{\text {VENT, }}$ is non-zero. [(kg of oxygen)/(kg of vent flow)]

GENT,KI; $_{1}$ = 1 or $2 ; K=2$ to NPROD

Concentration of product of combustion $\mathrm{K}$ in the component of the vent flow entering space I, provided such vent flow component is nonzero, i.e., provided $\dot{M}_{\text {VENT, }}$ is non-zero. [(unit of product)/(kg of vent flow)]

$\dot{M}_{U, I}\left[\dot{M}_{L,}\right] ; I=1$ or 2

If space I is an inside room: Rate at which mass is added to the upper [lower] layer of room I due to the vent flow component which enters the other space. Note that this will always be negative, since the layer which supplies the material flowing to the other space will always have mass extracted from it. [W]

If space I is an "outside room": $\dot{M}_{U, I}$ is the rate at which mass is added to space I due to the vent flow component which enters the other space (i.e., the inside room). Note that this will always be negative, since an outside space which supplies material flowing through the vent to an adjacent space will always have mass extracted from it. $\dot{M}_{L,}$ is identical to $\dot{M}_{U, 1}$. [W] 


$$
\dot{M}_{\text {VENT, } i} ; I=1 \text { to } 2
$$

Mass flow rate of the vent flow component entering space $\mathrm{I} .[\mathrm{kg} / \mathrm{s}]$

$$
P_{O 2, L, I}\left[P_{O 2, U, I}\right] ; I=1 \text { or } 2
$$

If space I is an inside room: Rate at which oxygen is added to the upper [lower] layer of room I due to the vent flow component which enters the other space. Note that this will always be negative, since the layer which supplies the material flowing through the vent to the other space will always have its convected oxygen extracted from it. [ $\left.\left(\mathrm{kg} \mathrm{of} \mathrm{O}_{2}\right) / \mathrm{s}\right]$

If space I is an "outside room": $P_{O 2, U, I}$ is the rate at which oxygen is added to space I due to the vent flow component which enters the other space (i.e., the inside room). Note that this will always be negative, since an outside space which supplies material flowing through the vent to an adjacent space will always have its convected oxygen extracted from it. $P_{O 2, L,}$ is identical to $P_{O 2, U, 1 \cdot}\left[\left(\mathrm{kg}\right.\right.$ of $\left.\left.\mathrm{O}_{2}\right) / \mathrm{s}\right]$

$P_{\text {O2,VENT, },} ; I=1$ to 2

Mass flow rate of oxygen of the vent flow component entering space I. [(kg of oxygen)/s]

$P_{K, L, I}\left[P_{K, U, I}\right] ; K=2$ to $N_{P R O D} ; I=1$ or 2

If space I is an inside room: Rate at which product of combustion $\mathrm{K}$ is added to the upper [lower] layer of room I due to the vent flow component which enters the other space. Note that this will always be negative since the layer which supplies the material flowing through the vent to the other space will always have its convected product of combustion $\mathrm{K}$ extracted from it. [(unit of product $\mathrm{K} / \mathrm{s}$ ]

If space $I$ is an "outside room": $P_{K, U, I}$ is the rate at which product of combustion $K$ is added to space I due to the vent flow component which enters the other space (i.e., the inside room). Note that this will always be negative, since an outside space which supplies material flowing through the vent to an adjacent space will always have the convected product of combustion $\mathrm{K}$ extracted from it. $P_{K, L I}$ is identical to $P_{K, U, 1}$ [(Unit of product $\left.K\right) / S$ ]

$P_{\text {KVENT,I }} ; 1=1$ to $2 ; K=2$ to $N_{\text {PROD }}$

Flow rate of product of combustion $\mathrm{K}$ in the vent flow component entering space I. [(unit of product $\mathrm{K}) / \mathrm{s}$ ]

$p_{1}\left[p_{2}\right]$

Absolute hydrostatic pressure in the top [bottom] space at the elevation of the vent. $[\mathrm{Pa}=$ $\left.\mathrm{kg} /\left(\mathrm{m} \cdot \mathrm{s}^{2}\right)\right]$

$Q_{U, I}\left[Q_{L, 1}\right] ; 1=1$ or 2

If space I is an inside room: Rate at which enthalpy added to the upper [lower] layer of room I due to the vent flow component which enters the other space. Note that this will always be negative, since the layer which supplies the material which flows to the other space will always have its convected enthalpy extracted from it. The enthalpy is based on the absolute temperature of the flow, $T_{\text {VENT, }} \cdot[\mathrm{W}$ ] 
If space I is an "outside room": $Q_{U, I}$ is the rate at which enthalpy is added to space I due to the vent flow component which enters the other space (i.e., the inside room). Note that this will always be negative, since an outside space which supplies material which flows through the vent to an adjacent space will always have its convected enthalpy extracted from it. The enthalpy is based on the absolute temperature of the flow, $T_{U, 1}$. $Q_{L, 1}$ is identical to $Q_{U, 1}$. [W]

$Q_{\text {VENT, }} ; 1=1$ to 2

Total enthalpy flow rate in the vent flow component entering space I. This is based on the absolute temperature of the flow, $\mathrm{T}_{\mathrm{VENT}, \mathrm{l}}[\mathrm{W}]$

$\mathrm{T}_{1}\left[\mathrm{~T}_{2}\right]$

Absolute temperature in the top [bottom] space at the elevation of the vent. [K]

$T_{\text {VENT, } ;} ;=1$ to 2

Absolute temperature of the vent flow component entering space I, provided such vent flow component is non-zero. [K]

$\Delta p$

$p_{2}-p_{1}$, i.e., difference between the pressure in the bottom space at the elevation of the vent, and the pressure in the top space at the elevation of the vent. $\left[\mathrm{Pa}=\mathrm{kg} /\left(\mathrm{m} \cdot \mathrm{s}^{2}\right)\right]$

$\rho_{1}\left[\rho_{2}\right]$

Density in the top [bottom] space at the elevation of the vent. $\left[\mathrm{kg} / \mathrm{m}_{3}\right]$

$\rho_{\text {VENT, } ; ~} I=1$ to 2

Density of the vent flow component entering space I, provided such vent flow component is nonzero. $\left[\mathrm{kg} / \mathrm{m}^{3}\right]$

INPUT

Av

Area of the vent $\left[\mathrm{m}^{2}\right]$.

$C_{L, K, I}\left[C_{U, K, I}\right] ; K=2$ to $N_{P R O D} ; l=1$ or 2

If space I is an inside room: Concentration of product of combustion $\mathrm{K}$ in lower [upper] layer of room I if the volume of the lower [upper] layer is non-zero (if the lower [upper] layer volume is zero then the $c_{L, K, I}\left[c_{U, K,}\right]$ value is not used in the calculation). [(unit of product $\left.K\right) /(\mathrm{kg}$ of layer)]

If space $l$ is an "outside room": $c_{L, K,}$ is the uniform concentration throughout the space of product of combustion $K ; c_{U, K, I}$ is specified as being identical to $c_{L, K, \cdot}$ [ (unit of product $\left.K\right) /(k g$ of local atmosphere)] 
$c_{L, 02,1}\left[c_{U, 02,1}\right] ; 1=1$ or 2

If space I is an inside room: Concentration of oxygen in lower [upper] layer of room I if the volume of the lower [upper] layer is non-zero (if the lower [upper] layer volume is zero then the $c_{L, 02,1}\left[c_{U, 02,1}\right]$ value is not used in the calculation). [(kg of oxygen)/(kg of layer)]

If space $l$ is an "outside room": $C_{L, 02,1}$ is the uniform concentration throughout the space of oxygen; $c_{U, 02,1}$ is specified as being identical to $c_{L, 02,1}[(\mathrm{~kg}$ of oxygen)/(kg of local atmosphere)]

$C_{p}$

Specific heat at constant pressure of the vent flow. $[\mathrm{W} \cdot \mathrm{s} /(\mathrm{kg} \cdot \mathrm{K})]$ (suggest $10^{3} \mathrm{~W} \cdot \mathrm{s} /(\mathrm{kg} \cdot \mathrm{K})$ for air as default)

$N_{\text {PMAX }}$

Maximum allowed number of products of combustion.

$\mathrm{N}_{\mathrm{PROD}}$

Number of products of combustion, including oxygen, being tracked in the simulation.

PDAT

Datum absolute pressure. $\left[\mathrm{Pa}=\mathrm{kg} /\left(\mathrm{m} \cdot \mathrm{s}^{2}\right)\right]$

$T_{L, 1}\left[T_{U, 1}\right] ; 1=1$ or 2

If space I is an inside room: Absolute temperature of the lower [upper] layer in room I if the volume of the lower [upper] layer is non-zero (if the lower [upper] layer volume is zero then the $T_{L,}\left[T_{U, 1}\right]$ value is not used in the calculation). $[K]$

If space $I$ is an "outside room": $T_{L,}$ is the uniform absolute temperature there, taken to be the temperature at the reference elevation, $y_{R E F, i} ; T_{U, I}$ is specified as being identical to $T_{L, I}[K]$

$\mathrm{Y}_{\text {CEIL, }}\left[\mathrm{y}_{\mathrm{REF}, \mathrm{I}}\right]$

If space I is an inside room: Elevation of the ceiling [floor] of room I above the datum elevation. [m]

If space $I$ is an "Outside room": $y_{C E I L, I}$ and $y_{R E F, I}$ are both identical and equal to the reference elevation of space I above the datum elevation, i.e., the specification must satisfy $y_{C E I L, I} \equiv y_{\text {REF,I. }}$ The latter identity, which will never be satisfied for an inside room, is a characteristic of the input data used to distinguish an inside room from an "outside room." [m]

$Y_{\text {LAYER, }, 1}$ I $=1$ or 2

If space I is an inside room: Elevation of the upper/lower layer interface in room I above the datum elevation. [m]

If space $I$ is an "outside room": $y_{\text {LAYER,I }}$ is specified as being identical to $y_{\text {REF,I. }}$ [m] 
YVENT

Elevation of the vent above the datum elevation. Note that $y_{V E N T}$ must be identical to either $\mathrm{Y}_{\text {CEILI }}$ or $y_{R E F,}$ for each of the one or two inside rooms involved in the calculation. [m]

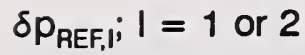

Pressure at the reference elevation, $y_{\mathrm{REF}, \mathrm{l}}$ in space $\mathrm{I}$ above the datum absolute pressure, $\mathrm{P}_{\mathrm{DAT}}$. If space $I$ is an inside room, then $\delta p_{R E F, I}$ and $y_{R E F, I}$ must correspond to the pressure and elevation, respectively, within the room and at the floor. $\left[\mathrm{Pa}=\mathrm{kg} /\left(\mathrm{m} \cdot \mathrm{s}^{2}\right)\right]$

$\varepsilon_{\mathrm{p}}$

Error tolerance for $\delta p_{\text {REF,l. }}$ If $p_{\text {ERROR,I }}$ is defined as the uncertainty in $\delta p_{\text {REF, }, ~} I=1$ or 2 , then $\mathrm{P}_{\text {ERROR,I }}$ satisfies

$$
\left|p_{\text {ERROR,I }}\right|<\varepsilon_{\mathrm{p}} \mathrm{p}_{\mathrm{o}}+\left|\delta \mathrm{p}_{\mathrm{REF}, \mathrm{I}}\right| \varepsilon_{\mathrm{p}}
$$

where $p_{0}=1.0 \mathrm{~Pa}$. The first term is based on an absolute error tolerance and dominates the above error bound when $\left|\delta p_{\mathrm{REF}, \mid}\right|$ is less than $1.0 \mathrm{~Pa}$. The second term is a relative error tolerance and dominates when $\left|\delta \mathrm{p}_{\mathrm{REF}, \mathrm{I}}\right|$ is greater than $1.0 \mathrm{~Pa}$. $\varepsilon_{\mathrm{p}}$ should be chosen to be consistent with the tolerance specified for the computation of $\delta p_{\mathrm{REF}, \mathrm{I}}$ terms in the overall compartment fire model computer code which uses this algorithm.

$\rho_{L, 1}\left[\rho_{U, I}\right] ; 1=1$ or 2

If space I is an inside room: Density of the lower [upper] layer in room I if the volume of the lower [upper] layer is non-zero (if the lower [upper] layer volume is zero then the $\rho_{L, 1}\left[\rho_{U, 1}\right]$ value is not used in the calculation). $\left[\mathrm{kg} / \mathrm{m}^{3}\right]$

If space I is an "outside room": $\rho_{L, I}$ is the uniform density there; $\rho_{U, I}$ is specified as being identical to $\rho_{\mathrm{L}, 1}\left[\mathrm{~kg} / \mathrm{m}^{3}\right]$

\section{CALCULATION}

1. Calculate $p_{1}$ for $1=1$ and 2 , and then $\Delta p$ (the $p_{1}$ calculation follows the DELP algorithm/subroutine of reference [8]):

$$
\begin{aligned}
& p_{1}=\delta p_{R E F, 1}+\delta p_{1}+p_{D A T} \\
& \Delta p=p_{2}-p_{1}=\left(\delta p_{R E F, 2}-\delta p_{R E F, 1}\right)+\left(\delta p_{2}-\delta p_{1}\right)
\end{aligned}
$$

where

$$
\begin{aligned}
& \text { if } y_{R E F, I} \leq y_{V E N T} \leq y_{L A Y E R, I} \text { then: } \delta p_{I}=-\rho_{L, I} g\left(y_{V E N T}-y_{R E F, I}\right) \\
& \text { else: } \delta p_{1}=-\rho_{L, I} g\left(Y_{\text {LAYER,I }}-y_{R E F, I}\right)-\rho_{U, I} g\left(y_{\text {VENT }}-y_{\text {LAYER, },}\right)
\end{aligned}
$$

and where $\mathrm{g}$, the acceleration of gravity, is $9.8 \mathrm{~m} / \mathrm{s}^{2}$. 
2. Calculate $\rho_{1}, T_{1}, C_{O 2,1}$ and the $C_{K,}, K=2$ to $N_{P R O D}$, for $I=1$ and 2 , and then $\Delta \rho$ :

$$
\begin{aligned}
& \text { if }\left\{\left[\left(y_{\text {VENT }}=y_{\text {REF, }}\right) \text { and }\left(y_{\text {LAYER,I }}=y_{\text {REF, }}\right)\right] \text { or }\left[\left(y_{\text {VENT }}=y_{\text {CEIL, })}\right) \text { and }\left(y_{\text {LAYER, }}<y_{\text {CEILL, }}\right)\right]\right\} \text { then: } \\
& \rho_{1}=\rho_{U, 1} T_{1}=T_{U, 1}, c_{O 2,1}=c_{U, O 2,1} \text { and } c_{K, 1}=c_{U, K, 1} \\
& \text { else: } \rho_{1}=\rho_{L, 1} T_{1}=T_{L, 1}, c_{O 2,1}=c_{L, 02,1} \text { and } c_{K, 1}=c_{L, K, 1} \\
& \Delta \rho=\rho_{1}-\rho_{2}
\end{aligned}
$$

3. Define $\dot{V}_{\text {ST,HIGH }}$ as the volume rate of flow through the vent, from the high- to the low-pressure space, that is predicted with a "standard," uni-directional-flow-type calculation (i.e., without regard to the effect of buoyancy, in general, or the stability of the cross-vent density configuration, in particular), where arbitrarily high cross-vent pressures are allowed. Here, the calculation follows the model of [5] as implemented in the VENTHP algorithm/subroutine of [6]. Calculate $\dot{V}_{\text {ST,HIGH}}$ :

If $\Delta p=0$ then: $\dot{V}_{S T, H I G H}=0$; skip to (the next) item 4 of the CALCULATION

If $\Delta p>0$ or $\Delta p<0$ then:

a. Define and compute $\rho_{\text {HIGH}}, \varepsilon$, and $\mathrm{x}$ :

If $\Delta p>0$, i.e., "standard" flow from (lower) space 2 to (upper) space 1 , then:

$$
\rho_{H I G H}=\rho_{2} ; \varepsilon=\Delta \mathrm{p} / \mathrm{p}_{2}
$$

If $\Delta p<0$, i.e., "standard" flow from (upper) space 1 to (lower) space 2, then:

$$
\begin{aligned}
& \rho_{\mathrm{HIGH}}=\rho_{1} ; \varepsilon=-\Delta \mathrm{p} / \mathrm{p}_{1} \\
& x=1-\varepsilon
\end{aligned}
$$

b. Compute $C(x)$, the vent flow coefficient, and $w(x)$ :

$$
\begin{aligned}
& C(x)=0.85-0.25 x=0.60+0.25 \varepsilon \\
& w(x)=\left\{\begin{array}{l}
1-[3 /(4 \gamma)] \varepsilon \text { if } 0<\varepsilon \leq 10^{-5} \\
f(x) /[2 \varepsilon]^{1 / 2} \text { if } 1 \geq \varepsilon>10^{-5}
\end{array}\right.
\end{aligned}
$$

where

$$
f(x)=\left\{\begin{array}{l}
\left\{[2 \gamma /(\gamma-1)] x^{2 / \gamma}\left[1-x^{(\gamma-1) / \gamma}\right]\right\}^{1 / 2} \text { if } \varepsilon<1-[2 /(\gamma+1)]^{\gamma /(\gamma-1)} \\
\left\{\gamma[2 /(\gamma+1)]^{(\gamma+1) /(\gamma-1)}\right\}^{1 / 2} \text { if } \varepsilon \geq 1-[2 /(\gamma+1)]^{\gamma /(\gamma-1)}
\end{array}\right.
$$

and where $\gamma$, the ratio of specific heats of the vent flow gas, is taken to be that of air, 1.40. Note that for the present horizontal vent application, the $C(x)$ of Eq. (10) is taken to be consistent with the standard incompressible limit for flow through circular sharpedged orifices in the sense that $C \rightarrow 0.60$ as $\varepsilon \rightarrow 0$ [9]. 
c. Define and compute $\Delta p_{c u T}^{1 / 2}$

$$
\Delta \mathrm{p}_{\mathrm{CUT}}^{1 / 2} \equiv\left[\varepsilon_{\mathrm{p}} \mathrm{MAX}\left(1.0 \mathrm{~Pa},\left|\delta \mathrm{p}_{\mathrm{REF}, 1}\right|,\left|\delta \mathrm{p}_{\mathrm{REF}, 2}\right|\right)\right]^{1 / 2}
$$

d. Define and compute $F_{\text {NOISE}}$, a numerical damping factor, and then $\dot{V}_{S T, H I G H}$ :

$$
\begin{aligned}
& F_{\text {NOISE }}=1.0-\exp \left(-|\Delta p|^{1 / 2} / \Delta p_{\text {CUT }}^{1 / 2}\right) \\
& \dot{V}_{\text {ST,HIGH }}=F_{\text {NOISE }} C(x) w(x)\left(2 / \rho_{\text {HIGH }}\right)^{1 / 2} A_{V}|\Delta p|^{1 / 2}
\end{aligned}
$$

The term $F_{\text {NOISE }}$ of Eq. (14) is designed to damp out the numerical noise (error) in the calculated value for $\Delta p$ that would otherwise be dominant in Eq. (15) when $\Delta p$ is small relative to the maximum of 1.0 pascal and the calculated reference pressures, $\delta p_{\mathrm{REF}, 1}$, $\delta p_{\text {REF,2. }}$. The term $\Delta p_{\text {cuT }}$ of Eq. (13) is an estimate of how small the maximum of $|\Delta p|$ must be to retain a few digits of accuracy in the calculation of $\Delta p$. When the calculated value of $|\Delta p|$ is smaller than $p_{C U T}$, this value and, therefore, the value of $\dot{V}_{S T, H I G H}$ in Eq. (15) will likely contain noise which should be damped. $F_{\text {NOISE }}$ is constructed to tend towards 1 when $|\Delta p|$ is large relative to $\Delta p_{c u r}$ and tends towards 0 when $|\Delta p|$ is small relative to $\Delta \mathrm{p}_{\text {cur }}$.

4. When the cross-vent density configuration is unstable $(\Delta \rho>0)$, mixed pressure- and buoyancydriven aspects of the flow have to be considered and the vent flow rates are calculated according to [2]. Define $\dot{V}_{B, H I G H}, \dot{V}_{B, L O W}$ as the reference-[2], buoyancy-affected, volume flow rates across the vent from the high-to-low and low-to-high pressure spaces, respectively.

If $\Delta \rho \leq 0: \dot{V}_{B, H I G H}=\dot{V}_{B, L O W}=0$; skip to (the next) item 5 of the CALCULATION

a. Calculate $\overline{\mathrm{T}}, \bar{\rho}, \mu(\overline{\mathrm{T}})$ in $\mathrm{m}^{2} / \mathrm{s}$ from [10], and $\varepsilon>0$ :

$$
\begin{aligned}
& \overline{\mathrm{T}}=\left(\mathrm{T}_{1}+\mathrm{T}_{2}\right) / 2 ; \bar{\rho}=\left(\rho_{1}+\rho_{2}\right) / 2 ; \\
& \mu(\overline{\mathrm{T}})=\bar{\rho}\left[0.04128\left(10^{-7}\right) \overline{\mathrm{T}}^{5 / 2} /(\overline{\mathrm{T}}+110.4)\right] ; \varepsilon=\Delta \rho / \rho>0
\end{aligned}
$$

b. $\quad$ Calculate $D$ and $\bar{G}$; if $p_{2}>p_{1}$, i.e., $\Delta p>0$, then replace $\varepsilon$ by $-\varepsilon<0$ :

$D=\left(4 A_{v} / \pi\right)^{1 / 2} ; \quad \bar{G} r=2 g D^{3}|\varepsilon| /[\mu(\bar{T}) / \rho]^{2} ;$ if $\Delta p>0$ then $\varepsilon=-\varepsilon$

c. Calculate conditions at the limit of uni-directional flow (i.e., the flooding condition) and the relative pressure, $\delta p^{*}$ :

$$
\begin{aligned}
& \dot{V}_{H I G H, F L O O D}=0.1754 A_{V}(2 g D|\varepsilon|)^{1 / 2} \exp (0.5536 \varepsilon) ; \\
& \Delta p_{F L O O D}=0.2427(4 g \Delta \rho D)(1+\varepsilon / 2) \exp (1.1072 \varepsilon) ; \\
& \delta p^{\star}=|\Delta p| / \Delta p_{F L O O D}
\end{aligned}
$$

d. Calculate $\sigma_{1}, \sigma_{2}$ and then $V_{B, \text { LOW }}, V_{B, H I G H}$ :

$$
\sigma_{1}=F_{\text {NOISE }} \mathrm{C}(\mathrm{x}) \mathrm{W}(\mathrm{x}) / 0.1780 ; \sigma_{2}=1.045
$$


If $\delta p^{\star} \geq 1$, expect uni-directional flow:

$$
\begin{aligned}
& V_{B, L O W}=0 \\
& \dot{V}_{B, H I G H}=\dot{V}_{\text {HIGH,FLOOD }}\left\{1-\sigma_{2}{ }^{2}+\left[\sigma_{2}{ }^{4}+\sigma_{1}{ }^{2}\left(\delta p^{\star}-1\right)\right]^{1 / 2}\right\}
\end{aligned}
$$

If $\delta p^{\star}<1$, expect mixed flow:

$$
\begin{aligned}
& \dot{V}_{E X, M A X}=0.055(4 / \pi) A_{V}(g D|\varepsilon|)^{1 / 2} \\
& m_{3}=-0.7070 ; M=\left(\sigma_{1} / \sigma_{2}\right)^{2}-1 \\
& \dot{V}_{B, L O W}=\dot{V}_{E X, M A X}\left[\left(1+m_{3} / 2\right)\left(1-\delta p^{\star}\right)^{2}-\left(2+m_{3} / 2\right)\left(1-\delta p^{\star}\right)\right]^{2} \\
& \dot{V}_{B, H I G H}=\dot{V}_{B, L O W}+\left\{M-\left[1+\left(M^{2}-1\right)\left(1-\delta p^{\star}\right)\right]^{1 / 2}\right\} \dot{V}_{\text {HIGH,FLOOD }} /(M-1)
\end{aligned}
$$

(Note: $\sigma_{1}$ of Eq. (21) is somewhat different than $\sigma_{1}$ in [2]. The modification here is provide for an analytic representation of vent flow which is continuous and uniformly valid even as $\delta p^{*}$ is increased to a level where compressibility effects become important. The result of [2] does not include the effect of compressibility.)

5. Following [2], when $\Delta \rho>0$ the above will be taken as the flow solution provided $\bar{G} r \geq 2\left(10^{7}\right)$. For smaller $G_{r}$, the reference-[2] solution begins to loose its validity, and there is no existing model for the flows the range $0<\bar{G} r<2\left(10^{7}\right)$. However, it is clear that the above-calculated "standard" flow must be approached as $\overline{\mathrm{G}} \mathrm{r} \rightarrow 0$.

Consistent with the above comments, when $\bar{G} r$ is in the range $0 \leq \bar{G} r<2\left(10^{7}\right)$, the vent flow will be estimated by:

$$
\text { flow }=\left(\text { "standard" flow) }+\left[\left(\text { reference-[2] flow) }-(\text { "standard" flow) }] \bar{G} r /\left[2\left(10^{7}\right)\right]\right.\right.\right.
$$

a. Define $\dot{V}_{\text {HIGH }}$ and $\dot{V}_{\text {Low }}$ as the volume flow rates across the vent from the high-to-low and low-to-high pressure spaces, respectively.

$$
\begin{aligned}
& \text { If } \Delta \rho \leq 0: \dot{V}_{\text {HIGH }}=\dot{V}_{\text {ST,HIGH }} ; \quad \dot{V}_{\text {LOW }}=0 \\
& \text { If } \Delta \rho>0 \text { and } 0<\overline{\mathrm{G}} r<2\left(10^{7}\right) \text { : } \\
& \begin{array}{l}
\left.\dot{V}_{H I G H}=\dot{V}_{S T, H I G H}+\dot{V}_{B, H I G H}-\dot{V}_{S T, H I G H}\right) \bar{G} r /\left[2\left(10^{7}\right)\right] \\
\dot{V}_{\text {LOW }}=\dot{V}_{B, L O W} \bar{G} r /\left[2\left(10^{7}\right)\right]
\end{array}
\end{aligned}
$$

If $\Delta \rho>0$ and $\bar{G} r \geq 2\left(10^{7}\right): \dot{V}_{\text {HIGH }}=\dot{V}_{B, H I G H} ; \quad \dot{V}_{\text {LOW }}=\dot{V}_{B, \text { LOW }}$

b. Define and calculate $\dot{V}_{V E N T, I} I=1$ and 2 , as the vent volume flow rate entering space $I$.

If $\Delta p \geq 0: \dot{V}_{\text {VENT,1 }}=\dot{V}_{\text {HIGH }} ; \dot{V}_{\text {VENT,2 }}=\dot{V}_{\text {LOW }}$

(i.e., flow to the upper space is the flow from the high- to the low-pressure space, and flow to the lower space is the flow from the low- to the high-pressure space) 
If $\Delta p<0: \dot{V}_{\text {VENT,1 }}=\dot{V}_{\text {LOW }} ; \dot{V}_{\text {VENT,2 }}=\dot{V}_{\text {HIGH }}$

(i.e., flow to the upper space is the flow from the low- to the high-pressure space, and flow to the lower space is the flow from the high- to the low-pressure space)

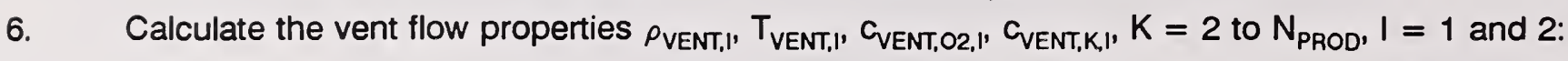

$$
\begin{aligned}
& \rho_{\mathrm{VENT}, 1}=\rho_{2}\left(p_{1} / p_{2}\right), \rho_{\mathrm{VENT}, 2}=\rho_{1}\left(p_{2} / p_{1}\right) ; T_{\mathrm{VENT}, 1}=T_{2}, T_{\mathrm{VENT}, 2}=T_{1} ; \\
& c_{\mathrm{VENT}, 02,1}=c_{O 2,2}, c_{\mathrm{VENT}, 02,2}=c_{O 2,1} ; c_{\mathrm{VENT}, \mathrm{K}, 1}=c_{\mathrm{K}, 2}, c_{\mathrm{VENT}, \mathrm{K}, 2}=c_{\mathrm{K}, 1}, \mathrm{~K}=2 \text { to } \mathrm{N}_{\mathrm{PROD}}
\end{aligned}
$$

7. Calculate the vent flow rates $\dot{\mathrm{M}}_{\mathrm{VENT}, \mathrm{l}} \mathrm{I}=1$ and 2:

$$
\dot{\mathrm{M}}_{\mathrm{VENT,I}}=\rho_{\mathrm{VENT,I}} \dot{\mathrm{V}}_{\mathrm{VENT}, \mathrm{I}}
$$

8. Calculate the vent flow rates $Q_{\text {VENT, }}, P_{\text {O2,VENT,l }}, P_{\text {KVENT,l }}, K=2$ to $N_{\text {PROD }}, I=1$ and 2 :

$$
\begin{aligned}
& Q_{V E N T, I}=\dot{M}_{\text {VENT,I }} C_{P} T_{V E N T, I} ; P_{\text {O2,VENT,I }}=\dot{M}_{\text {VENT,I }} C_{V E N T, 02,1} \\
& P_{\text {KVENT,I }}=\dot{M}_{\text {VENT, }} C_{V E N T, K I}, K=2 \text { to } N_{\text {PROD }}
\end{aligned}
$$

9. Calculate rates at which flows are added to layers of each space as a result of the vent flow extracted from it. First consider space $1(I=1, J=2)$ and then space $2(I=2, J=1)$. For either case:

If $\left\{\left[\left(y_{V E N T}=y_{\text {REF, }}\right)\right.\right.$ and $\left.\left(y_{\text {LAYER,I }}=y_{\text {REF, }}\right)\right]$ or $\left[\left(y_{\text {VENT }}=y_{\text {CEILI, }}\right)\right.$ and $\left.\left.\left(y_{\text {LAYER,I }}<y_{\text {CEIL, }}\right)\right]\right\}$ (i.e., the vent flow to room $J$ is extracted from the upper layer of room $I$ and, if space $I$ is an inside room, the lower layer of room I is unchanged) then:

$$
\begin{aligned}
& \dot{M}_{U, I}=-\dot{M}_{V E N T, J}, \dot{M}_{L, I}=0 ; Q_{U, I}=-Q_{V E N T, J}, Q_{L, I}=0 ; \\
& P_{O 2, U, I}=-P_{O 2, V E N T, J}, P_{O 2, L, I}=0 ; P_{K U, I}=-P_{K V E N T, J}, P_{K, L I}=0
\end{aligned}
$$

If $y_{\text {REF, }}=y_{\text {CEILII }}$ (i.e., space $\mathrm{I}$ is an outside space) modify the results of Eqs. (33) as follows:

$$
\dot{M}_{L, 1}=\dot{M}_{U, 1} ; Q_{L, 1}=Q_{U, 1} ; P_{O 2, L, 1}=P_{O 2, U, 1} ; P_{K, L, 1}=P_{K, U, I}
$$

If the condition above Eqs. (33) is not satisfied (i.e., the vent flow to room $\mathrm{J}$ is extracted from the lower layer of room $I$ and, if space $I$ is an inside room, the upper layer of room $I$ is unchanged) then:

$$
\begin{aligned}
& \dot{M}_{L, I}=-\dot{M}_{V E N T, J}, \dot{M}_{U, I}=0 ; Q_{L, I}=-Q_{V E N T, J}, Q_{U, I}=0 ; \\
& P_{O 2, L, I}=-P_{O 2, V E N T, J}, P_{O 2, U, I}=0 ; P_{K, L I}=-P_{K, V E N T, J}, P_{K, U, I}=0
\end{aligned}
$$

If $y_{\text {REF,I }}=y_{\text {CEILII }}$ (i.e., space I is an outside space) modify the results of Eqs. (35) as follows:

$$
\dot{M}_{U, 1}=\dot{M}_{L, 1} ; Q_{U, 1}=Q_{L, 1} ; P_{O 2, U, 1}=P_{O 2, L,} ; P_{K, U, 1}=P_{K, L, I}
$$




\section{REFERENCES}

[1] Cooper, L.Y., "VENTCF - Calculation of the Flow Through a Horizontal Ceiling/Floor Vent Connecting Two Spaces," APPENDIX of: "An Algorithm and Associated Computer Subroutine for Calculating Flow Through a Horizontal Ceiling/Floor Vent in a Zone-Type Compartment Fire Model," NISTIR 90-4402, National Institute of Standards and Technology, Gaithersburg MD, October 1990.

[2] Cooper, L.Y., "Combined Buoyancy-and Pressure-Driven Flow Through a Horizontal Vent," NISTIR 5384, National Institute of Standards and Technology, Gaithersburg MD, April 1994.

[3] Cooper, L.Y., "Combined Buoyancy- and Pressure-Driven Flow Through a Horizontal Vent: Theoretical Considerations," Cooper, L.Y., NISTIR 5252, National Institute of Standards and Technology, Gaithersburg MD, September 1993.

[4] Emmons, H., "Vent Flows," Sect. 1/Chapter 8 of SFPE Handbook of Fire Protection Engineering, SFPE, Boston, pp. 130-138, 1988.

[5] Cooper, L.Y., "Calculating Flows Through Vertical Vents in Zone Fire Models," Combustion Science and Technology, Vol. 63, Nos. 1-3, pp. 43-50, 1989.

[6] Cooper, L.Y. and Forney, G.P., "VENTHP - Calculation of the Flow of Mass, Enthalpy, Oxygen, and Other Products of Combustion Through a Vertical Constant-Width Vent in a Wall Segment Common to Two Rooms;" an entry in: "Consolidated Compartment Fire Model (CCFM) Computer Code Application CCFM.VENTS - Part III: Algorithms and Subroutines," Cooper, L.Y., and Forney, G.P., Editors, NISTIR 4344, National Institute of Standards and Technology, July 1990.

[7] Cooper, L.Y., "VENTCF2: An Algorithm and Associated Computer Subroutine for Calculating Flow Through a Horizontal Ceiling/Floor Vent in a Zone-Type Compartment Fire Model," to appear as NISTIR, National Institute of Standards and Technology, Gaithersburg MD.

[8] Cooper, L.Y. and Forney, G.P., "DELP - Calculation of the Absolute Hydrostatic Pressure at a Specified Elevation in Each of Two Adjacent Rooms and the Pressure Difference;" an entry in: "Consolidated Compartment Fire Model (CCFM) Computer Code Application CCFM.VENTS - Part III: Algorithms and Subroutines," Cooper, L.Y., and Forney, G.P., Editors, NISTIR 4344, National Institute of Standards and Technology, July 1990.

[9] Shapiro, A.H., The Dynamics and Thermodynamics of Compressible Fluid Flow: Volume 1, Roland Press, New York, p. 100, 1953.

[10] Hilsenrath, J., et al, Tables of Thermal Properties of Gases, NBS circular 564, National Institute of Standards and Technology (presently the National Institute of Standards and Technology), Gaithersburg MD, Nov. 1955.

\section{SUBROUTINE VARIABLES}

All nomenclature in the subroutine is identical to the nomenclature used above except for:

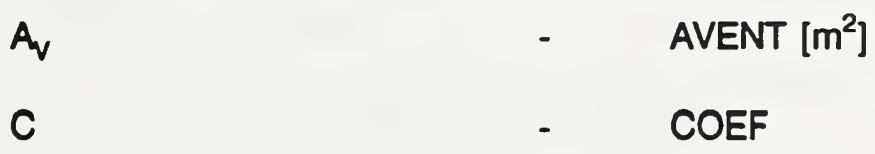




\begin{tabular}{|c|c|c|}
\hline$c_{p}$ & - & $\mathrm{CP}[\mathrm{W} \cdot \mathrm{s} /(\mathrm{kg} \cdot \mathrm{K})]$ \\
\hline$c_{L, K, 1} c_{U, K, I}$ & - & $\begin{array}{l}\operatorname{CONL}(K, I), \operatorname{CONU}(K, I), I=1 \text { or } 2[(\text { unit of product } K) /(\mathrm{kg} \\
\text { of layer })]\end{array}$ \\
\hline$c_{L, 02,11} c_{U, 02,1}$ & - & $\begin{array}{l}\operatorname{CONL}(1, I), \operatorname{CONU}(1, I), I=1 \text { or } 2[(\mathrm{~kg} \text { of oxygen }) /(\mathrm{kg} \text { of } \\
\text { layer })]\end{array}$ \\
\hline CVENT,KII & - & $\begin{array}{l}\operatorname{CVENT}(K, I), I=1 \text { or } 2[(\text { unit of product } K) /(\mathrm{kg} \text { of vent } \\
\text { flow) }\end{array}$ \\
\hline GENT,02,1 & - & $\operatorname{CVENT}(1,1), 1=1$ or $2[(\mathrm{~kg}$ of oxygen $) /(\mathrm{kg}$ of vent flow $)]$ \\
\hline$c_{k, 1}$ & - & $C(K, I), I=1$ or $2[($ unit of product $K) /(\mathrm{kg}$ of vent flow) \\
\hline$c_{02,1}$ & - & $C(1,1), I=1$ or $2[(\mathrm{~kg}$ of oxygen $) /(\mathrm{kg}$ of vent flow) $]$ \\
\hline$F_{\text {NOISE }}$ & $\cdot$ & FNOISE [dimensionless] \\
\hline$f$ & - & FF [dimensionless] \\
\hline$\overline{\mathrm{G}} \mathrm{r}$ & - & GR [dimensionless] \\
\hline g & - & $9.8 \mathrm{~m} / \mathrm{s}^{2}$ \\
\hline M & - & $\mathrm{XM}$ [dimensionless] \\
\hline$\dot{M}_{L, 1}, \dot{M}_{U, 1}$ & - & $X M L(l), X M U(l), I=1$ or $2[\mathrm{~kg} / \mathrm{s}]$ \\
\hline$\dot{M}_{\text {VENT,I }}$ & - & $\operatorname{XMVENT}(I), I=1$ or $2[\mathrm{~kg} / \mathrm{s}]$ \\
\hline$m_{3}$ & - & XM3 [dimensionless] \\
\hline$N_{\text {PMAX }}$ & - & NPMAX [dimensionless] \\
\hline$N_{\text {PROD }}$ & - & NPROD [dimensionless] \\
\hline$P_{K, L, 1} P_{K, U, I}$ & - & $\mathrm{PL}(\mathrm{K}, \mathrm{l}), \mathrm{PU}(\mathrm{K}, \mathrm{I}), \mathrm{I}=1$ or $2[($ unit of product $\mathrm{K} / \mathrm{s}]$ \\
\hline$P_{\text {KVENT,I }}$ & - & PVENT(K,I), I = 1 or $2[$ (unit of product $K) / s]$ \\
\hline$P_{O 2, L, 1}, P_{O 2, U, 1}$ & - & $\mathrm{PL}(1, \mathrm{I}), \mathrm{PU}(1, \mathrm{l}), \mathrm{I}=1$ or $2[(\mathrm{~kg}$ of oxygen $) / \mathrm{s}]$ \\
\hline$P_{O 2, V E N T, I}$ & - & $\operatorname{PVENT}(1,1), 1=1$ or $2[(\mathrm{~kg}$ of oxygen $) / \mathrm{s}]$ \\
\hline PDAT & - & PDATUM $\left[\mathrm{Pa}=\mathrm{kg} /\left(\mathrm{m} \cdot \mathrm{s}^{2}\right)\right]$ \\
\hline$p_{1}$ & - & $P(l), I=1$ or $2\left[\mathrm{~Pa}=\mathrm{kg} /\left(\mathrm{m} \cdot \mathrm{s}^{2}\right)\right]$ \\
\hline$Q_{L, 1} Q_{U, 1}$ & - & $Q L(I), Q U(I), I=1$ or $2[W]$ \\
\hline$Q_{\text {VENT,I }}$ & - & QVENT(I), I = 1 or $2[\mathrm{~W}]$ \\
\hline & & ENTCF2 - 12 \\
\hline
\end{tabular}


TBAR [K]

$T_{1}$

$T(I), I=1$ or $2[\mathrm{~K}]$

$T_{L,}, T_{U, 1}$

$T L(I), T U(I), I=1$ or $2[K]$

$T_{\text {VENT,I }}$

$\operatorname{TVENT}(\mathrm{I}), \mathrm{l}=1$ or $2[\mathrm{~K}]$

$\dot{\mathrm{V}}_{\mathrm{B}, \mathrm{HIGH}}$

VBHIGH $=V B(1)$ if $\Delta p \geq 0,=V B(2)$ if $\Delta p \leq 0\left[\mathrm{~m}^{3} / \mathrm{s}\right]$

$\dot{V}_{B, \text { LOW }}$

VBLOW $=V B(2)$ if $\Delta p \geq 0,=V B(1)$ if $\Delta p \leq 0\left[\mathrm{~m}^{3} / \mathrm{s}\right]$

$\dot{V}_{E X, M A X}$

VEXMAX $\left[\mathrm{m}^{3} / \mathrm{s}\right]$

$\dot{\mathrm{V}}_{\text {HIGH}}, \dot{\mathrm{V}}_{\text {LOW }}$

VHIGH, VLOW $\left[\mathrm{m}^{3} / \mathrm{s}\right]$

$\dot{V}_{\text {HIGH,FLOOD }}$

VHIGHFL $\left[\mathrm{m}^{3} / \mathrm{s}\right]$

$\dot{V}_{S T, H I G H}$

$V=V S T(1)$ if $\Delta p>0,=V S T(2)$ if $\Delta p<0\left[\mathrm{~m}^{3} / \mathrm{s}\right]$

$\dot{V}_{\text {VENT,I }}$

$\operatorname{VVENT}(I), I=1$ or $2\left[\mathrm{~m}^{3} / \mathrm{s}\right]$

w

$W$ [dimensionless]

$x$

$X$ [dimensionless]

$y_{\text {CELLI }}$

YCEIL(I), I $=1$ or $2[\mathrm{~m}]$

Y'AYER,I

$\operatorname{YLAY}(I), I=1$ or $2[\mathrm{~m}]$

$y_{\text {REF,I }}$

$\operatorname{YREF}(\mathrm{I}), \mathrm{I}=1$ or $2[\mathrm{~m}]$

$\mathrm{Y}_{\mathrm{VENT}}$

WENT [m]

$\gamma$

$\Delta \mathrm{p}$

1.40

$\Delta \mathrm{p}_{\mathrm{cUT}}^{1 / 2}$

$\operatorname{DELP}\left[\mathrm{Pa}=\mathrm{kg} /\left(\mathrm{m} \cdot \mathrm{s}^{2}\right)\right]$

$\Delta \mathrm{p}_{\mathrm{FLOOD}}$

$\mathrm{DPC} 1 \mathrm{D} 2\left[\mathrm{~Pa}=\mathrm{kg} /\left(\mathrm{m} \cdot \mathrm{s}^{2}\right)\right]$

$\Delta \rho$

DELPFD $\left[\mathrm{Pa}=\mathrm{kg} /\left(\mathrm{m} \cdot \mathrm{s}^{2}\right)\right]$

$\delta p$.

DELDEN $\left[\mathrm{kg} / \mathrm{m}^{3}\right]$

$\delta p_{1}$

DPDDPFL $\left[\mathrm{Pa}=\mathrm{kg} /\left(\mathrm{m} \cdot \mathrm{s}^{2}\right)\right]$

$\delta p_{\text {REF,I }}$

$\mathrm{DP}(\mathrm{l}), \mathrm{I}=1$ or $2\left[\mathrm{~Pa}=\mathrm{kg} /\left(\mathrm{m} \cdot \mathrm{s}^{2}\right)\right]$

$\operatorname{DPREF}(\mathrm{l}), \mathrm{I}=1$ or $2\left[\mathrm{~Pa}=\mathrm{kg} /\left(\mathrm{m} \cdot \mathrm{s}^{2}\right)\right]$

$\varepsilon$

EPS [dimensionless] 


$\varepsilon_{\mathrm{p}}$
$\mu$
$\rho_{\mathrm{HIGH}}$
$\bar{\rho}$
$\rho_{\mathrm{I}}$
$\rho_{\mathrm{L}, 1} \rho_{\mathrm{U}, \mathrm{I}}$
$\rho_{\mathrm{VENT,I}}$
$\sigma_{1}$
$\sigma_{2}$

EPSP [dimensionless]

$\mathrm{XMEW}\left[\mathrm{m}^{2} / \mathrm{s}\right]$

DENHIGH $\left[\mathrm{kg} / \mathrm{m}^{3}\right]$

DENBAR $\left[\mathrm{kg} / \mathrm{m}^{3}\right]$

$\operatorname{DEN}(l), I=1$ or $2\left[\mathrm{~kg} / \mathrm{m}^{3}\right]$

$\operatorname{DENL}(\mathrm{l}), \operatorname{DENU}(\mathrm{I}), \mathrm{I}=1$ or $2\left[\mathrm{~kg} / \mathrm{m}^{3}\right]$

$\operatorname{DENVNT}(\mathrm{l}), \mathrm{I}=1$ or $2\left[\mathrm{~kg} / \mathrm{m}^{3}\right]$

SIGMA1 [dimensionless]

SIGMA2 [dimensionless]

\section{PREPARED BY}

Leonard Y. Cooper

December 1993 


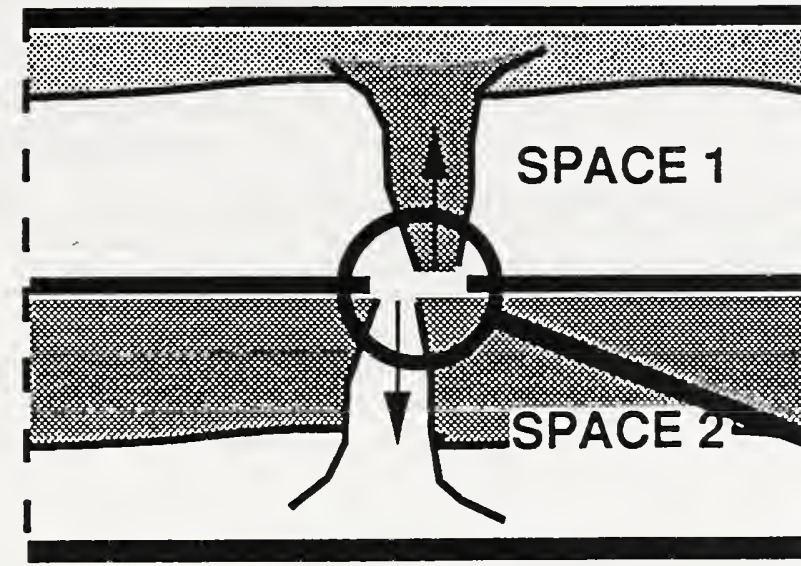

(a)

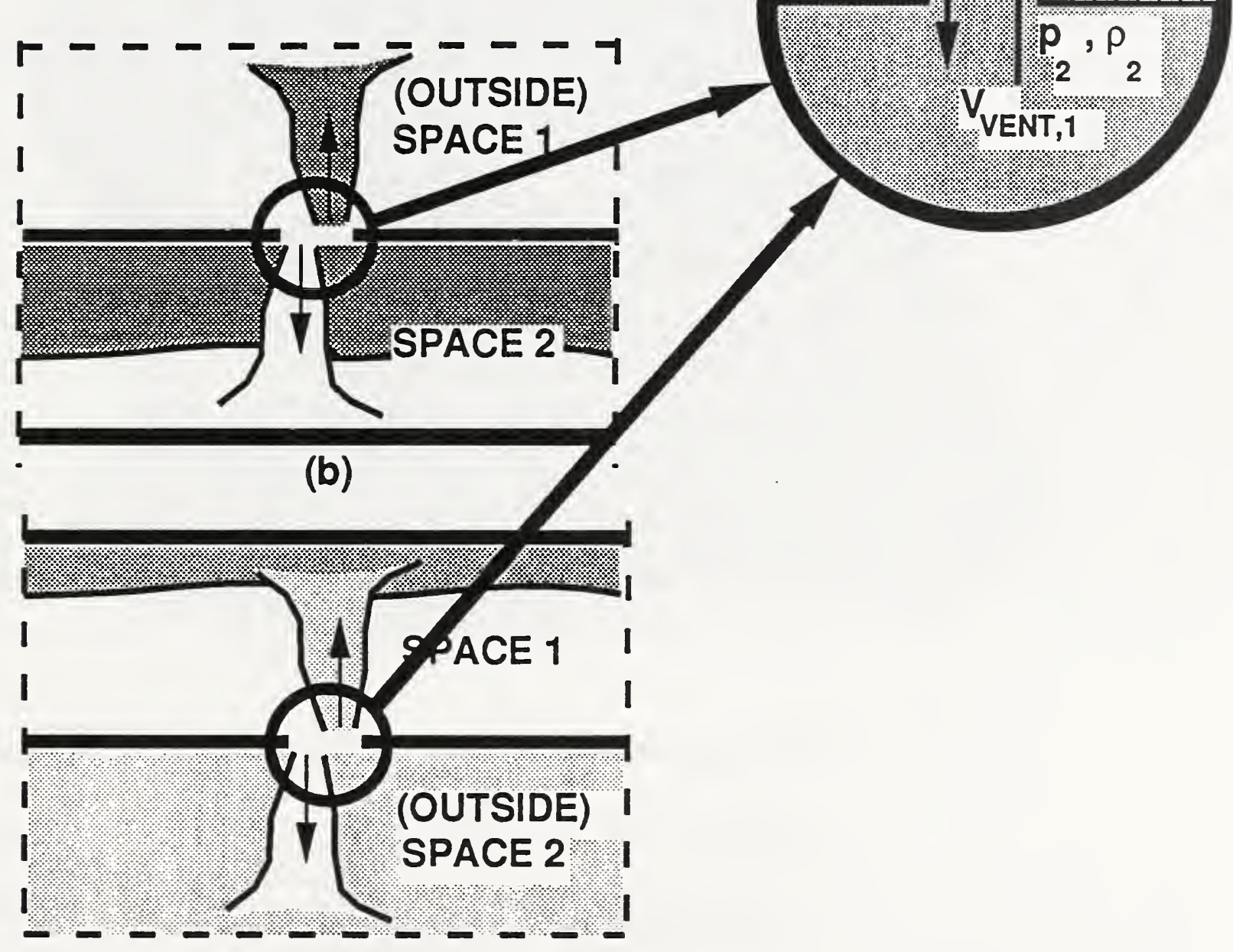

(c)

Figure 1. The posslble configurations of the two spaces jolned by a horlzontal ceiling/floor vent with space 1 above space 2: a) two inside rooms; b) an outslde space above an inside room; c) an inside room over an outside space. 


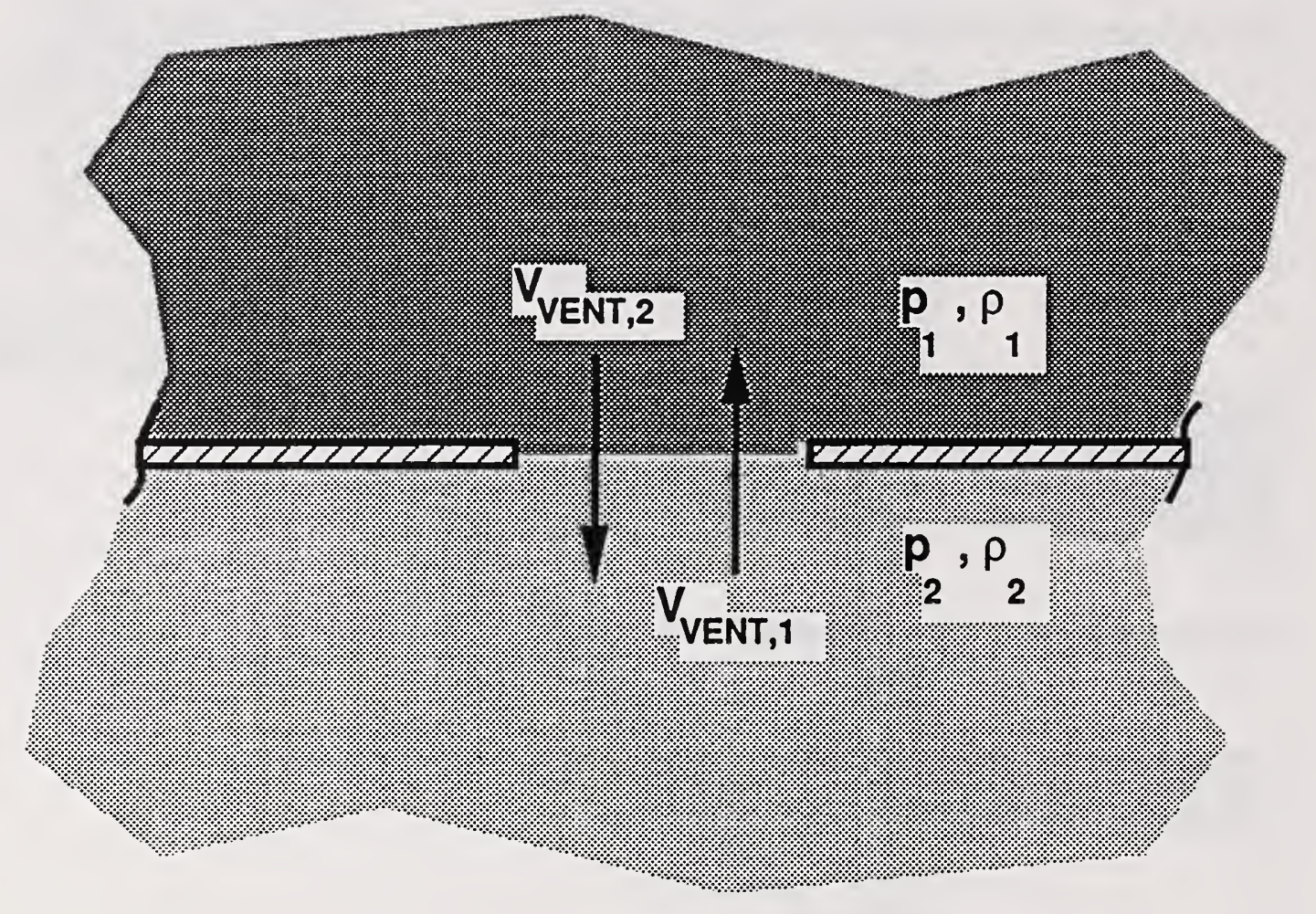

Figure 2. The geometry and conditions locai to a horizontai ceiling/fioor vent which determine the characteristics of the vent fiow. 


\section{SUBROUTINE VENTCF2}

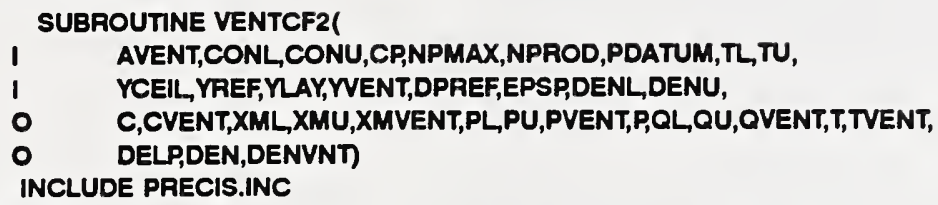


c

c

$c$

C

$c$

c

C

C

c

C

C*END

$C *$ (t)

C NOTE THAT NPMAX2 SHOULD BE BIGGER THAT NPMAX

$C$

PARAMETER (NPMAX2 $=10$ )

DIMENSION CONL(NPMAX2,2), CONU(NPMAX2,2), $\pi(2), T U(2)$

DIMENSION YCEIL(2), YREF(2), $\operatorname{MAY}(2), \operatorname{DPREF(2)}$

DIMENSION DENL(2), DENU(2)

DIMENSION C(NPMAX2,2), CVENT(NPMAX2,2), XML(2), XMU(2)

DIMENSION XMVENT(2)

DIMENSION PL(NPMAX2,2), PU(NPMAX2,2), PVENT(NPMAX2,2), P(2)

DIMENSION OL(2),OU(2)

DIMENSION OVENT(2), T(2), TVENT(2), DEN(2), DENVNT(2)

DIMENSION DP(2),VB(2),VST(2), VVENT(2)

PARAMETER $(\mathrm{OAM}=1.40 \mathrm{D0})$

DATA IFIAST/O/

SAVE IFIRST,OAMCUT,GAMMAX

PARAMETER $(G=9.80 D 0)$

PARAMETER (PI $=3.14159265400)$

PARAMETER (STOMA2 $=1.045 \mathrm{DO})$

PARAMETER (XM3 $=-0.7070 D 0)$

$O R=0 . D O$

VHOHFL $=0 . D O$

DELPFL $=0 . D O$

DO $5 \mid=1,2$

$\operatorname{VST}(I)=0.00$

$V B(I)=0 . D O$

QVENT $(I)=0 . D 0$

XMVENT $(1)=0 . D 0$

DO 2 NP $=1$,NPROD

PVENT $(N P, 1)=0 . D 0$

CONTINUE

CHE FOULWINO CODE SEGMENT COMPUTES CONSTANTS REQUIRED BY VENTCF2. C* IT IS EXECUTED THE FIRST TIME VENTCF IS CALED.

AN INSIDE ROOM I = $1(1=2)$ OR TO AN OUTSIDE SPACE I RATE AT WHICH PRODUCT $K$ IS ADDED TO THE UPPER LAYER OF ROOM I = $1(I=2)$ OR TO AN OUTSIDE SPACE I FLOW RATE OF PRODUCT K IN THE VENT FLOW COMPONENT FLOW RATE OF ENTHALPY IN THE VENT FLOW COMPONENT ENTERING SPACE I [K] VENT PRESSURE DIFFERENCE, $P(2) \cdot P(1),[P A=$ DENSITY IMMEDIATELY ABOVE (IN SPACE I = 1) AND BELOW N SPACE I = 2) THE VENT [KG/M**3] DENSITY OF THE VENT FLOW COMPONENT ENTERING SPACE I KO/M*3] ABSOLUTE TEMPERATURE IMMEDIATELY ABOVE (IN SPACE I = 1) AND BELOW (IN SPACE I = 2) THE VENT [K] URE OF THE VENT FLOW COMPONENT 


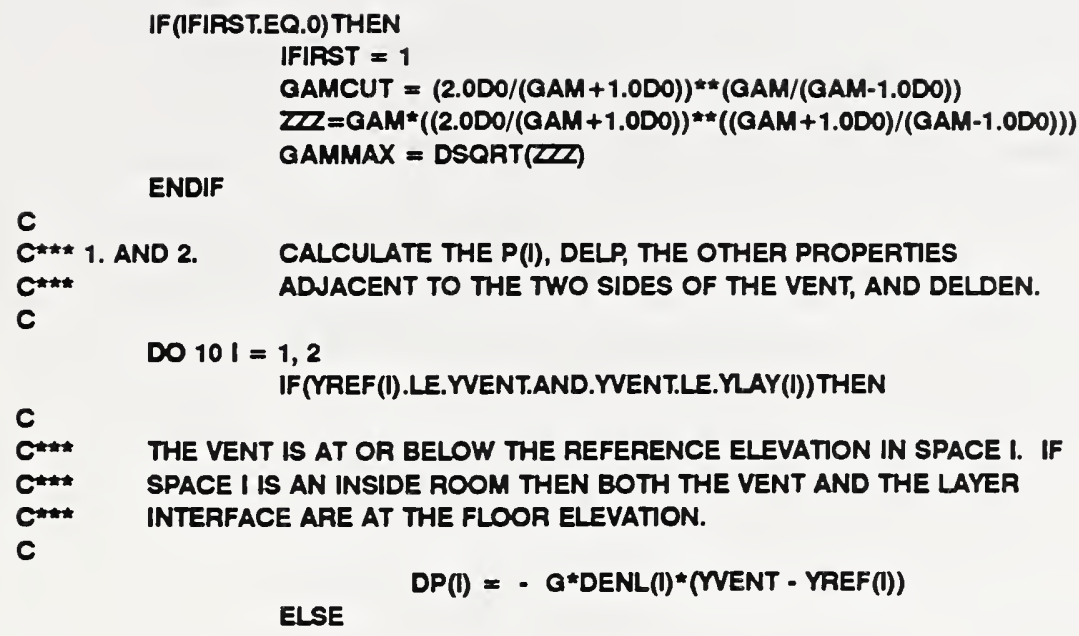




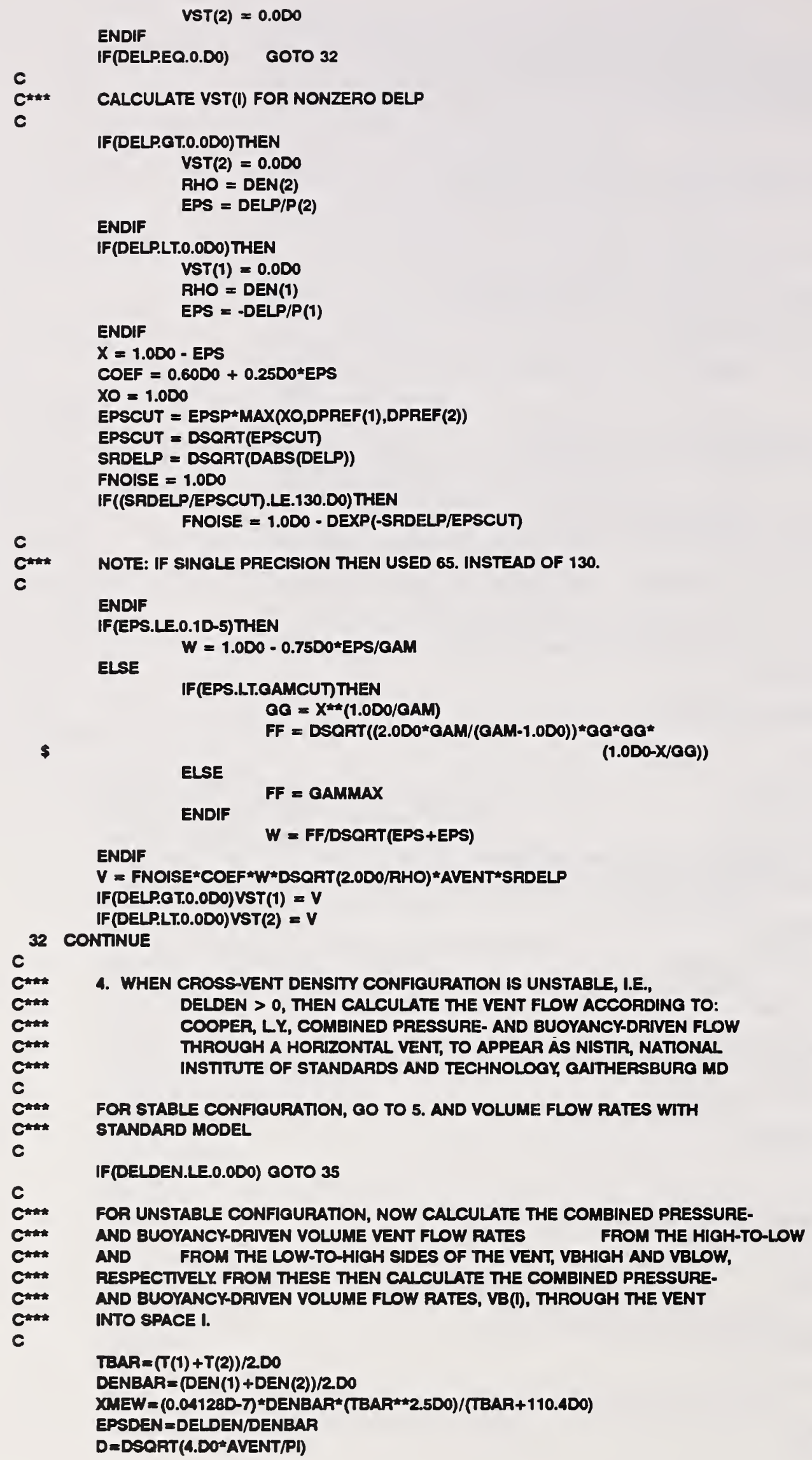


$Q R=2 . D 0^{*} Q^{*}\left(D^{* * 3}\right) * E P S D E N /((X M E W / D E N B A R) * * 2 . D 0)$

IF(DELP.QT.0.DO) EPSDEN =-EPSDEN

VHIGHFL $=0.1754 D 0 * A V E N T * D S Q R T(2 . D 0 * Q * D * D A B S(E P S D E N)$ )

$D E L P F L=0.2427 D 0^{*}\left(4 . D 0^{*} G^{*} D A B S(E P S D E N * D E N B A R) * D\right) *(1 . D 0+E P S D E N / 2 . D 0)$

DEXP(0.5536D0*EPSDEN)

1

DPDDPFL=DABS(DELP)/DELPFL

DEXP(1.1072D0^EPSDEN)

SIQMA1 $=$ FNOISE $*$ COEF $* W / 0.1780 D 0$

IF(DPDDPFLGE.1.DO)THEN

VBLOW $=0 . D O$

VBHIGH $=$ VHIGHFL* $(1 . D O-(S I G M A 2 * * 2 . D 0)+$

1

ELSE

DSORT(SIGMA2**4.DO+(SIOMA1**2.D0)* (DPDDPFL-1.D0)))

VEXMAX $=0.05500^{\star}(4 . D O / P I) \star A V E N T * D S Q R T\left(Q^{\star} D^{\star D D A B S}\right.$ (EPSDEN))

$X M=(S I G M A 1 / S I G M A 2) * * 2 . D O-1 . D 0$

VBLOW=VEXMAX*(((1.DO+XM3/2.DO)*((1.DO-DPDDPFL)**2)-

1

IF(DPDDPFLEQ.0.DO)THEN

$(2 . D 0+X M 3 / 2 . D 0) *(1 . D O-D P D D P F L)) * * 2 . D 0)$

ELSE

VBHIOH=VBLOW

VBHIOH =VBLOW +

(XM-DSORT(1.DO+(XM**2.DO-1.DO)*(1.DO-DPDDPFL)))*

ENDIF

ENDIF

IF(DELP.QT.O.DO)THEN

$V B(1)=V B H I G H$

VB(2) $=$ VBLOW

ELSE

VB(1) $=$ VBLOW

$\mathrm{VB}(2)=\mathrm{VBHIOH}$

ENDIF

5. CALCULATE WENT(I), THE VOLUME RATE OF FLOW THROUGH

THE VENT INTO SPACE ।

CONTINUE

IF(DELDEN.LE.0.0D0)THEN

$$
\text { VENT(1) = VST(1) }
$$

ELSE

$$
\text { WENT(2) }=\text { VST(2) }
$$

IF((O.DO.LT.QR).AND.(GR.LT.2.DT))THEN

WENT(1) $=$ VST(1) + (GR/2.DT * (VB(1)-VST(1))

VENT(2) $=V S T(2)+($ (GR/2.D7) * $($ BB(2)-VST (2))

$$
\text { ELSE }
$$

VVENT(1) $=\mathrm{VB}(1)$

ENDIF

VVENT(2) $=$ VB(2)

ENDIF

CHat:

c

6. CALCULATE THE VENT FLOW PROPERTIES

$$
\begin{aligned}
& \operatorname{DENVNT}(1)=\operatorname{DEN}(2) \star P(1) / P(2) \\
& \operatorname{DENVNT}(2)=\operatorname{DEN}(1) \star P(2) / P(1) \\
& \operatorname{TVENT}(1)=T(2) \\
& \operatorname{TVENT}(2)=T(1) \\
& \operatorname{DO} 50 \mathrm{~K}=1, \operatorname{NPROD} \\
& \operatorname{CVENT}(K, 1)=C(K, 2) \\
& \text { CVENT }(K, 2)=C(K, 1)
\end{aligned}
$$

CONTINUE

C

c

60

CALCULATE THE VENT MASS fLOW RATES

DO $601=1,2$

CONTINUE

XMVENT(I) = DENVNT(I)*VVENT(I)

c

c

8. CALCULATE THE REST OF THE VENT FLOW RATES

DO $70 \mathrm{I}=1,2$ 


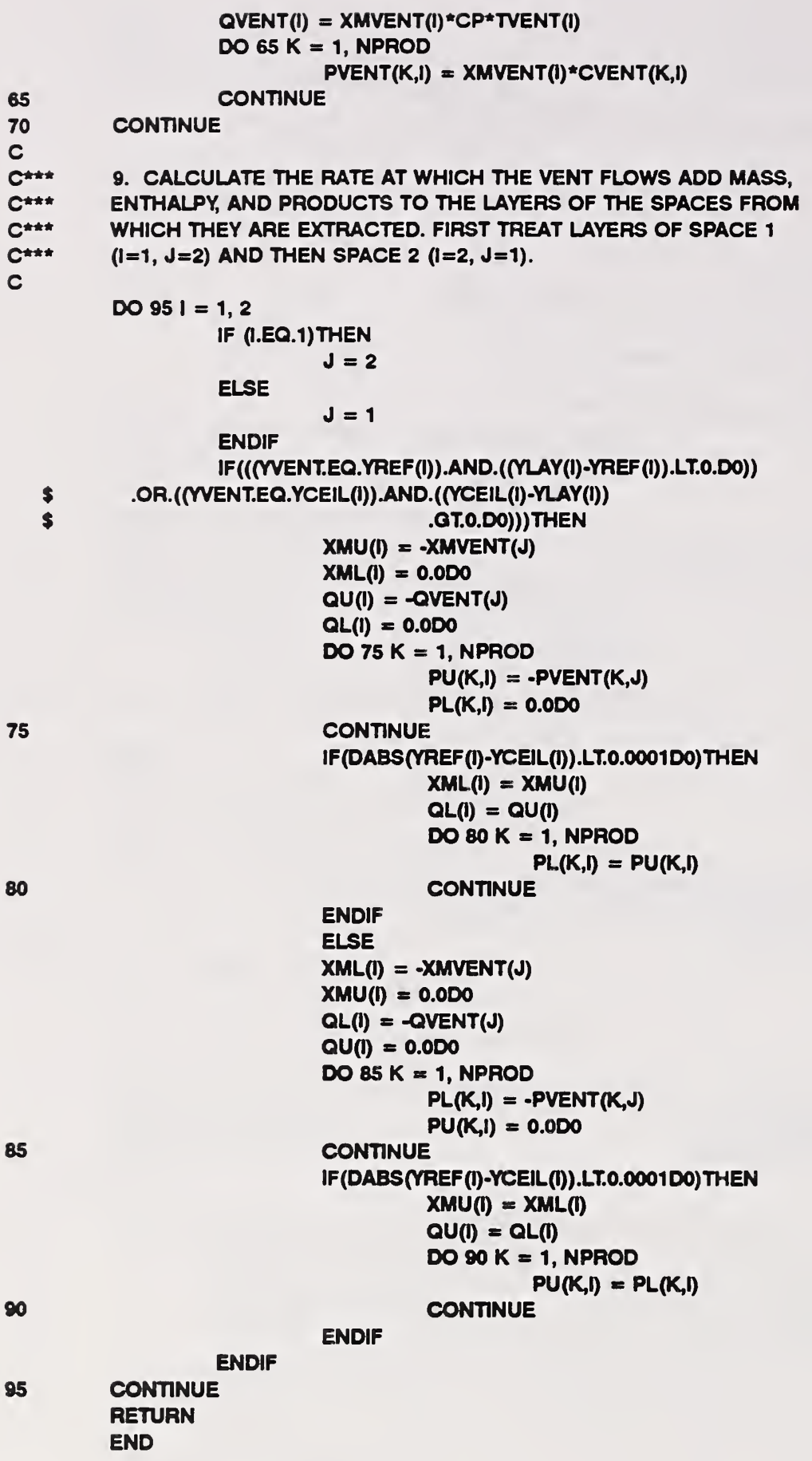



VENTCF2A - CALCULATION OF THE FLOW THROUGH A HORIZONTAL CEILING/FLOOR VENT CONNECTING TWO SPACES WITH "SMOOTHING" OF LAYER EXTRACTION RATES AT TIMES OF RELATIVELY THIN ADJACENT-VENT LAYERS

\section{DESCRIPTION}

Consider an instant of time during the simulation of a multi-room compartment fire environment. This algorithm calculates the flow of mass, enthalpy, oxygen, and other products of combustion through a horizontal vent located in a ceiling/floor partition common to any two inside rooms of the facility or between an inside room and the outside environment local to the vent. VENTCF2A is a modification of VENTCF2 [1]. It provides special considerations for "smoothing" rates of layer extraction from the flow source room at times of relatively thin adjacent-vent layers. When used in a full zone model, and depending on the integration software for the particular model, the considerations in VENTCF2A eliminate singularities that may cause convergence problems in fire simulations at times when adjacent-vent layers are growing or shrinking from near-zero depths.

Depicted in Figure 1a is the vent and the two spaces when they are both inside rooms of a multi-room facility. Figures $1 \mathrm{~b}$ and $1 \mathrm{c}$ depict the situation when the two spaces involve one inside room of the facility and one outside space, either above or below the room, in which is simulated the outside environment local to the vent.

As in Figure 1, designate the top space as space 1 and the bottom space as space 2. It is assumed that the temperature, density, concentration of oxygen and of other products of combustion of interest in the upper and lower layer of each inside room and in the environment local to the vent of an outside space are specified. Also specified in each inside room are: the elevation above the datum elevation of the floor, and the upper-layer/lower-layer interface; and the pressure at the floor above the specified datum pressure. Specified in an outside space are: a reference elevation above the datum elevation, and the pressure at this reference elevation above the specified datum pressure.

When the upper gas is less dense than the lower gas, i.e., the fluid configuration is stable, the flow through the vent is determined by a traditional orifice-type flow model. Then, flow is determined by the cross-vent pressure difference without any regard for buoyancy effects (see, e.g., [2] and [3]) and the present algorithm/subroutine is identical to that of VENTCF [4]. When the configuration is unstable and the upper gas is more dense than the lower gas, the effects of combined pressure and buoyancy forces can be significant. For example if the cross-vent pressure is relatively small, the unstable density configuration leads to an exchange-type of flow, with gas in the lower space rising into the upper space and gas from the upper space dropping into the lower space, where the flow rate from the high- to the low-pressure side of the vent is the larger of the two. Also, even when the cross-vent pressure difference large enough to produce uni-directional flow, the effect of buoyancy can be great enough to reduce significantly the flow rate from what it would be in the absence of a cross-vent density difference. In the present algorithm, for the case of unstable configurations the calculation of the flow between the two spaces is based on the theory developed and presented in [5].

For unstable density configurations, the model of [5] and, therefore, the VENTCF2 and VENTCF2A algorithms/subroutines are for flow through a circular, shallow (i.e., small ratio of depth to diameter), horizontal vent. It is also expected that the model will give reasonable estimates of flow even for noncircular vents, provided the aspect ratio (maximum-to-minimum span) of a vent shape of interest is not too much different than 1. Indeed, one of the example calculations of [5], which includes comparisons with some relevant experimental data, provides limited support for the applicability of the model in the case of square vents. However, USE OF VENTCF2 AND VENTCF2A IN HIGH-ASPECT-RATIO AND/OR MODERATE-TO-LARGE-DEPTH VENT SCENARIOS IS NOT VALID when cross-vent pressure differences 
are small-to-moderate compared to $\Delta \mathrm{p}_{\mathrm{FLOOD}}$. Results beyond those developed in [5] are required before the present work can be used for the latter types of vent shape.

The geometry and the conditions local to the vent which determine the characteristics of the vent flow are depicted in Figure 2. These include: the densities, $\rho_{1}$ and $\rho_{2}$, and the hydrostatic pressures, $p_{1}$ and $p_{2}$, at the elevation, but away from the immediate vicinity of the vent in the upper and lower spaces, respectively, and the area, $A_{v}$, and shape of the vent. Regarding the shape, at the present time results for horizontal vent flows are only available for circular or square vents. Other properties local to the vent and indicated in Figure 2 are $T_{1}$ and $T_{2}$, the absolute temperatures, $c_{O 2,1}$ and $c_{O 2,2}$, the concentrations of oxygen, and $\mathrm{c}_{\mathrm{K}, 1}$ and $\mathrm{c}_{\mathrm{K}, 2}, \mathrm{~K}=2$ to $\mathrm{N}_{\mathrm{PROD}}$, the concentrations of a product of combustion $\mathrm{K}$.

To simulate fire scenarios at times when vent flows are driven by arbitrarily high cross-vent pressure differences (i.e., when compressibility effects begin to be significant), whether for stable or unstable crossvent density configurations, both VENTCF2 and VENTCF2A implement the ideas introduced in reference [3] and implemented previously in the algorithm/subroutines VENTHP [6] and VENTCF [4]. Such high cross-vent pressure differences could occur, for example, in fire scenarios involving flows through cracks in otherwise hermetically-sealed fire compartments.

The feature which defines the diffence between VENTCF2 and VENTCF2A is in the treatment of the source of the vent flow when the adjacent-vent layer in the source room is relatively thin. When the thickness of the vent-adjacent layer, $\delta y$, is large enough, it is assumed in VENTCF2A that the flow driven through the vent is extracted entirely from this layer. Unless $\delta y=0$, this assumption is always made in the VENTCL2 model/algorithm, i.e., independent of the size of $\delta y$. However, in VENTCL2A, when $\delta y$ is smaller than some specified, non-zero, characteristic thickness, $\delta$, the model/algorithm assumes that only the fraction $\delta y / \delta$ of the net volumetric rate of flow driven through the vent from the room is extracted from the vent-adjacent layer, the remaining fraction, $(1-\delta y / \delta)$, being extracted from the far layer.

It is reasonable to take the characteristic thickness, $\delta$, as being of the order of the characteristic span of the vent opening, taken as to equivalent vent diameter, $D=\left(4 A_{v} / \pi\right)^{1 / 2}$, but never greater than a characteristic distance related to the height of the room, $\mathrm{H}$, from which the flow is extracted. Here $\delta$ is taken to be $\delta=\min (D / 2, H / 2)$.

\section{OUTPUT}

$\mathrm{c}_{02,1}\left[\mathrm{c}_{\mathrm{O}, 2}\right]$

Concentration of oxygen of the flow from the top [bottom] space as it enters the vent. [(kg of oxygen)/(kg of layer)]

$c_{K, 1}\left[c_{K, 2}\right]$

Concentration of product $K$ of the flow from the top [bottom] space as it enters the vent. [(unit of product $\mathrm{K}) /(\mathrm{kg}$ of layer)]

QVENT,O2, i I $=1$ or 2

Concentration of oxygen in the component of the vent flow entering space I, provided such vent flow component is non-zero, i.e., provided $\dot{M}_{\text {VENT, }}$ is non-zero. [( $\mathrm{kg}$ of oxygen)/(kg of vent flow)]

$C_{V E N T, K, 1} ; I=1$ or $2 ; K=2$ to NPROD 
Concentration of product of combustion $\mathrm{K}$ in the component of the vent flow entering space $\mathrm{I}$, provided such vent flow component is nonzero, i.e., provided $\dot{M}_{\mathrm{VENT}, \mathrm{I}}$ is non-zero. [(unit of product)/(kg of vent flow)]

$\dot{M}_{U, I}\left[\dot{M}_{L, 1}\right] ; I=1$ or 2

If space I is an inside room: Rate at which mass is added to the upper [lower] layer of room I due to the vent flow component which enters the other space. Note that this will always be negative, since the layer which supplies the material flowing to the other space will always have mass extracted from it. [W]

If space I is an "outside room": $\dot{M}_{U, I}$ is the rate at which mass is added to space I due to the vent flow component which enters the other space (i.e., the inside room). Note that this will always be negative, since an outside space which supplies material flowing through the vent to an adjacent space will always have mass extracted from it. $\dot{M}_{L, I}$ is identical to $\dot{M}_{U, l}$. [W]

$\dot{M}_{\text {VENT, }, ~} I I=1$ to 2

Mass flow rate of the vent flow component entering space $\mathrm{l} .[\mathrm{kg} / \mathrm{s}]$

$P_{O 2, L, 1}\left[P_{O 2, U, I}\right] ; I=1$ or 2

If space $I$ is an inside room: Rate at which oxygen is added to the upper [lower] layer of room I due to the vent flow component which enters the other space. Note that this will always be negative, since the layer which supplies the material flowing through the vent to the other space will always have its convected oxygen extracted from it. [( $\left.\left.\mathrm{kg} \mathrm{of} \mathrm{O}_{2}\right) / \mathrm{s}\right]$

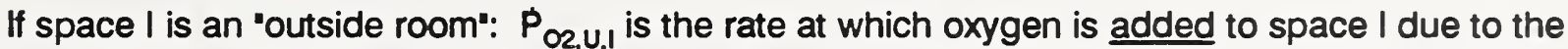
vent flow component which enters the other space (i.e., the inside room). Note that this will always be negative, since an outside space which supplies material flowing through the vent to an adjacent space will always have its convected oxygen extracted from it. $P_{O 2, L, 1}$ is identical to $P_{O 2, U, 1 \cdot}\left[\left(\mathrm{kg}\right.\right.$ of $\left.\left.\mathrm{O}_{2}\right) / \mathrm{s}\right]$

$P_{\text {OZ,VENT, }, ~} I=1$ to 2

Mass flow rate of oxygen of the vent flow component entering space I. [( $\mathrm{kg}$ of oxygen)/s]

$P_{K, L I}\left[P_{K, U, I}\right] ; K=2$ to $N_{P R O D} ; I=1$ or 2

If space I is an inside room: Rate at which product of combustion $\mathrm{K}$ is added to the upper [lower] layer of room I due to the vent flow component which enters the other space. Note that this will always be negative since the layer which supplies the material flowing through the vent to the other space will always have its convected product of combustion $\mathrm{K}$ extracted from it. [(unit of product $\mathrm{K} / \mathrm{s}$ ]

If space $I$ is an "outside room": $P_{K, U, I}$ is the rate at which product of combustion $K$ is added to space I due to the vent flow component which enters the other space (i.e., the inside room). Note that this will always be negative, since an outside space which supplies material flowing through the vent to an adjacent space will always have the convected product of combustion $K$ extracted from it. $P_{K, L,}$ is identical to $P_{K, U, l}$ [(unit of product $\left.K\right) / s$ ]

$P_{\text {KVENT, }} ; I=1$ to $2 ; K=2$ to $N_{\text {PROD }}$ 
Flow rate of product of combustion $\mathrm{K}$ in the vent flow component entering space I. [(unit of product $\mathrm{K}) / \mathrm{s}]$

$p_{1}\left[p_{2}\right]$

Absolute hydrostatic pressure in the top [bottom] space at the elevation of the vent. [Pa $=$ $\left.\mathrm{kg} /\left(\mathrm{m} \cdot \mathrm{s}^{2}\right)\right]$

$Q_{U, I}\left[Q_{L, I}\right] ;=1$ or 2

If space I is an inside room: Rate at which enthalpy added to the upper [lower] layer of room I due to the vent flow component which enters the other space. Note that this will always be negative, since the layer which supplies the material which flows to the other space will always have its convected enthalpy extracted from it. The enthalpy is based on the absolute temperature of the flow, $T_{\text {VENT, }}$. $[W]$

If space $I$ is an "outside room": $Q_{U, I}$ is the rate at which enthalpy is added to space I due to the vent flow component which enters the other space (i.e., the inside room). Note that this will always be negative, since an outside space which supplies material which flows through the vent to an adjacent space will always have its convected enthalpy extracted from it. The enthalpy is based on the absolute temperature of the flow, $T_{U, 1} Q_{L, 1}$ is identical to $Q_{U, 1}$. $[W]$

$Q_{\text {VENT,i }} ;=1$ to 2

Total enthalpy flow rate in the vent flow component entering space I. This is based on the absolute temperature of the flow, $\mathrm{T}_{\mathrm{VENT}, \mathrm{l}}$ [W]

$T_{1}\left[T_{2}\right]$

Absolute temperature of the flow from the top [bottom] space as it enters the vent. [K]

$T_{\text {VENT, },} ; I=1$ to 2

Absolute temperature of the vent flow component entering space I, provided such vent flow component is non-zero. [K]

$\Delta p$

$p_{2}-p_{1}$, i.e., difference between the pressure in the bottom space, at the elevation of the vent, and the pressure in the top space, at the elevation of the vent. $\left[\mathrm{Pa}=\mathrm{kg} /\left(\mathrm{m} \cdot \mathrm{s}^{2}\right)\right]$

$\rho_{1}\left[\rho_{2}\right]$

Density of the flow from the top [bottom] space as it enters the vent. [ $\left.\mathrm{kg} / \mathrm{m}_{3}\right]$

$\rho_{\text {VENT, } ;}$ I $1=1$ to 2

Density of the vent flow component entering space I, provided such vent flow component is nonzero. $\left[\mathrm{kg} / \mathrm{m}^{3}\right]$

INPUT

VENTCF2A - 4 
$A_{V}$

Area of the vent $\left[\mathrm{m}^{2}\right]$.

$c_{L, K, I}\left[c_{U, K, I}\right] ; K=2$ to $N_{P R O D} ; I=1$ or 2

If space I is an inside room: Concentration of product of combustion $\mathrm{K}$ in lower [upper] layer of room I if the volume of the lower [upper] layer is non-zero (if the lower [upper] layer volume is zero then the $c_{L, K, I}\left[c_{U, K, I}\right]$ value is not used in the calculation). [(unit of product $\left.K\right) /(\mathrm{kg}$ of layer)]

If space I is an "outside room": $c_{L, K, I}$ is the uniform concentration throughout the space of product of combustion $K ; c_{U, K, l}$ is specified as being identical to $c_{L, K, V}$. [(unit of product $\left.K\right) /(\mathrm{kg}$ of local atmosphere)]

$C_{L, 02,1}\left[c_{U, 02,1}\right] ; I=1$ or 2

If space I is an inside room: Concentration of oxygen in lower [upper] layer of room I if the volume of the lower [upper] layer is non-zero (if the lower [upper] layer volume is zero then the $c_{L, 02,1}\left[c_{u, 02,1}\right]$ value is not used in the calculation). [( $\mathrm{kg}$ of oxygen)/(kg of layer)]

If space $I$ is an "outside room": $C_{L, O 2,1}$ is the uniform concentration throughout the space of oxygen; $c_{U, 02,1}$ is specified as being identical to $c_{L, 02,1}[(\mathrm{~kg}$ of oxygen)/(kg of local atmosphere)]

$C_{p}$

Specific heat at constant pressure of the vent flow. $[\mathrm{W} \cdot \mathrm{s} /(\mathrm{kg} \cdot \mathrm{K})]$ (suggest $10^{3} \mathrm{~W} \cdot \mathrm{s} /(\mathrm{kg} \cdot \mathrm{K})$ for air as default)

$N_{\text {PMAX }}$

Maximum allowed number of products of combustion.

$\mathrm{N}_{\text {PROD }}$

Number of products of combustion, including oxygen, being tracked in the simulation.

PDAT

Datum absolute pressure. $\left[\mathrm{Pa}=\mathrm{kg} /\left(\mathrm{m} \cdot \mathrm{s}^{2}\right)\right]$

$T_{L,}\left[T_{U, 1}\right] ; I=1$ or 2

If space I is an inside room: Absolute temperature of the lower [upper] layer in room I if the volume of the lower [upper] layer is non-zero (if the lower [upper] layer volume is zero then the $T_{L,}\left[T_{U, 1}\right]$ value is not used in the calculation). [K]

If space $I$ is an "outside room": $T_{L I}$ is the uniform absolute temperature there, taken to be the temperature at the reference elevation, $y_{R E F, i} ; T_{U, I}$ is specified as being identical to $T_{L, 1}[K]$

$y_{\text {CEILI, }}\left[y_{\text {REF, }}\right]$ 
If space I is an inside room: Elevation of the ceiling [floor] of room I above the datum elevation. [m]

If space $I$ is an "outside room": $y_{C E L L,}$ and $y_{R E F, I}$ are both identical and equal to the reference elevation of space I above the datum elevation, i.e., the specification must satisfy $y_{C E I L, I} \equiv y_{\text {REF,I }}$. The latter identity, which will never be satisfied for an inside room, is a characteristic of the input data used to distinguish an inside room from an "outside room." [m]

YLAYER, 1 I I $=1$ or 2

If space I is an inside room: Elevation of the upper/lower layer interface in room I above the datum elevation. [m]

If space $I$ is an "outside room": $y_{\text {LAYER, }}$ is specified as being identical to $y_{\text {REF,I }}$ [m]

$\mathrm{Y}_{\text {VENT }}$

Elevation of the vent above the datum elevation. Note that $\mathrm{y}_{\text {VENT }}$ must be identical to either $\mathrm{y}_{\text {CEILI }}$ or $y_{R E F, I}$ for each of the one or two inside rooms involved in the calculation. [m]

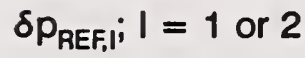

Pressure at the reference elevation, $y_{\mathrm{REF}, \mathrm{l}}$ in space $\mathrm{I}$ above the datum absolute pressure, $\mathrm{p}_{\mathrm{DAT}}$. If space $I$ is an inside room, then $\delta p_{R E F, I}$ and $y_{R E F, I}$ must correspond to the pressure and elevation, respectively, within the room and at the floor. $\left[\mathrm{Pa}=\mathrm{kg} /\left(\mathrm{m} \cdot \mathrm{s}^{2}\right)\right]$

$\varepsilon_{\mathrm{p}}$

Error tolerance for $\delta p_{R E F, l}$. If $p_{\text {ERROR, }}$ is defined as the uncertainty in $\delta p_{\text {REF, }}, I=1$ or 2 , then PERROR,I satisfies

$$
\left|P_{E R R O R, I}\right|<\varepsilon_{p} p_{0}+\left|\delta p_{R E F, I}\right| \varepsilon_{p}
$$

where $p_{0}=1.0 \mathrm{~Pa}$. The first term is based on an absolute error tolerance and dominates the above error bound when $\left|\delta \mathrm{p}_{\mathrm{REF}, \mathrm{I}}\right|$ is less than $1.0 \mathrm{~Pa}$. The second term is a relative error tolerance and dominates when $\left|\delta p_{\mathrm{REF,I}}\right|$ is greater than $1.0 \mathrm{~Pa}$. $\varepsilon_{\mathrm{p}}$ should be chosen to be consistent with the tolerance specified for the computation of $\delta p_{R E F, I}$ terms in the overall compartment fire model computer code which uses this algorithm.

$\rho_{L, I}\left[\rho_{U, I}\right] ; I=1$ or 2

If space I is an inside room: Density of the lower [upper] layer in room I if the volume of the lower [upper] layer is non-zero (if the lower [upper] layer volume is zero then the $\rho_{L I}\left[\rho_{U, I}\right]$ value is not used in the calculation). $\left[\mathrm{kg} / \mathrm{m}^{3}\right]$

If space I is an "outside room": $\rho_{L, I}$ is the uniform density there; $\rho_{U, I}$ is specified as being identical to $\rho_{\mathrm{LI}} .\left[\mathrm{kg} / \mathrm{m}^{3}\right]$

\section{CALCULATION}


Set all output to zero. If $A_{V}=0$ then calculation is complete, if not then:

1. Calculate $p_{1}$ for $1=1$ and 2 , and then $\Delta p$ (the $p_{1}$ calculation follows the DELP algorithm/subroutine of reference [7]):

$$
\begin{aligned}
& p_{1}=\delta p_{R E F, I}+\delta p_{1}+p_{D A T} \\
& \Delta p=p_{2}-p_{1}=\left(\delta p_{R E F, 2}-\delta p_{R E F, 1}\right)+\left(\delta p_{2}-\delta p_{1}\right)
\end{aligned}
$$

where

$$
\begin{aligned}
& \text { if } y_{R E F, I} \leq y_{V E N T} \leq y_{\text {LAYER,I }} \text { then: } \delta p_{1}=-\rho_{L, I} g\left(y_{V E N T}-y_{R E F, I}\right) \\
& \text { else: } \delta p_{1}=-\rho_{L, I} g\left(y_{\text {LAYER,I }}-y_{\text {REF, },}\right)-\rho_{U, I} g\left(y_{\text {VENT }}-y_{\text {LAYER, },}\right)
\end{aligned}
$$

and where $g$, the acceleration of gravity, is $9.8 \mathrm{~m} / \mathrm{s}^{2}$.

2. Calculate $D, \delta_{1}, \delta y_{1}, \rho_{1}, T_{1}, c_{O 2,1}$, and the $c_{K, 1}, K=2$ to $N_{P R O D}$, for $I=1$ and 2 , and then $\Delta \rho$ :

$$
D=\left(4 A_{\sqrt{ }} / \pi\right)^{1 / 2}
$$

If $\mathrm{y}_{\text {CEILI }}>\mathrm{y}_{\mathrm{REF,I}}$ then (space $\mathrm{I}$ is an inside space and)

$$
\delta_{1}=\min \left[\left(y_{\text {CEIL, }}-y_{\text {REF, },}\right) / 2, D / 2\right] ; \delta y_{1}=\left|y_{\text {LAYER,I }}-y_{\text {VENT }}\right|
$$

else $\left(y_{\text {CEIL, }}=y_{\text {REF,I }}\right.$, space $I$ is an outside space, and $)$

$$
\delta_{1}=D / 2 ; \delta y_{1}=0
$$

If $\delta y_{1}>\delta_{1}$ then (vent flow from space I is extracted from the vent-adjacent layer):

If $I=1$ (i.e., the upper room) then

$$
\rho_{1}=\rho_{L, 1}, T_{1}=T_{L, 1}, c_{O 2,1}=c_{L, 02,1} \text { and } c_{K, 1}=c_{L, K, 1}
$$

else $(I=2$, i.e., the lower room and $)$

$$
\rho_{2}=\rho_{U, 2}, T_{2}=T_{U, 2}, c_{O 2,2}=c_{U, 02,2} \text { and } c_{K, 2}=c_{U, K, 2}
$$

else $\left(\delta y_{1} \leq \delta_{1}\right.$ and the vent flow from space I is extracted from both layers)

$$
\begin{aligned}
& \text { If I = } 1 \text { (i.e., the upper room) then } \\
& \rho_{1}=\rho_{U, 1}\left(1-\delta y_{1} / \delta_{1}\right)+\rho_{L, 1} \delta y_{1} / \delta_{1} ; T_{1}=T_{U, 1} \rho_{U, 1} / \rho_{1} ; \\
& c_{O O_{, 1}}=\left[c_{U, 02,1} \rho_{U, 1}\left(1-\delta y_{1} / \delta_{1}\right)+c_{L, 02,1} \rho_{L, 1} \delta y_{1} / \delta_{1}\right] / \rho_{1} ; \\
& c_{K, 1}=\left[c_{U, K, 1} \rho_{U, 1}\left(1-\delta y_{1} / \delta_{1}\right)+c_{L, K, 1} \rho_{L, 1} \delta y_{1} / \delta_{1}\right] / \rho_{1}, K=2, N_{P R O D}
\end{aligned}
$$

else $(I=2$, i.e., the lower room and) 


$$
\begin{aligned}
& \rho_{2}=\rho_{\mathrm{L}, 2}\left(1-\delta \mathrm{y}_{2} / \delta_{2}\right)+\rho_{\mathrm{U}, 2} \delta \mathrm{y}_{2} / \delta_{2} ; T_{2}=T_{L, 2} \rho_{\mathrm{L}, 2} / \rho_{2} ; \\
& \mathrm{C}_{O 2,2}=\left[\mathrm{C}_{\mathrm{L}, 02,2} \rho_{\mathrm{L}, 2}\left(1-\delta \mathrm{y}_{2} / \delta_{2}\right)+\mathrm{c}_{\mathrm{U}, 02,2} \rho_{\mathrm{U}, 2} \delta \mathrm{y}_{2} / \delta_{2}\right] / \rho_{2} ; \\
& \mathrm{C}_{\mathrm{K}, 2}=\left[\mathrm{C}_{\mathrm{L}, \mathrm{K}, 2} \rho_{\mathrm{L}, 2}\left(1-\delta \mathrm{y}_{2} / \delta_{2}\right)+\mathrm{c}_{\mathrm{U}, \mathrm{K}, 2} \rho_{\mathrm{U}, 2} \delta \mathrm{y}_{2} / \delta_{2}\right] / \rho_{2}, \mathrm{~K}=2, \mathrm{~N}_{\mathrm{PROD}}
\end{aligned}
$$

$$
\Delta \rho=\rho_{1}-\rho_{2}
$$

3. Define $\dot{V}_{\text {ST,HIGH }}$ as the volume rate of flow through the vent, from the high- to the low-pressure space, that is predicted with a "standard," unidirectional-flow-type calculation (i.e., without regard to the effect of buoyancy, in general, or the stability of the cross-vent density configuration, in particular), where arbitrarily high cross-vent pressures are allowed. Here, the calculation follows the model of [3] as implemented in the VENTHP algorithm/subroutine of [6]. Calculate $\dot{V}_{\text {ST,HIGH }}$ :

If $\Delta p=0$ then: $\dot{V}_{S T, H I G H}=0$; skip to (the next) item 4 of the CALCULATION

If $\Delta p>0$ or $\Delta p<0$ then:

a. Define and compute $\rho_{\mathrm{HIG}}, \varepsilon$, and $\mathrm{X}$ :

If $\Delta p>0$, i.e., 'standard' flow from (lower) space 2 to (upper) space 1, then:

$$
\rho_{\mathrm{HIGH}}=\rho_{2} ; \varepsilon=\Delta \mathrm{p} / \mathrm{p}_{2}
$$

If $\Delta p<0$, i.e., "standard" flow from (upper) space 1 to (lower) space 2, then:

$$
\rho_{\mathrm{HIGH}}=\rho_{1} ; \varepsilon=-\Delta \mathrm{p} / \mathrm{p}_{1}
$$

$$
x=1-\varepsilon
$$

b. Compute $C(x)$, the vent flow coeffient, and $w(x)$ :

$$
\begin{aligned}
& C(x)=0.85-0.25 x=0.60+0.25 \varepsilon \\
& w(x)=\left\{\begin{array}{l}
1-[3 /(4 \gamma)] \varepsilon \text { if } 0<\varepsilon \leq 10^{-5} \\
f(x) /[2 \varepsilon]^{1 / 2} \text { if } 1 \geq \varepsilon>10^{-5}
\end{array}\right.
\end{aligned}
$$

where

$$
f(x)=\left\{\begin{array}{l}
\left\{[2 \gamma /(\gamma-1)] x^{2 / \gamma}\left[1-x^{(\gamma-1) / \gamma}\right]\right\}^{1 / 2} \text { if } \varepsilon<1-[2 /(\gamma+1)]^{\gamma /(\gamma-1)} \\
\left\{\gamma[2 /(\gamma+1)]^{(\gamma+1) /(\gamma-1)}\right\}^{1 / 2} \text { if } \varepsilon \geq 1-[2 /(\gamma+1)]^{\gamma /(\gamma-1)}
\end{array}\right.
$$

and where $\gamma$, the ratio of specific heats of the vent flow gas, is taken to be that of air, 1.40. Note that for the present horizontal vent application, the $C(x)$ of Eq. (10) is taken to be consistent with the standard incompressible limit for flow through circular sharpedged orifices in the sense that $C \rightarrow 0.60$ as $\varepsilon \rightarrow 0$ [8].

c. Define and compute $\Delta \mathrm{p}_{\mathrm{cuT}}^{1 / 2}$ :

$$
\Delta p_{\text {CUT }}^{1 / 2} \equiv\left[\varepsilon_{p} M A X\left(1.0 P a,\left|\delta p_{R E F, 1}\right|,\left|\delta p_{R E F, 2}\right|\right)\right]^{1 / 2}
$$


d. Define and compute $F_{\text {NOISE }}$, a numerical damping factor, and then $\dot{V}_{\text {ST,HIGH}}$ :

$$
\begin{aligned}
& F_{\text {NOISE }}=1.0-\exp \left(-|\Delta p|^{1 / 2} / \Delta p_{\text {CUT }}^{1 / 2}\right) \\
& \dot{V}_{\text {ST,HIGH }}=F_{\text {NOISE }} \mathrm{C}(x) w(x)\left(2 / \rho_{\text {HIGH }}\right)^{1 / 2} A_{V}|\Delta p|^{1 / 2}
\end{aligned}
$$

The term $F_{\text {NOISE }}$ of Eq. (14) is designed to damp out the numerical noise (error) in the calculated value for $\Delta p$ that would otherwise be dominant in Eq. (15) when $\Delta p$ is small relative to the maximum of 1.0 pascal and the calculated reference pressures, $\delta p_{R E F, 1}$ $\delta p_{\mathrm{REF}, 2 \cdot}$ The term $\Delta \mathrm{p}_{\mathrm{CUT}}$ of Eq. (13) is an estimate of how small the maximum of $|\Delta \mathrm{p}|$ must be to retain a few digits of accuracy in the calculation of $\Delta p$. When the calculated value of $|\Delta \mathrm{p}|$ is smaller than $\mathrm{p}_{\mathrm{cuT}}$, this value and, therefore, the value of $\dot{V}_{\mathrm{ST}, \mathrm{HIGH}}$ in Eq. (15) will likely contain noise which should be damped. $F_{\text {NOISE }}$ is constructed to tend towards 1 when $|\Delta p|$ is large relative to $\Delta p_{c u r}$ and tends towards 0 when $|\Delta p|$ is small relative to $\Delta \mathrm{p}_{\text {cut }}$.

4. When the cross-vent density configuration is unstable $(\Delta \rho>0)$, mixed pressure- and buoyancydriven aspects of the flow have to be considered and the vent flow rates are calculated according to [5]. Define $\dot{V}_{B, H I G H}, \dot{V}_{B, L O W}$ as the reference-[5], buoyancy-affected, volume flow rates across the vent from the high-to-low and low-to-high pressure spaces, respectively.

If $\Delta \rho \leq 0: \dot{V}_{B, H I G H}=\dot{V}_{B, L O W}=0$; skip to (the next) item 5 of the CALCULATION

a. Calculate $\overline{\mathrm{T}}, \bar{\rho}, \mu(\overline{\mathrm{T}})$ in $\mathrm{m}^{2} / \mathrm{s}$ from [12], and $\varepsilon>0$ :

$$
\begin{aligned}
& \overline{\mathrm{T}}=\left(T_{1}+\mathrm{T}_{2}\right) / 2 ; \bar{\rho}=\left(\rho_{1}+\rho_{2}\right) / 2 ; \mu(\overline{\mathrm{T}})=\bar{\rho}\left[0.04128\left(10^{-7}\right) \overline{\mathrm{T}}^{5 / 2} /(\overline{\mathrm{T}}+110.4)\right] ; \\
& \varepsilon=\Delta \rho / \bar{\rho}>0
\end{aligned}
$$

b. $\quad$ Calculate $\bar{G}$; if $p_{2}>p_{1}$, i.e., $\Delta p>0$, then replace $\varepsilon$ by $-\varepsilon<0$ :

$$
\overline{\mathrm{G}} \mathrm{r}=2 \mathrm{gD} \mathrm{D}^{3}|\varepsilon| /[\mu(\overline{\mathrm{T}}) / \bar{\rho}]^{2} ; \text { if } \Delta \mathrm{p}>0 \text { then } \varepsilon=-\varepsilon
$$

c. Calculate conditions at the limit of unidirectional flow (i.e., the flooding condition) and the relative pressure, $\delta p^{\star}$ :

$$
\begin{aligned}
& \dot{V}_{H I G H, F L O O D}=0.1754 A_{V}(2 g D|\varepsilon|)^{1 / 2} \exp (0.5536 \varepsilon) ; \\
& \Delta p_{F L O O D}=0.2427(4 g \Delta \rho D)(1+\varepsilon / 2) \exp (1.1072 \varepsilon) ; \\
& \delta p^{*}=|\Delta p| / \Delta p_{F L O O D}
\end{aligned}
$$

d. Calculate $\sigma_{1}, \sigma_{2}$ and then $V_{B, L O W}, V_{B, H I G H}$ :

$$
\sigma_{1}=\mathrm{F}_{\text {NOISE }} \mathrm{C}(\mathrm{x}) \mathrm{W}(\mathrm{x}) / 0.1780 ; \sigma_{2}=1.045
$$

If $\delta p^{*} \geq 1$, expect uni-directional flow:

$$
V_{B, L O W}=0 ; \dot{V}_{B, H I G H}=\dot{V}_{H I G H, F L O O D}\left\{1-\sigma_{2}^{2}+\left[\sigma_{2}^{4}+\sigma_{1}^{2}\left(\delta p^{*}-1\right)\right]^{1 / 2}\right\}
$$

If $\delta p^{\star}<1$, expect mixed flow: 


$$
\begin{aligned}
& \dot{V}_{E X, M A X}=0.055(4 / \pi) A_{V}(g D|\varepsilon|)^{1 / 2} ; m_{3}=-0.7070 ; M=\left(\sigma_{1} / \sigma_{2}\right)^{2}-1 \\
& \dot{V}_{B, L O W}=\dot{V}_{E X, M A X}\left[\left(1+m_{3} / 2\right)\left(1-\delta p^{\star}\right)^{2}-\left(2+m_{3} / 2\right)\left(1-\delta p^{\star}\right)\right]^{2} \\
& \dot{V}_{B, H I G H}=\dot{V}_{B, L O W}+\left\{M-\left[1+\left(M^{2}-1\right)\left(1-\delta p^{\star}\right)\right]^{1 / 2}\right\} \dot{V}_{H I G H, F L O O D} /(M-1)
\end{aligned}
$$

(Note: $\sigma_{1}$ of Eq. (21) is somewhat different than $\sigma_{1}$ in [5]. The modification here is provide for an analytic representation of vent flow which is continuous and uniformly valid even as $\delta p^{*}$ is increased to a level where compressibility effects become important. The result of [5] does not include the effect of compressibility.)

5. Following [5], when $\Delta \rho>0$ the above will be taken as the flow solution provided $\bar{G} r \geq 2\left(10^{7}\right)$. For smaller Gr, the reference-[5] solution begins to loose its validity, and there is no existing model for the flows the range $0<\overline{G r}<2\left(10^{7}\right)$. However, it is clear that the above-calculated "standard" flow must be approached as $\overline{\mathrm{G}} \mathrm{r} \rightarrow 0$.

Consistent with the above comments, when $\bar{G} r$ is in the range $0 \leq \bar{G} r<2\left(10^{7}\right)$, the vent flow will be estimated by:

$$
\text { flow }=(\text { "standard" flow })+\left[\left(\text { reference-[5] flow) }-(\text { "standard" flow) }] \bar{G} r /\left[2\left(10^{7}\right)\right]\right.\right.
$$

a. Define $\dot{\mathrm{V}}_{\mathrm{HIGH}}$ and $\dot{\mathrm{V}}_{\mathrm{LOW}}$ as volume flow rates across the vent from the high-to-low and lowto-high pressure spaces, respectively.

$$
\begin{aligned}
& \text { If } \Delta \rho \leq 0: \dot{V}_{\text {HIGH }}=\dot{V}_{\text {ST,HIGH}} ; \dot{V}_{\text {LOW }}=0 \\
& \text { If } \begin{aligned}
\Delta \rho> & 0 \text { and } 0<\bar{G}_{r}<2\left(10^{7}\right): \\
& \dot{V}_{\text {HIGH }}=\dot{V}_{\text {ST,HIGH }}+\left(\dot{V}_{B, H I G H}-\dot{V}_{\text {ST,HIGH }}\right) \overline{G r} /\left[2\left(10^{7}\right)\right] \\
& \dot{V}_{\text {LOW }}=\dot{V}_{\text {B.LOW }} \bar{G}_{r} /\left[2\left(10^{7}\right)\right]
\end{aligned}
\end{aligned}
$$

If $\Delta \rho>0$ and $\overline{G r} \geq 2\left(10^{7}\right): \dot{V}_{H I G H}=\dot{V}_{B, H I G H} ; \quad \dot{V}_{\text {LOW }}=\dot{V}_{B, \text { LOW }}$

b. Define and calculate $\dot{V}_{\text {VENT, }}, I=1$ and 2 , as the vent volume flow rate entering space $I$.

If $\Delta p \geq 0: \dot{V}_{\text {VENT,1 }}=\dot{V}_{\text {HIGH }} ; \dot{V}_{\text {VENT,2 }}=\dot{V}_{\text {LOW }}$

(i.e., flow to the upper space is the flow from the high- to the low-pressure space, and flow to the lower space is the flow from the low- to the high-pressure space)

If $\Delta p<0: \dot{V}_{\text {VENT,1 }}=\dot{V}_{\text {LOW }} ; \dot{V}_{\text {VENT,2 }}=\dot{V}_{\text {HIGH }}$

(i.e., flow to the upper space is the flow from the low- to the high-pressure space, and flow to the lower space is the flow from the high- to the low-pressure space)

6. Calculate the vent flow properties $\rho_{\text {VENT, },} T_{\text {VENT, },} C_{\text {VENT,O2, },} C_{\text {VENT,K, }}, K=2$ to $N_{\text {PROD }}, 1=1$ and 2 :

$$
\rho_{\text {VENT,1 }}=\rho_{2}\left(p_{1} / p_{2}\right), \rho_{\text {VENT,2 }}=\rho_{1}\left(p_{2} / p_{1}\right) ; T_{\text {VENT,1 }}=T_{2}, T_{\text {VENT,2 }}=T_{1} ;
$$




$$
c_{V E N T, O 2,1}=c_{O 2,2}, c_{V E N T, O 2,2}=c_{O 2,1} ; c_{V E N T, K, 1}=c_{K, 2}, c_{V E N T, K, 2}=c_{K, 1}, K=2 \text { to } N_{P R O D}
$$

7. Calculate the vent flow rates $\dot{M}_{\mathrm{VENT}, \mathrm{I}}, \mathrm{I}=1$ and 2:

$$
\dot{M}_{\text {VENT,I }}=\rho_{\text {VENT,I }} \dot{V}_{\text {VENT,I }}
$$

8. Calculate the vent flow rates $Q_{\text {VENT, }}, P_{\text {O2,VENT, }}, P_{K, V E N T, I}, K=2$ to $N_{\text {PROD }}, I=1$ and 2 :

$$
\begin{aligned}
& Q_{\text {VENT,I }}=\dot{M}_{\text {VENT,I }} C_{p} T_{\text {VENT,I }} ; P_{\text {O2,VENT,I }}=\dot{M}_{\text {VENT,I }} C_{\text {VENT,O2,I }} ; \\
& P_{\text {KVENT,I }}=\dot{M}_{\text {VENT,I }} C_{\text {VENT,K, },}, K=2 \text { to } N_{\text {PROD }}
\end{aligned}
$$

9. Calculate rates at which flows are added to layers of each space as a result of the vent flow extracted from it. First consider space $1(I=1, J=2)$ and then space $2(I=2, J=1)$. For either case:

If $\delta y_{1}>\delta_{1}$ then (vent flow from space I is extracted from the vent-adjacent layer):

$$
\begin{aligned}
& \text { If I }=1 \text { (i.e., the upper room) then } \\
& \dot{M}_{L, 1}=-\dot{M}_{V E N T, 2}, \dot{M}_{U, 1}=0 ; Q_{L, 1}=-Q_{V E N T, 2}, Q_{U, 1}=0 ; \\
& P_{O 2, L, 1}=-P_{O 2, V E N T, 2}, P_{O 2, U, 1}=0 ; \\
& P_{K, L, 1}=-P_{K, V E N T, 2}, P_{K, U, 1}=0, K=2, N_{P R O D} \\
& \text { If } y_{C E I L, 1}=y_{R E F, 1} \text { then (room } 1 \text { is an outside room and) } \\
& \quad \dot{M}_{U, 1}=\dot{M}_{L, 1} ; Q_{U, 1}=Q_{L, 1} ; \\
& P_{O 2, U, 1}=P_{O 2, L, 1} ; P_{K, U, 1}=P_{K, L, 1}, K=2, N_{P R O D}
\end{aligned}
$$

else $(I=2$, i.e., the lower room and)

$$
\begin{aligned}
& \dot{M}_{U, 2}=-\dot{M}_{V E N T, 1}, \dot{M}_{L, 2}=0 ; Q_{U, 2}=-Q_{V E N T, 1}, Q_{L, 2}=0 ; \\
& P_{O 2, U, 2}=-P_{O 2, V E N T, 1}, P_{O 2, L, 2}=0 ; \\
& P_{K, U, 2}=-P_{K, V E N T, 1}, P_{K, L, 2}=0, K=2, N_{P R O D} \\
& \text { If } y_{C E I L, 2}=y_{R E F, 2} \text { then (room } 2 \text { is an outside room and) } \\
& \dot{M}_{U, 2}=\dot{M}_{L, 2} ; Q_{U, 2}=Q_{L, 2} ; \\
& P_{O 2, U, 2}=P_{O 2, L, 2} ; P_{K, U, 2}=P_{K, L, 2}, K=2, N_{P R O D}
\end{aligned}
$$

else $\left(\delta y_{1} \leq \delta_{1}\right.$ and the vent flow from space $I$ is extracted from both layers)

If $I=1$ (i.e., the upper room) then

$$
\dot{M}_{U, 1}=-\rho_{U, 1}\left(1-\delta y_{1} / \delta_{1}\right) \dot{V}_{V E N T, 2} ; \dot{M}_{L, 1}=-\rho_{L, 1}\left(\delta y_{1} / \delta_{1}\right) \dot{V}_{V E N T, I}
$$




$$
\begin{aligned}
& Q_{U, 1}=\dot{M}_{U, 1} C_{P} T_{U, 1} ; Q_{L, 1}=\dot{M}_{L, 1} C_{P} T_{L, 1} \\
& P_{O 2, U, 1}=\dot{M}_{U, 1} c_{U, O 2,1} ; P_{O 2, L, 1}=\dot{M}_{L, 1} c_{L, O 2,1} \\
& P_{K U, 1}=\dot{M}_{U, 1} c_{U, K, 1} ; P_{K L, 1}=\dot{M}_{L, 1} C_{L, K, 1} ; K=2, N_{P R O D} \\
& \text { If } y_{C E L L, 1}=y_{R E F, 1} \text { then (room } 1 \text { is an outside room and) } \\
& \quad \dot{M}_{L, 1}=\dot{M}_{U, 1} ; Q_{L, 1}=Q_{U, 1} ; \\
& \quad P_{O 2, L, 1}=P_{O 2, U, 1} ; P_{K, L, 1}=P_{K, U, 1}, K=2, N_{P R O D}
\end{aligned}
$$

else $(l=2$, i.e., the lower room and $)$

$$
\begin{aligned}
& \dot{M}_{\mathrm{L}, 2}=-\rho_{\mathrm{L}, 2}\left(1-\delta y_{2} / \delta_{2}\right) \dot{V}_{\mathrm{VENT}, 1} ; \dot{M}_{\mathrm{U}, 2}=-\rho_{\mathrm{U}, 2}\left(\delta y_{2} / \delta_{2}\right) \dot{V}_{\mathrm{VENT}, 1} ; \\
& Q_{L, 2}=\dot{M}_{L, 2} C_{p} T_{L, 2} ; Q_{U, 2}=\dot{M}_{U, 21} C_{p} T_{U, 2} ; \\
& P_{\mathrm{O}, \mathrm{LL}, 2}=\dot{M}_{\mathrm{L}, 2} \mathrm{C}_{\mathrm{L}, 02,2} ; P_{\mathrm{O}, \mathrm{U}, 2}=\dot{M}_{\mathrm{U}, 2} \mathrm{C}_{\mathrm{U}, \mathrm{O}, 2,2} \\
& P_{K, L, 2}=\dot{M}_{L, 2} C_{L, K, 2} ; P_{K U, 2}=\dot{M}_{U, 2} C_{U, K, 2} ; K=2, N_{P R O D} ; \\
& \text { If } y_{C E L L, 2}=y_{R E F, 2} \text { then (room } 2 \text { is an outside room and) } \\
& \dot{M}_{\mathrm{U}, 2}=\dot{M}_{L, 2} ; Q_{U, 2}=Q_{L, 2} ; \\
& P_{O 2, U, 2}=P_{O 2, L, 2} ; P_{K, U, 2}=P_{K, L, 2} K=2, N_{P R O D}
\end{aligned}
$$

\section{REFERENCES}

[1] Cooper, L.Y., "VENTCF2: An Algorithm and Associated Computer Subroutine for Calculating Flow Through a Horizontal Ceiling/Floor Vent in a Zone-Type Compartment Fire Model," to appear as NISTIR, National Institute of Standards and Technology, Gaithersburg MD.

[2] Emmons, H., "Vent Flows," Sect. 1/Chapter 8 of SFPE Handbook of Fire Protection Engineering, SFPE, Boston, pp. 130-138, 1988.

[3] Cooper, L.Y., "Calculating Flows Through Vertical Vents in Zone Fire Models," Combustion Science and Technology, Vol. 63, Nos. 1-3, pp. 43-50, 1989.

[4] Cooper, L.Y., "VENTCF - Calculation of the Flow Through a Horizontal Ceiling/Floor Vent Connecting Two Spaces," APPENDIX of: "An Algorithm and Associated Computer Subroutine for Calculating Flow Through a Horizontal Ceiling/Floor Vent in a Zone-Type Compartment Fire Model," NISTIR 90-4402, National Institute of Standards and Technology, Gaithersburg MD, October 1990.

[5] Cooper, L.Y., "Combined Buoyancy- and Pressure-Driven Flow Through a Horizontal, Circular Vent," Cooper, LY., NISTIR 5384, National Institute of Standards and Technology, Gaithersburg MD, April 1994. 
[6] Cooper, L.Y. and Forney, G.P., "VENTHP - Calculation of the Flow of Mass, Enthalpy, Oxygen, and Other Products of Combustion Through a Vertical Constant-Width Vent in a Wall Segment Common to Two Rooms;" an entry in: "Consolidated Compartment Fire Model (CCFM) Computer Code Application CCFM.VENTS - Part III: Algorithms and Subroutines," Cooper, L.Y., and Forney, G.P., Editors, NISTIR 4344, National Institute of Standards and Technology, July 1990.

[7] Cooper, L.Y. and Forney, G.P., 'DELP - Calculation of the Absolute Hydrostatic Pressure at a Specified Elevation in Each of Two Adjacent Rooms and the Pressure Difference;" an entry in: "Consolidated Compartment Fire Model (CCFM) Computer Code Application CCFM.VENTS - Part III: Algorithms and Subroutines," Cooper, L.Y., and Forney, G.P., Editors, NISTIR 4344, National Institute of Standards and Technology, July 1990.

[8] Shapiro, A.H., The Dynamics and Thermodynamics of Commpressible Fluid Flow: Volume 1, Roland Press, New York, p. 100, 1953.

\section{SUBROUTINE VARIABLES}

All nomenclature in the subroutine is identical to the nomenclature used above except for:

\begin{tabular}{|c|c|c|}
\hline$A_{v}$ & - & AVENT $\left[\mathrm{m}^{2}\right]$ \\
\hline C & - & COEF \\
\hline$C_{p}$ & - & $\mathrm{CP}[\mathrm{W} \cdot \mathrm{s} /(\mathrm{kg} \cdot \mathrm{K})]$ \\
\hline$c_{L, K, 1}, c_{U, K, I}$ & - & $\begin{array}{l}\operatorname{CONL}(K, I), \operatorname{CONU}(K, I), I=1 \text { or } 2[\text { (unit of product } K) /(\mathrm{kg} \\
\text { of layer })]\end{array}$ \\
\hline$C_{L, 02,1}, c_{U, 02,1}$ & - & $\begin{array}{l}\operatorname{CONL}(1, l), \operatorname{CONU}(1, l), 1=1 \text { or } 2[(\mathrm{~kg} \text { of oxygen }) /(\mathrm{kg} \text { of } \\
\text { layer })]\end{array}$ \\
\hline GENT,K,I & - & $\begin{array}{l}\text { CVENT(K,I), I = } 1 \text { or } 2[\text { (unit of product } K) /(\mathrm{kg} \text { of vent } \\
\text { flow) }\end{array}$ \\
\hline GVNT,02,1 & - & CVENT(1,I), I = 1 or $2[(\mathrm{~kg}$ of oxygen)/(kg of vent flow)] \\
\hline$c_{k, 1}$ & - & $C(K, I), I=1$ or $2[($ unit of product $K) /(\mathrm{kg}$ of vent flow) \\
\hline$c_{02,1}$ & - & $C(1, \mathrm{l}), \mathrm{I}=1$ or $2[(\mathrm{~kg}$ of oxygen $) /(\mathrm{kg}$ of vent flow $)]$ \\
\hline$F_{\text {NOISE }}$ & - & FNOISE [dimensionless] \\
\hline$f$ & - & FF [dimensionless] \\
\hline$\overline{\mathrm{G}} \mathrm{r}$ & - & GR [dimensionless] \\
\hline g & - & $9.8 \mathrm{~m} / \mathrm{s}^{2}$ \\
\hline M & - & $\mathrm{XM}$ [dimensionless] \\
\hline$\dot{M}_{L, 1}, \dot{M}_{U, 1}$ & - & $X M L(I), X M U(I), I=1$ or $2[\mathrm{~kg} / \mathrm{s}]$ \\
\hline
\end{tabular}




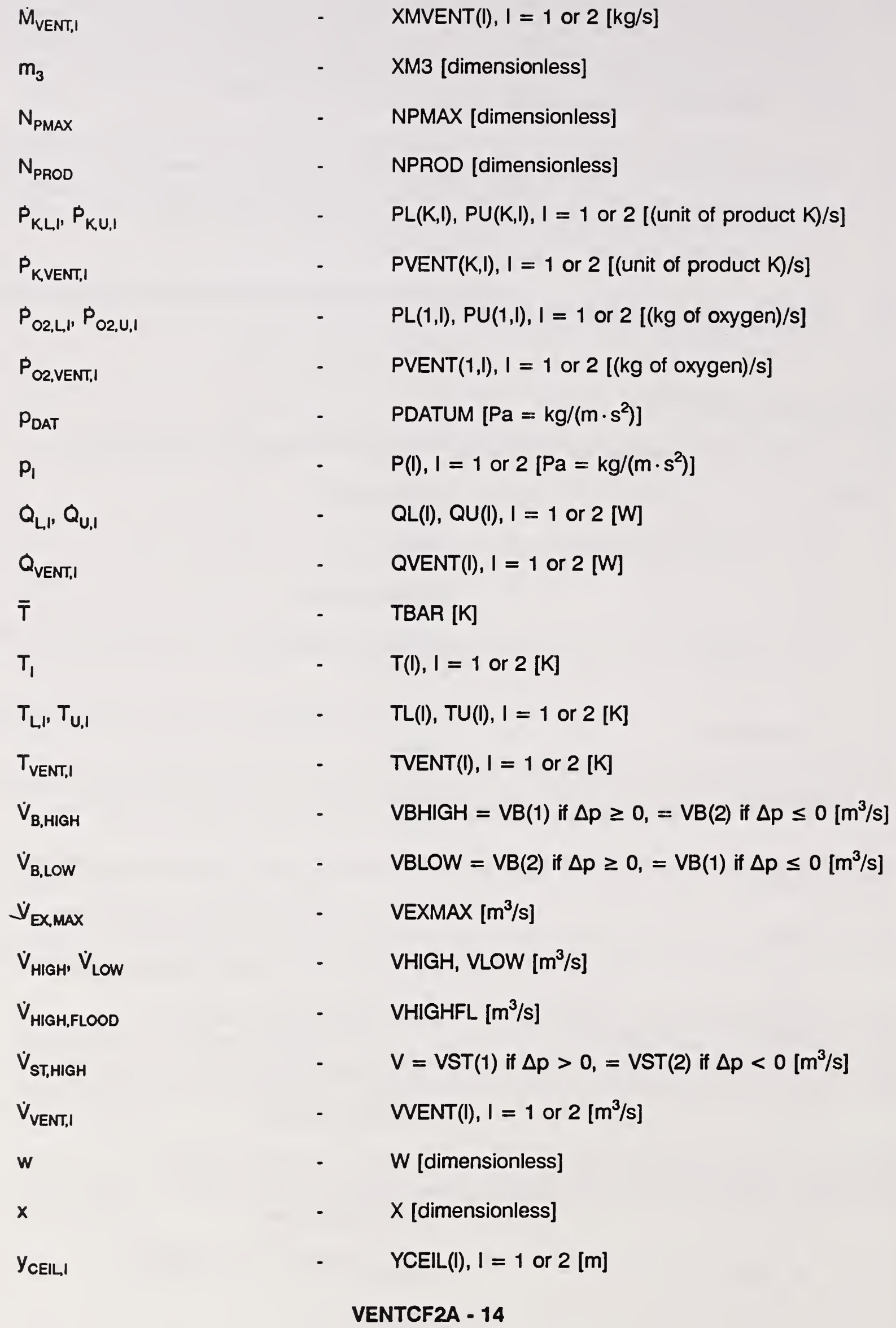

XM3 [dimensionless]

NPMAX [dimensionless]

NPROD [dimensionless]

$\mathrm{PL}(\mathrm{K}, \mathrm{I}), \mathrm{PU}(\mathrm{K}, \mathrm{I}), \mathrm{I}=1$ or $2[($ unit of product $K) / \mathrm{s}]$

$\operatorname{PVENT}(K, I), I=1$ or $2[($ unit of product $K) / S]$

$\mathrm{PL}(1, \mathrm{l}), \mathrm{PU}(1, \mathrm{l}), \mathrm{I}=1$ or $2[(\mathrm{~kg}$ of oxygen)/s]

$\operatorname{PVENT}(1, \mathrm{l}), \mathrm{I}=1$ or $2[(\mathrm{~kg}$ of oxygen $) / \mathrm{s}]$

PDATUM $\left[\mathrm{Pa}=\mathrm{kg} /\left(\mathrm{m} \cdot \mathrm{s}^{2}\right)\right]$

$P(l), I=1$ or $2\left[\mathrm{~Pa}=\mathrm{kg} /\left(\mathrm{m} \cdot \mathrm{s}^{2}\right)\right]$

$Q L(I), Q U(I), I=1$ or $2[W]$

$\operatorname{QVENT}(\mathrm{I}), \mathrm{I}=1$ or 2 [W]

TBAR $[K]$

$T(I), I=1$ or $2[K]$

$T L(I), T U(I), I=1$ or $2[K]$

$\operatorname{TVENT}(\mathrm{I}), \mathrm{I}=1$ or $2[\mathrm{~K}]$

$\mathrm{VBHIGH}=\mathrm{VB}(1)$ if $\Delta p \geq 0,=\mathrm{VB}(2)$ if $\Delta p \leq 0\left[\mathrm{~m}^{3} / \mathrm{s}\right]$

$\mathrm{VBLOW}=\mathrm{VB}(2)$ if $\Delta p \geq 0,=\mathrm{VB}(1)$ if $\Delta p \leq 0\left[\mathrm{~m}^{3} / \mathrm{s}\right]$

VEXMAX $\left[\mathrm{m}^{3} / \mathrm{s}\right]$

VHIGH, VLOW $\left[\mathrm{m}^{3} / \mathrm{s}\right]$

VHIGHFL $\left[\mathrm{m}^{3} / \mathrm{s}\right]$

$V=\operatorname{VST}(1)$ if $\Delta p>0,=\operatorname{VST}(2)$ if $\Delta p<0\left[\mathrm{~m}^{3} / \mathrm{s}\right]$

WENT(l), $\mathrm{l}=1$ or $2\left[\mathrm{~m}^{3} / \mathrm{s}\right]$

W [dimensionless]

X [dimensionless]

YCEIL(I), I = 1 or 2 [m]

VENTCF2A - 14 


\begin{tabular}{|c|c|c|}
\hline $\mathrm{Y}_{\text {LAYER, }}$ & - & $\operatorname{YLAY}(\mathrm{l}), \mathrm{I}=1$ or $2[\mathrm{~m}]$ \\
\hline$y_{\text {REF,I }}$ & - & $\operatorname{YREF}(\mathrm{l}), \mathrm{I}=1$ or $2[\mathrm{~m}]$ \\
\hline $\mathrm{Y}_{\text {VENT }}$ & - & WENT [m] \\
\hline$\gamma$ & - & 1.40 \\
\hline$\Delta p$ & - & $D E L P\left[P a=k g /\left(m \cdot s^{2}\right)\right]$ \\
\hline$\Delta p_{\text {CUT }}^{1 / 2}$ & - & $\mathrm{DPC} 1 \mathrm{D} 2\left[\mathrm{~Pa}=\mathrm{kg} /\left(\mathrm{m} \cdot \mathrm{s}^{2}\right)\right]$ \\
\hline$\triangle \mathrm{p}_{\mathrm{FLOOD}}$ & - & DELPFD $\left[\mathrm{Pa}=\mathrm{kg} /\left(\mathrm{m} \cdot \mathrm{s}^{2}\right)\right]$ \\
\hline$\Delta \rho$ & - & DELDEN $\left[\mathrm{kg} / \mathrm{m}^{3}\right]$ \\
\hline$\delta_{1}$ & - & $\operatorname{DEL}(l), l=1$ or $2[\mathrm{~m}]$ \\
\hline$\delta p_{\star}$ & - & DPDDPFL $\left[\mathrm{Pa}=\mathrm{kg} /\left(\mathrm{m} \cdot \mathrm{s}^{2}\right)\right]$ \\
\hline$\delta p_{1}$ & - & $\mathrm{DP}(\mathrm{l}), \mathrm{I}=1$ or $2\left[\mathrm{~Pa}=\mathrm{kg} /\left(\mathrm{m} \cdot \mathrm{s}^{2}\right)\right]$ \\
\hline$\delta p_{\text {REF,I }}$ & - & $\operatorname{DPREF}(\mathrm{l}), \mathrm{I}=1$ or $2\left[\mathrm{~Pa}=\mathrm{kg} /\left(\mathrm{m} \cdot \mathrm{s}^{2}\right)\right]$ \\
\hline$\delta y_{1}$ & - & $\operatorname{DELYY}(\mathrm{l}), \mathrm{I}=1$ or $2[\mathrm{~m}]$ \\
\hline$\varepsilon$ & - & EPS [dimensionless] \\
\hline$\varepsilon_{\mathrm{p}}$ & - & EPSP [dimensionless] \\
\hline$\mu$ & - & $\mathrm{XMEW}\left[\mathrm{m}^{2} / \mathrm{s}\right]$ \\
\hline$\rho_{\text {HIGH }}$ & - & DENHIGH $\left[\mathrm{kg} / \mathrm{m}^{3}\right]$ \\
\hline $\bar{\rho}$ & - & DENBAR $\left[\mathrm{kg} / \mathrm{m}^{3}\right]$ \\
\hline$\rho_{1}$ & - & $\operatorname{DEN}(\mathrm{l}), \mathrm{I}=1$ or $2\left[\mathrm{~kg} / \mathrm{m}^{3}\right]$ \\
\hline$\rho_{L, 1}, \rho_{U, I}$ & - & $\operatorname{DENL}(l), \operatorname{DENU}(l), l=1$ or $2\left[\mathrm{~kg} / \mathrm{m}^{3}\right]$ \\
\hline$\rho_{\text {VENT,I }}$ & - & DENVNT(I), I = 1 or $2\left[\mathrm{~kg} / \mathrm{m}^{3}\right]$ \\
\hline$\sigma_{1}$ & - & SIGMA1 [dimensionless] \\
\hline$\sigma_{2}$ & - & SIGMA2 [dimensionless] \\
\hline
\end{tabular}

\section{PREPARED BY}

Leonard Y. Cooper

December 1993 


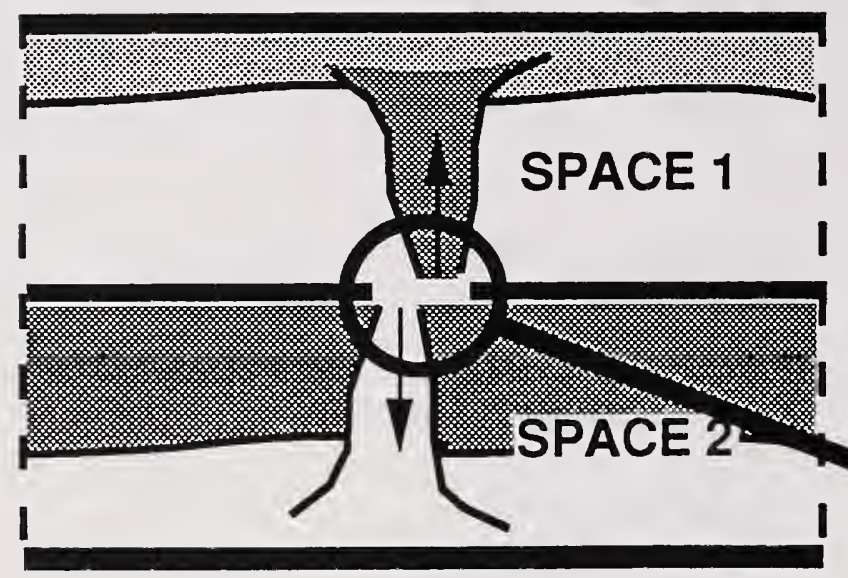

(a)

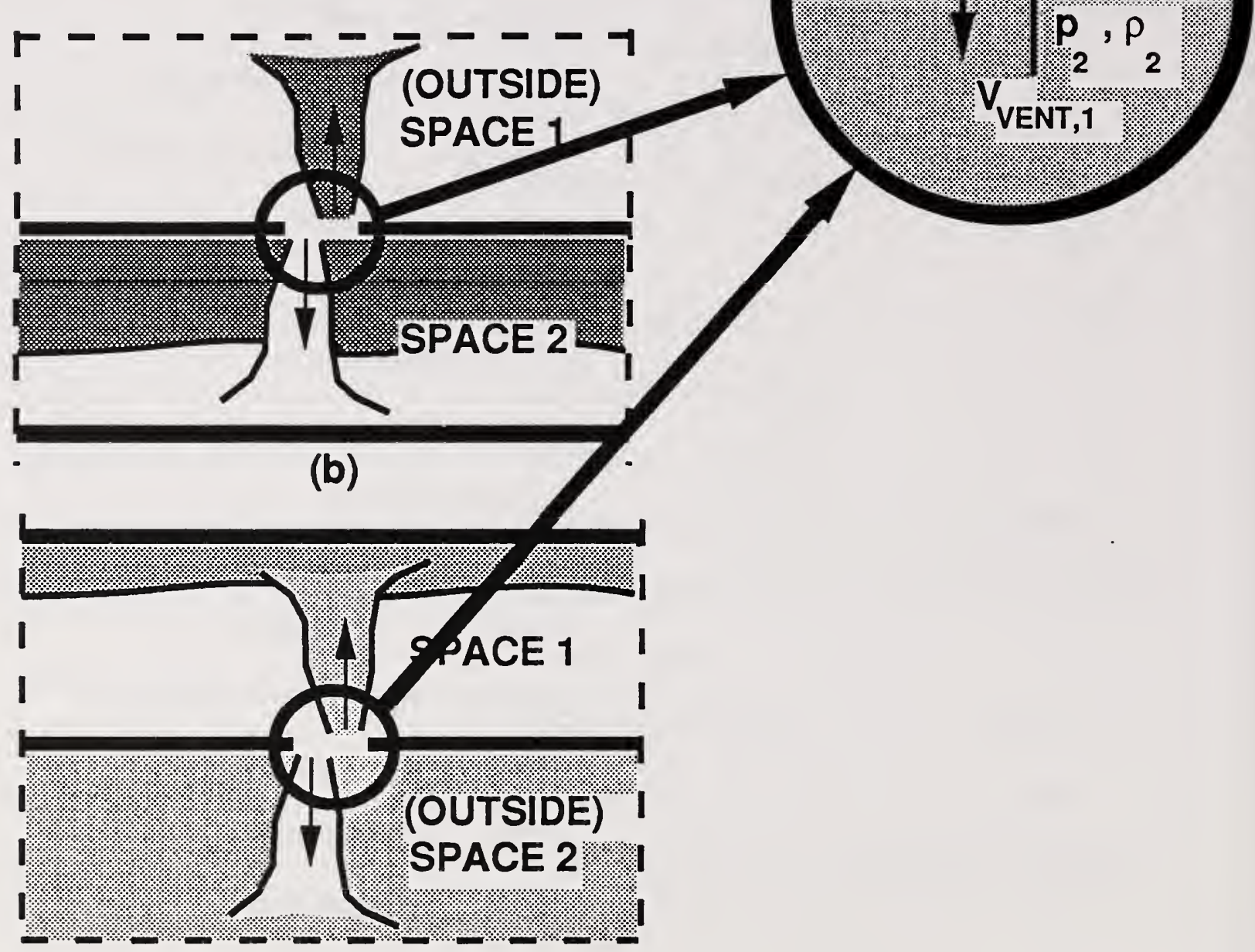

(c)

Figure 1. The possible configurations of the two spaces joined by a horizontal celling/fioor vent with space 1 above space 2: a) two inside rooms; b) an outside space above an inside room; c) an inside room over an outside space. 


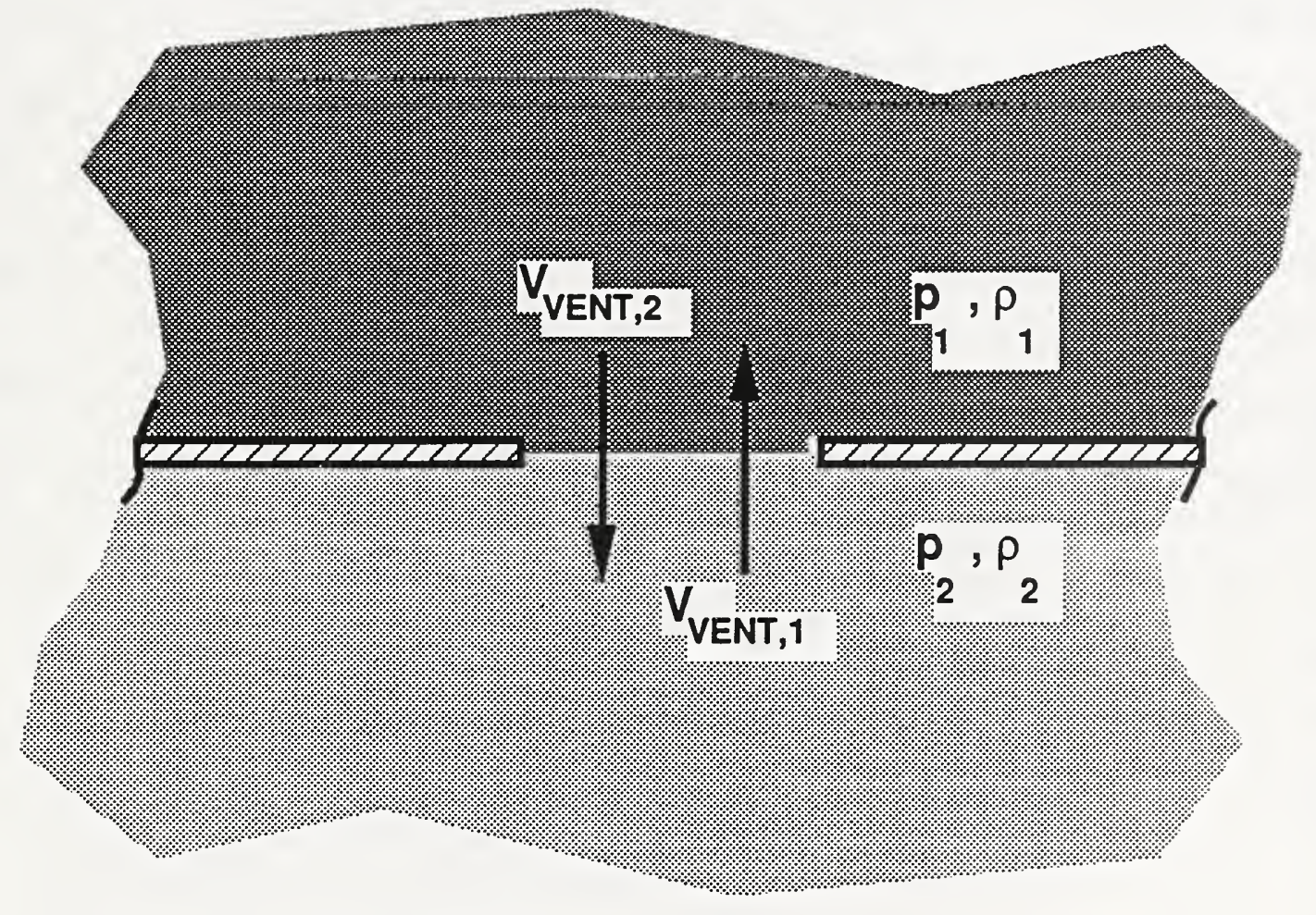

Figure 2. The geometry and conditions local to a horlzontal celling/floor vent which determine the characterlstics of the vent flow. 


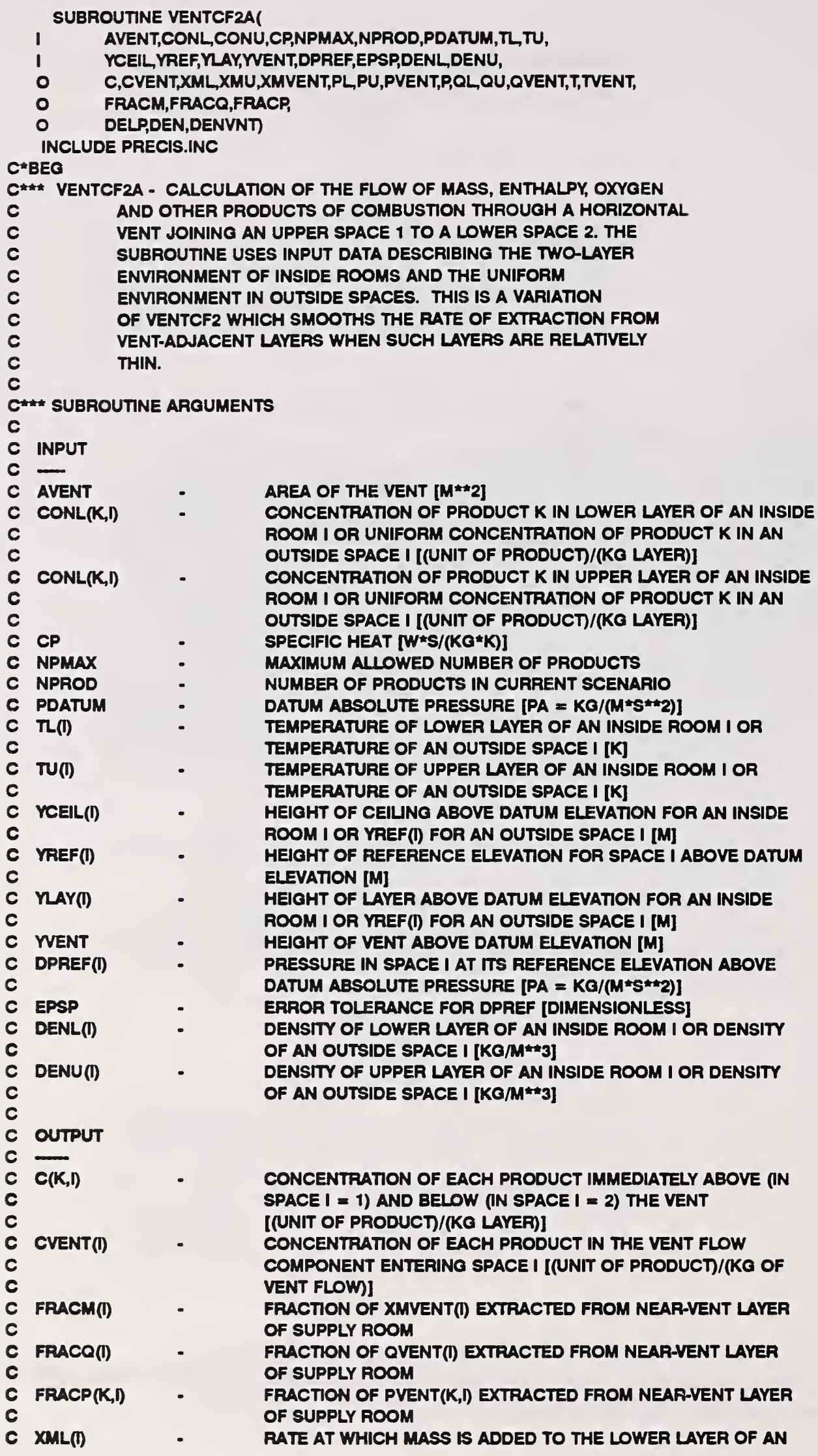




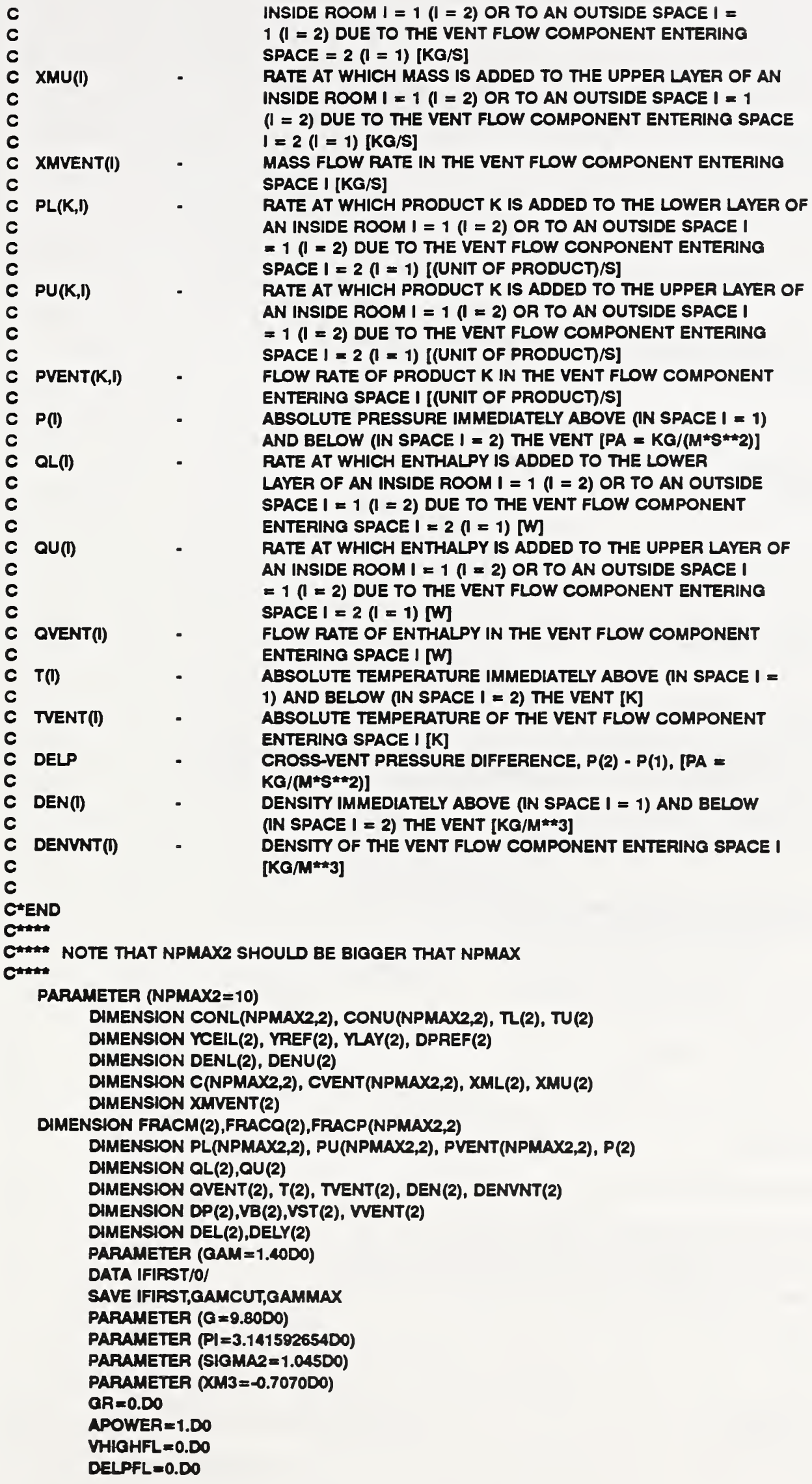




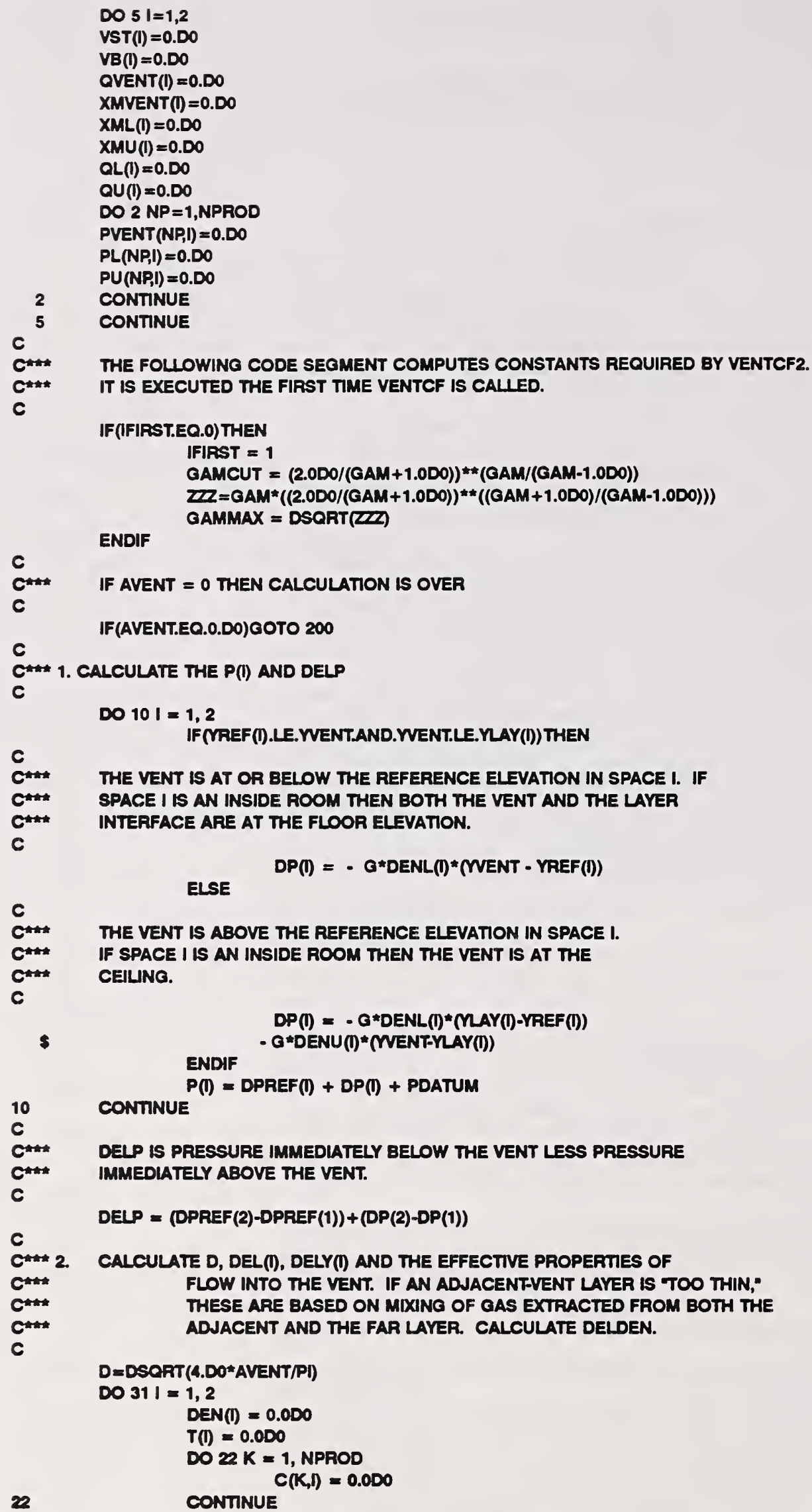

C

CW DELP IS PRESSURE IMMEDIATELY BELOW THE VENT LESS PRESSURE

C IMMEDIATELYY ABOVE THE VENT.

C

DELP $=(\operatorname{DPREF}(2)-\operatorname{DPREF}(1))+(\operatorname{DP}(2)-\operatorname{DP}(1))$

C 2. CALCULATE D, DEL((), DELY(0) AND THE EFFECTIVE PROPERTIES OF

CW FLW INTO THE VENT. IF AN ADJACENTVENT LAVER IS TOO THIN, THESE ARE BASED ON MIXING OF GAS EXTRACTED FROM BOTH THE ADJACENT AND THE FAR LAYER. CALCULATE DELDEN.

C 
C

c

C

C***

C

24

26

28

31 CONTINUE

C

Ct:

cat

C

C

C*: 3. CALCULATE VST(D), THE "STANDARD" VOLUME RATE OF FLOW

C* THROUGH THE VENT INTO SPACE I

C

C*: CalCuLATE VST(I) IF DELP $=0$

c

IF(DELP.EQ.0.0DO)THEN

$$
\text { VST(1) }=0.000
$$

ENDIF

$\operatorname{VST}(2)=0.000$

IF(DELP.EQ.0.DO) COTO 32

C

C* CALCULATE VST(I) FOR NONZERO DELP

IF(DELP.OT.0.0DO)THEN

DEL(I) $=$ MIN $($ YCEIL.(I)-YREF $(I)) / 2 . D 0, D / 2 . D 0)$

$\operatorname{DELY}(\mid)=$ DABS MLAY $(I) \cdot$ YVENT

$D E L(I)=D / 2 . D 0$

$\operatorname{ELY}(I)=0 . D 0$

ENDIF

COMPUTE EFFECTIVE NEAR-VENT PROPERTIES:

IF(I.EO.1)THEN

$$
\begin{aligned}
& \text { DEN(1)=DENL(1) } \\
& T(1)=T L(1) \\
& \text { DO } 24 \quad K=1, N P R O D \\
& \\
& \quad C(K, 1)=\text { CONL(K,1) }
\end{aligned}
$$

CONTINUE

$\operatorname{DEN}(2)=\operatorname{DENU}(2)$

$T(2)=T U(2)$

DO $26 K=1, N P R O D$

$C(K, 2)=\operatorname{CONU}(K, 2)$

CONTINUE

ENDIF

IF(I.EQ.1)THEN

$T(1)=T U(1) \star D E N U(1) / D E N(1)$

DO $28 \quad K=1, N P R O D$

$C(K, 1)=\left(C O N U(K, 1) * D E N U(1)^{*}\right.$

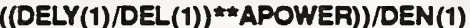

CONTINUE

$T(2)=\pi(2) *$ DENL(2)/DEN(2)

DO $30 \mathrm{~K}=1$,NPROD

$C(K, 2)=(C O N L(K, 2) \approx D E N L(2)$

CONTINUE

ENDIF

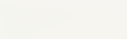

DELDEN IS DENSITY IMMEDIATELY ABOVE THE VENT LESS DENSITY

DENTYMMEOIATELY BELOW THE VENT

c

$\operatorname{DEN}(1)=\operatorname{DENU}(1) *(1 . \operatorname{DO}-((\operatorname{DELY}(1) / D E L(1)) * A P O W E R))$

+ DENL(1)*((DELY(1)/DEL(1)) *\#APOWER

(1.DO-((DELY(1)/DEL(1)) *AAPOWER))

$\operatorname{DEN}(2)=\operatorname{DENL}(2) *(1 . \operatorname{DO}-((\operatorname{DELY}(2) / D E L(2)) *$ APOWER $))$

+ DENU(2)*((DELY(2)/DEL(2)) $*$ APOWER

$\star(1 . D O-($ DELY(2)/DEL(2)) *AAPOWER )

$+\operatorname{CONU}(K, 2) * \operatorname{DENU}(2) *((D E L Y(2) / D E L(2)) *$ APOWER $)) / D E N(2)$

VENTCF2A - 21 


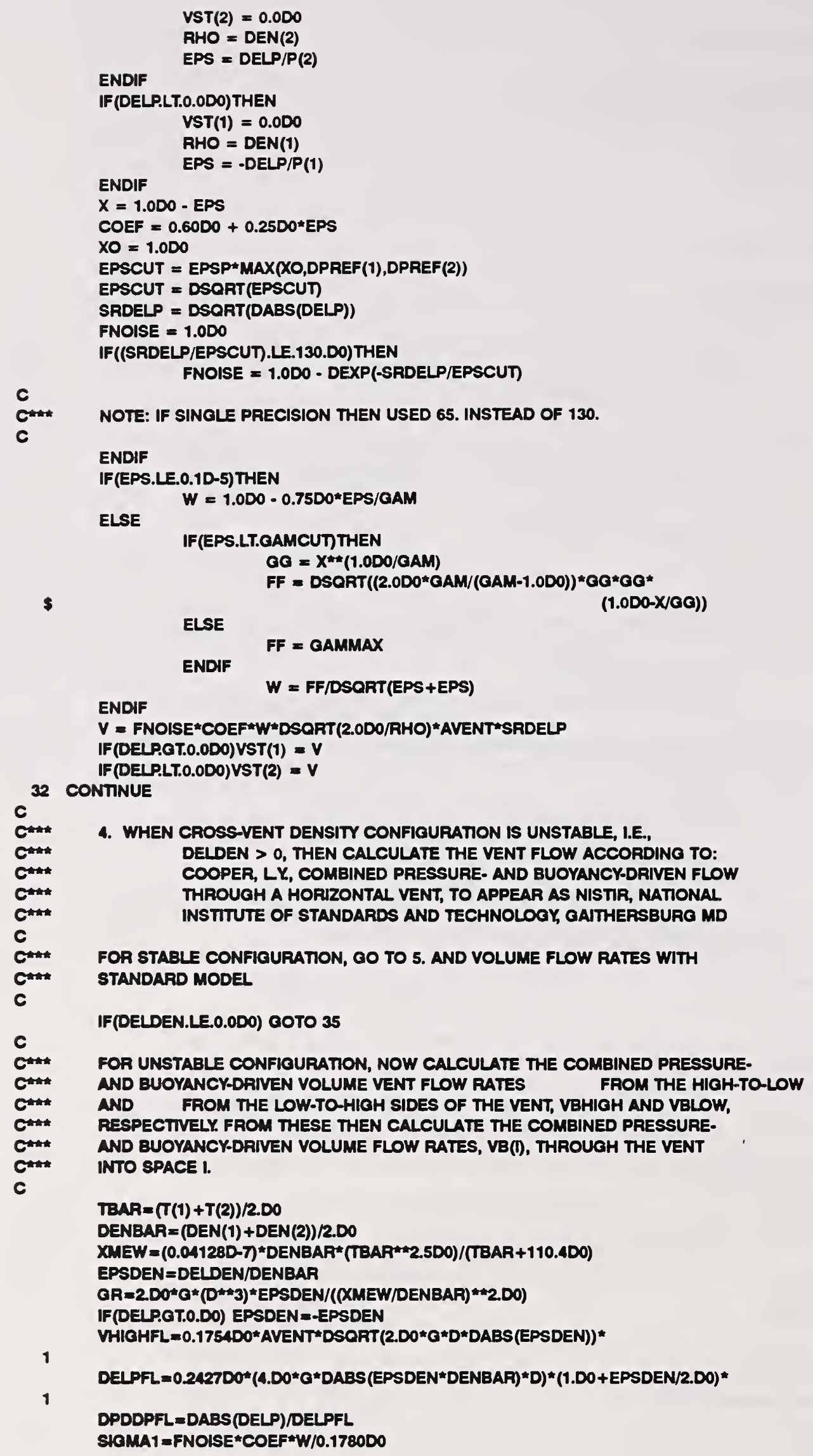




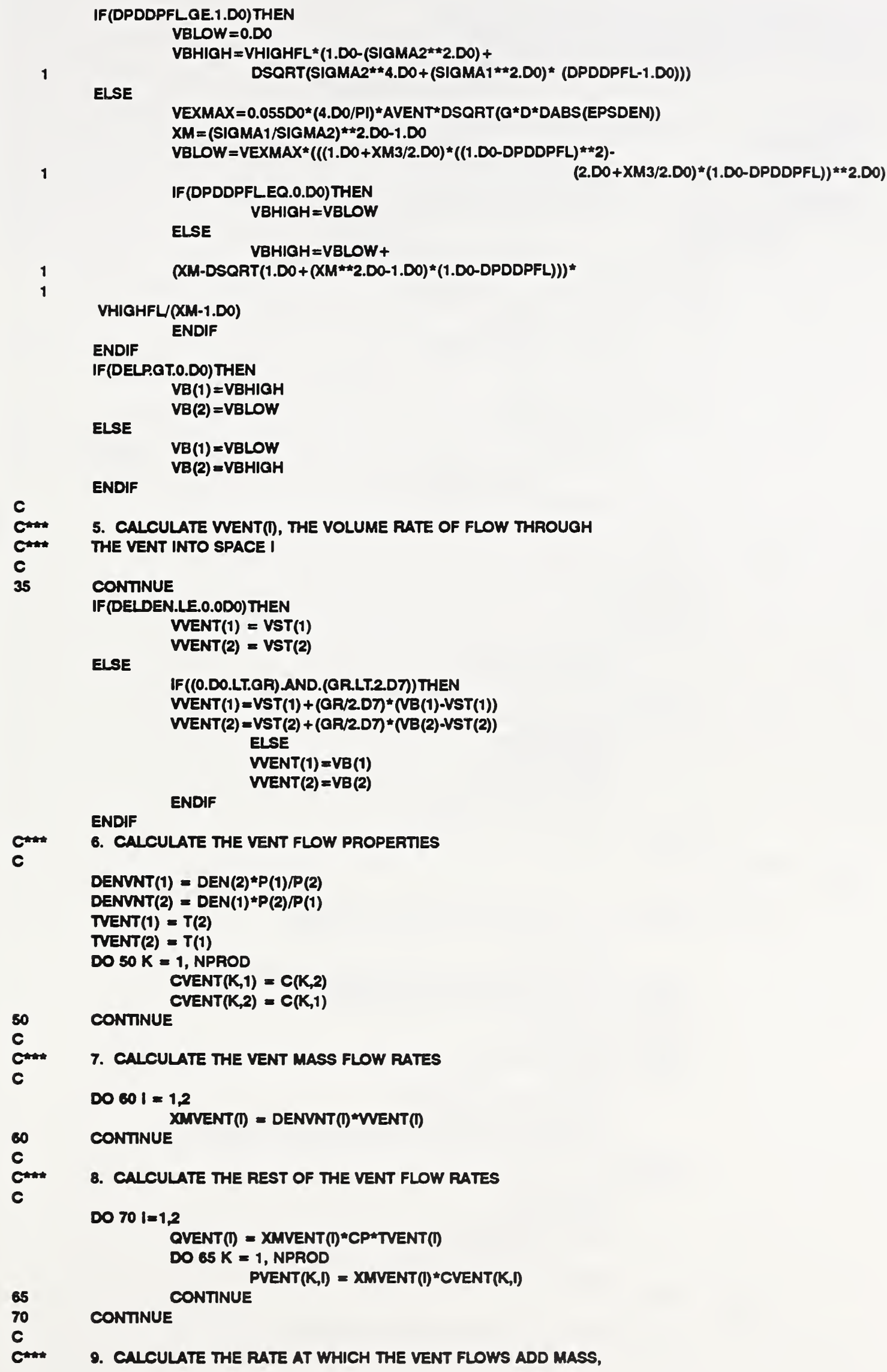




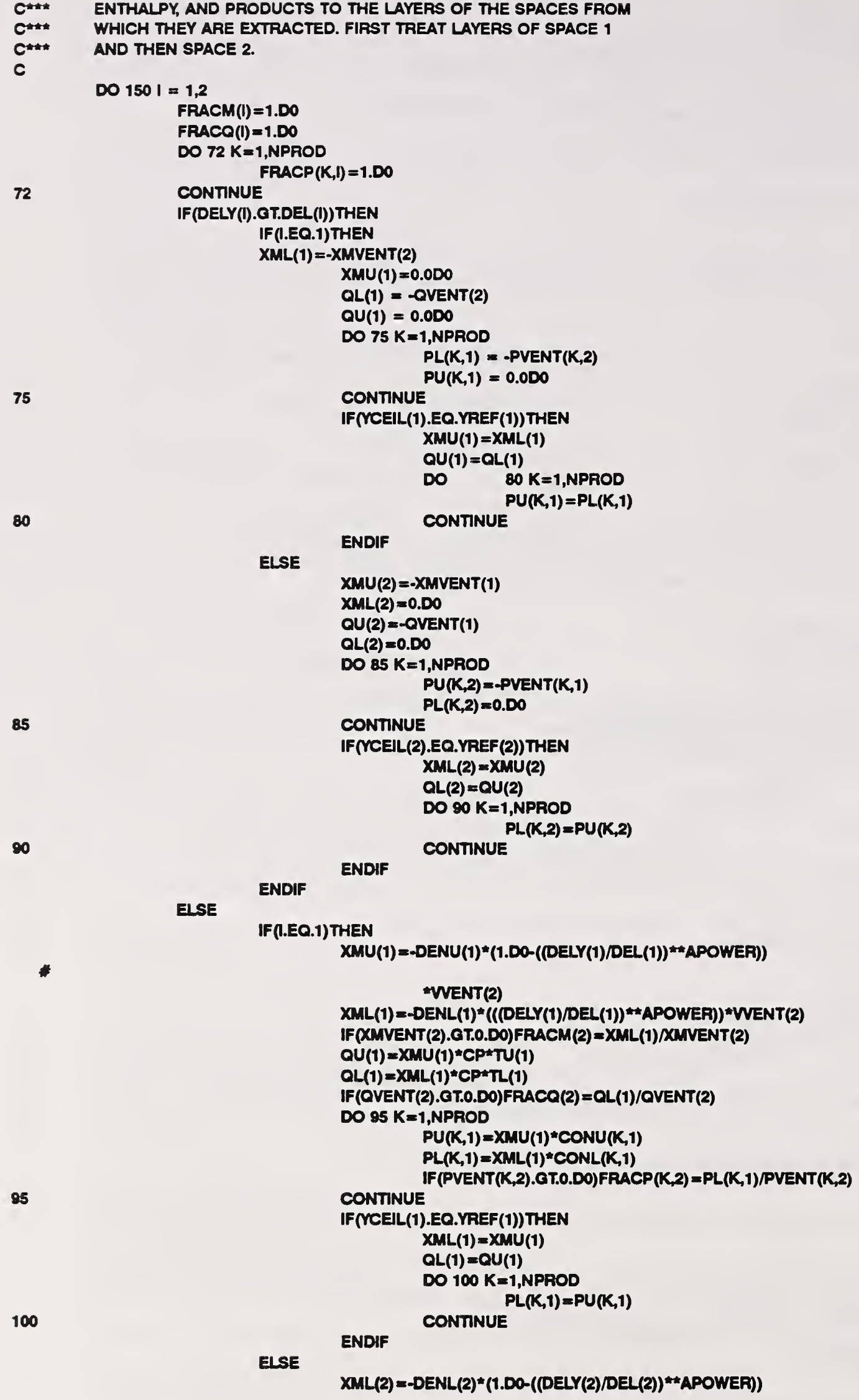

80

ENDIF

ELSE

$X M U(2)=-X M V E N T(1)$

$X M L(2)=0 . D O$

QU(2) $=-$ QVENT(1)

$Q L(2)=0 . D 0$

DO $85 K=1, N P R O D$

PU(K,2) $=+$ PVENT $(K, 1)$

CONTINUE $P L(K, 2)=0 . D O$

IF(MCEIL(2).EQ.YREF(2))THEN

$X M L(2)=X M U(2)$

$\mathrm{QL}(2)=\mathrm{QU}(2)$

DO $90 \mathrm{~K}=1$,NPROD

PL(K,2) $=P U(K, 2)$

$\infty$

ENDIF

CONTINUE

ENDIF

ELSE

IF(1.EQ.1)THEN

$X M U(1)=-D E N U(1) *(1 . D O-((D E L Y(1) / D E L(1)) * * A P O W E R))$

-VENT(2)

$X M L(1)=-D E N L(1) *(((D E L Y(1) / D E L(1)) * A$ APOWER $)) * V E N T(2)$

IF(XMVENT(2).0T.0.D0)FRACM(2) $=X M L(1) / X M V E N T(2)$

$\mathrm{QU}(1)=X N U(1) \star C P \star T U(1)$

$Q L(1)=X M L(1) * C P * T L(1)$

IF(QVENT(2).QT.0.DO)FRACQ(2) $=$ QL(1)/QVENT(2)

DO $95 K=1$,NPROD

$\operatorname{PU}(K, 1)=X M U(1) * \operatorname{CONU}(K, 1)$

$P L(K, 1)=X M L(1) * C O N L(K, 1)$

25 IF (PVENT(K,2). GT.0.DO)FRACP $(K, 2)=$ PL(K, 1)/PVENT $(K, 2)$

CONTINUE

IF(YCEIL(1).EQ.YREF(1))THEN

$X M L(1)=X M U(1)$

$Q L(1)=Q U(1)$

DO $100 \mathrm{~K}=1, \mathrm{NPROD}$

100 $P L(K, 1)=P U(K, 1)$

ENDIF

CONTINUE

ELSE

$X M L(2)=-D E N L(2) *(1 . D Q-((D E L Y(2) / D E L(2)) * \star A P O W E R))$ 
VENT(1)

$X M U(2)=-\operatorname{DENU}(2) *(((D E L Y(2) / D E L(2)) * * A P O W E R))$ *WENT(1)

IF(XMVENT(1). OT.0.DO)FRACM(1) =XMU(2)/XMVENT(1)

$\mathrm{QL}(2)=\mathrm{XML}(2) * C P * T L(2)$

$\mathrm{QU}(2)=\mathrm{XMU}(2){ }^{\star} \mathrm{CP} * \mathrm{TU}(2)$

IF(QVENT(1).OT.0.DO)FRACQ(1) =QU(2)/QVENT(1)

DO $105 K=1$,NPROD

$\operatorname{PL}(K, 2)=X M L(2) * C O N L(K, 2)$

$\operatorname{PU}(K, 2)=X M U(2) \star C O N U(K, 2)$

105 CONTINUE

IF(PVENT $(K, 1) .0$ T.0.DO)FRACP $(K, 1)=$ PU $(K, 2) /$ PVENT $(K, 1)$

IF(YCEIL(2).EO.YREF(2))THEN

$X M U(2)=X M L(2)$

$\mathrm{QU}(2)=\mathrm{QL}(2)$

DO $110 K=1, N P R O D$

110

$$
\text { PU }(K, 2)=P L(K, 2)
$$

$\begin{array}{ll} & \text { ENDIF ENDIF } \\ 150 & \text { CONTINUE } \\ 200 & \text { CONTINUE } \\ \text { RETURN } \\ \text { END }\end{array}$

CONTINUE

ENDIF 

$\overline{\text { NIST-114 }}$

(REV. 6-93)

ADMAN 4.09
U.S. DEPARTMENT OF COMMERCE

NATIONAL INSTITUTE OF STANDARDS AND TECHNOLOGY

MANUSCRIPT REVIEW AND APPROVAL

INSTRUCTIONS: ATTACH ORIGINAL OF THIS FORM TO ONE (1) COPY OF MANUSCRIPT AND SEND TO THE SECRETARY, APPROPRIATE EDITORIAL REVIEW BOARD. TITLE AND SUBTITLE (CITE IN FULL)

VENTCF2: AN ALGORITHM AND ASSOCIATED FORTRAN 77 SUBROUTINE FOR CALCULATING FLOW THROUGH A HORIZONTAL CEILING/FLOOR VENT IN A ZONE-TYPE COMPARTMENT FIRE MODEL

\begin{tabular}{|l|l|l|}
\hline CONTRACT OR GRANT NUMBER & TYPE OF REPORT AND/OR PERIOD COVERED \\
\hline AUTHOR(S) (LAST NAME, FIRST INITIAL, SECOND INITIAL) & $\begin{array}{l}\text { PERFORMING ORGANIZATION (CHECK (X) ONE BOX) } \\
\text { COOPE, L.Y. . }\end{array}$ & $\begin{array}{l}\text { NIST/GAITHERSBURO } \\
\text { NIST/BOULER } \\
\text { JILA/BOULDER }\end{array}$ \\
\hline
\end{tabular}

LABORATORY AND DIVISION NAMES IFIRST NIST AUTHOR ONLY

Fire Safety Engineering Division, Building and Fire Research Laboratory

SPONS ORING ORGANIZATION NAME AND COMPLETE ADORESS (STREET, CITY, STATE, ZIP)

\section{PROPOSED FOR NIST PUBUCATION}

JOURNAL OF RESEARCH (NIST JRES)

J. PHYS. \& CHEM. REF. DATA (JPCRO)

HANDBOOK (NIST HB)

SPECLAL PUBUCATION (NIST SP)

TECHNICAL NOTE (NIST TN)

PROPOSED FOR NON-NIST PUBLCATION (CITE FULUY

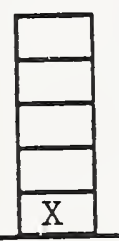

MONOGRAPH (NIST MN) NATL STO. REF. DATA SERIES (NIST NSRDS) FEOERAL INF. PROCESS. STOS. (NIST FIPS) UST OF PUBUCATIONS (NIST LP) NIST INTERAGENCY/INTERNAL REPORT (NISTIR)
(ERB USE ONLY)

\begin{tabular}{|c|c|c|}
\hline \multicolumn{2}{|l|}{ ERB CONTROL NUMBER } & DIVISION \\
\hline $\begin{array}{l}\text { PUBUCATION REPORT NUMBE } \\
\text { NISTIR } 5470\end{array}$ & & CATEGORY CODE \\
\hline $\begin{array}{l}\text { PUBUCATION DATE } \\
\text { August } 1994\end{array}$ & NUM & BER PRINTED PAGE \\
\hline
\end{tabular}

NIST/GAITHERSBURO

JILA/BOULDER

LETTER CIR CULAR BUILDING SCIENCE SERIES PRODUCT STANDARDS OTHER

\begin{tabular}{l|l|l}
\hline & $\square . S$.
\end{tabular} UOREION

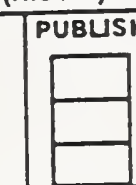

PAPER

CD-RO

DISKETTE (SPECIF)

OTHER (SPECIFY)

SUPPLEMENTARY NOTES

ABSTRACT (A 2000-CHARACTER OR LESS FACTUAL SUMMARY OF MOST SIGNIFICANT INFORMATION. IF DOCUMENT INCLU, IF NECESSARY.)

OR UTERATURE SURVEY, CITE IT HERE. SPELL OUT ACRONYMS ON FIRST REFERENCE) (CON

An aigorthm and associated FORTRAN 77 subroutine, calied VENTCF2, is presented for calcuiating the effects on two-layer compartment fire environments of the quasi-steady flow through a circular, shallow (i.e., small ratio of depth to diameter), horlzontal vent connecting two spaces. The two spaces can be elther two inside rooms of a multi-room faclilty or one inside room and the outside amblent environment local to the vent. The description of the flow through the vent is determined by combining considerations of the uni-directional-type of flow driven by a cross-vent pressure difference and, when appropriate, the combined pressure- and buoyancy-driven flows which occur when the density configuration across the vent is unstabie, l.e., a relatively cool, dense gas in the upper space overlays a less dense gas in the lower space. In the aigorithm, caiculation of the rates of flow exchange between the two spaces is based on previously reported model equations. Characteristics of the geometry and the Instantaneous environments of the two spaces are assumed to be known and specified as inputs. The outputs caiculated by the algorlthm/subroutine are the rates and the propertles of the vent flow at the elevation of the vent as it enters the top space from the bottom space and/or as it enters the bottom space from the top space. Rates of mass, enthaipy, and products of combustion extracted by the vent flows from upper and lower layers of inside room environments and from outside ambient spaces are determined explicilly. The algorlthm/subroutine is an advanced version of the algorithm/subroutine VENTCF. The subroutine is completely modular, and it is sultable for general use in two-layer, multi-room, zone-type fire model computer codes. It has been tested over a wide range of Input varlables and these tests are described.

KEY WORDS (MAXIMUM OF 9; 28 CHARACTERS AND SPACES EACH; SEPARATE WITH SEMICOLONS; ALPHABETIC ORDER; CAPITALZE ONLY PROPER MAMES)

building fires; compartment fires; computer models; fire models; mathematical models; vents; zone models

AVAILABIUTY

\begin{tabular}{|l|}
\hline $\mathrm{X}$ \\
\hline $\mathrm{X}$ \\
\hline
\end{tabular}



